Materials and Technology Division

Oak Ridge National Laboratory

\title{
An Innovative Technique for Evaluating the Integrity and Durability of Wind Turbine Blade Composites FY2010 Report
}

Jy-An John Wang and Fei Ren

Date Published: September 2010

Prepared by

OAK RIDGE NATIONAL LABORATORY

Oak Ridge, Tennessee 37831-6283

Managed by

UT-BATTELLE, LLC

For the

U.S. DEPARTMENT OF ENERGY

under contract DE-AC05-00OR22725 
This report was prepared as an account of work sponsored by an agency of the United States Government. Neither the United States Government nor any agency thereof, nor any of their employees, makes any warrant, express or implied, or assumes any legal liability or responsibility for the accuracy, completeness, or usefulness of any information, apparatus, product, or process disclosed, or represents that its use would not infringe privately owned rights. Reference herein to any specific commercial product, process, or service by trade name, trademark, manufacturer, or otherwise, does not necessarily constitute or imply its endorsement, recommendation, or favoring by the United State Government or any agency thereof. The views and opinions of authors expressed herein do not necessarily state or reflect those of the United States Government or any agency thereof. 


\section{ACKNOWLEDGEMENTS}

This research was sponsored by the Wind Energy Program of Department of Energy and was carried out at Oak Ridge National Laboratory under contract DE-AC05-00OR22725 with UTBattelle, LLC. The authors are grateful to Mr. Stanton Hadley and Dr. Brennan Smith supporting this project.

The epoxy materials included in this study were provided by Gougeon Brothers, Inc. and Molded Fiber Glass Companies (MFG). The authors would like to thank Mr. Williams Bertelsen at Gougeon Brothers, Inc. and Mr. Carl LaFrance at Molded Fiber Glass Companies for their support and helpful discussions.

The authors would like to thank Dr. Hsin Wang and Mr. Charles Chan of ORNL for their assistance and helpful discussions regarding the infrared imaging, and Dr. Dan Naus and Dr. James Hemrick of ORNL for their comments and suggestions after reviewing this report. 
DRAFT 


\section{DRAFT}

\section{Table of Contents}

LIST OF FIGURES

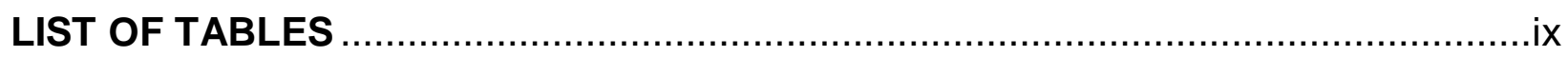

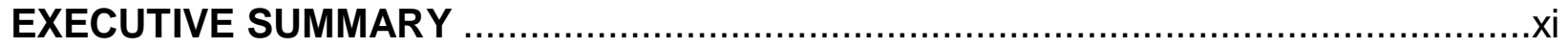

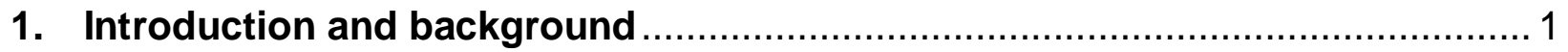

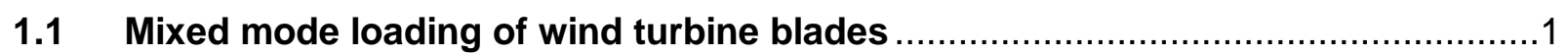

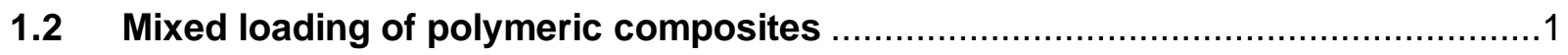

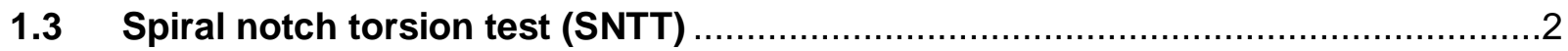

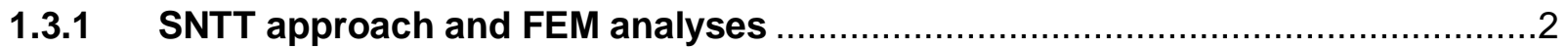

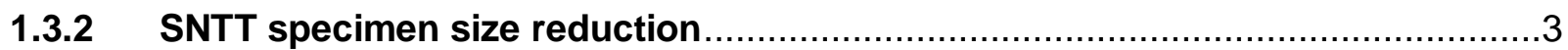

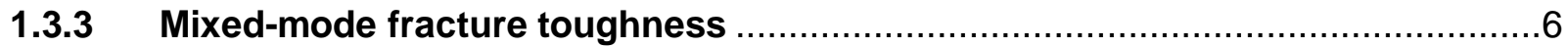

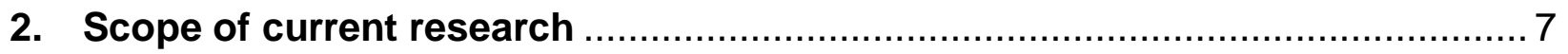

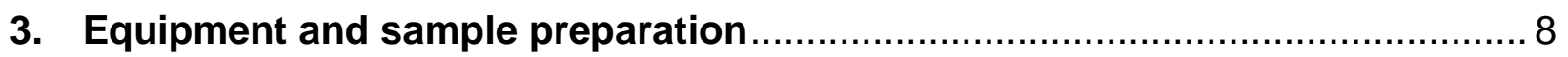

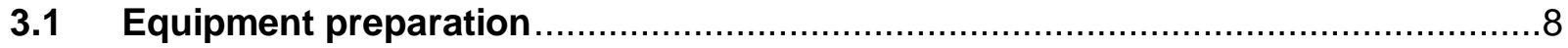

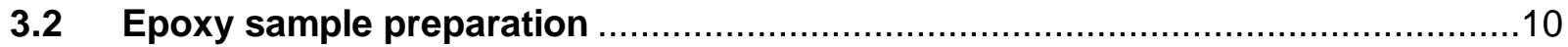

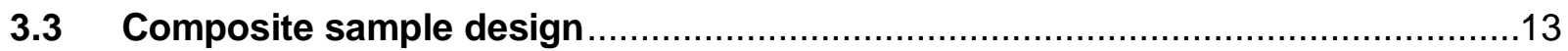

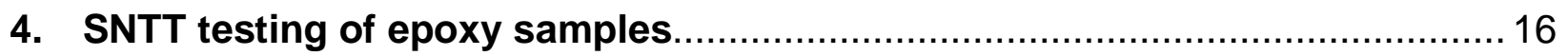

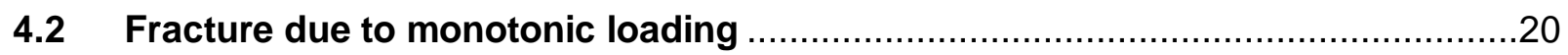

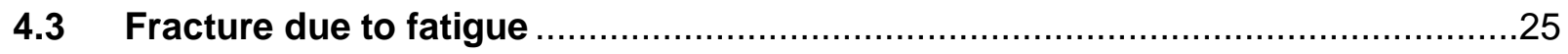

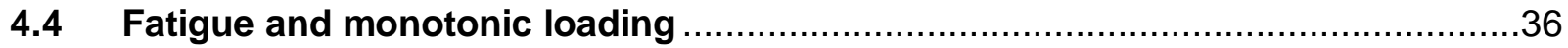

5. Finite Element Model Development for SNTT Epoxy Samples ....................... 44

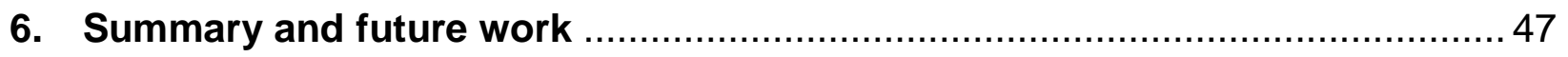

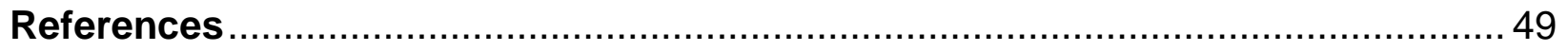

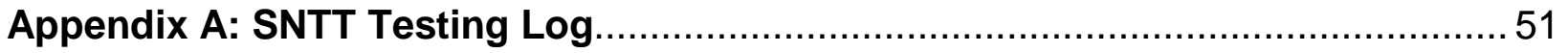




\section{LIST OF FIGURES}

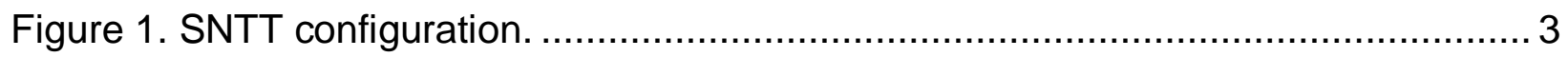

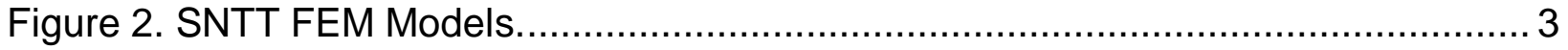

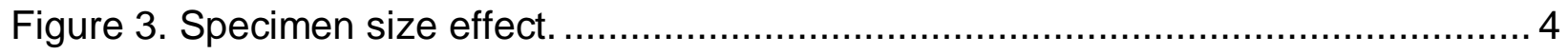

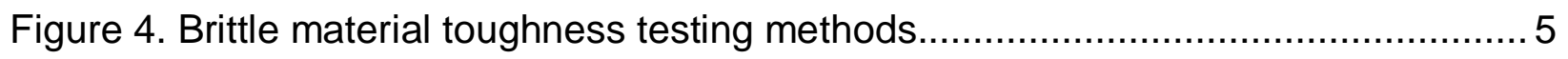

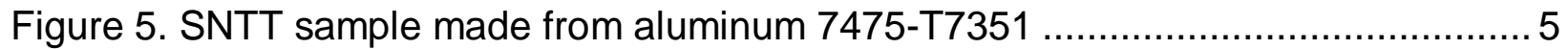

Figure 6. Illustration of SNTT approach using a radiator hose . ........................... 6

Figure 7. MTS 809 Axial/torsional test system used for SNTT ........................... 8

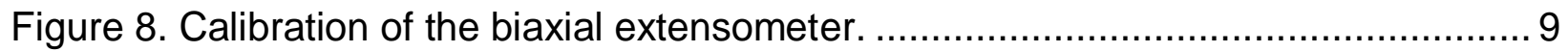

Figure 9. Block diagram of the capacitive data acquisition system........................ 9

Figure 10. The IR imaging system used to monitor SNTT samples. ...................... 10

Figure 11. Pictures showing raw epoxy materials received from (a) Gougeon Brothers, Inc. and (b) Molded Fiber Glass Companies. .................................. 11

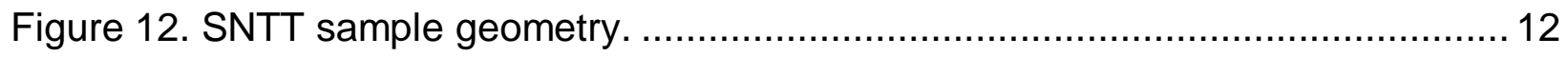

Figure 13. Pictures showing machined samples made from epoxy materials provided by

(a) Gougeon Brothers, Inc. and (b) Molded Fiber Glass Companies. ........... 12

Figure 14. Proposed methods for fabricating composite SNTT samples................... 15

Figure 15. IR images of an epoxy sample during SNTT testing: (a) before testing, (b)

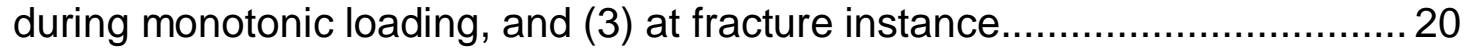

Figure 16. The torque-rotation plots of tested SNTT samples ........................... 20

Figure 17. Pictures showing (a) the fractured MFG-1 sample, and (b) its fracture

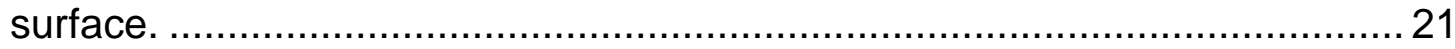

Figure 18. Images showing the fracture surfaces of (a) GB2-1 and (b) GB2-6.......... 22

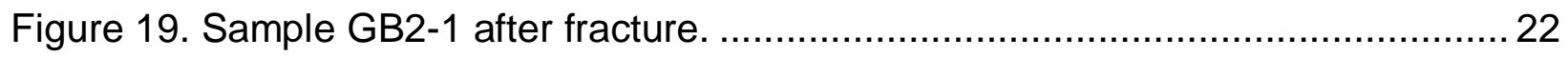

Figure 20. Picture showing one fractured half of sample GB3-1. ......................... 23

Figure 21. Images showing (a) the fracture surface and (b) the fracture origin of sample

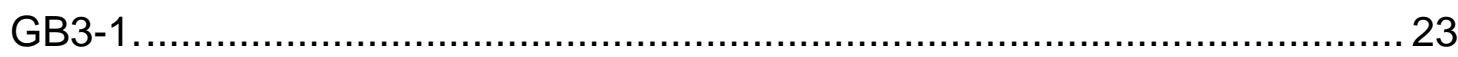

Figure 22. Images showing fracture surfaces of (a) GB3-6, (b) GB4-1, and (c) GB4-4. 24 Figure 23. Images showing the fracture surfaces of (a) GB3-8 and (b) GB3-9. .......... 25

Figure 24. External factors influencing the fatigue behavior of materials. .................26 
Figure 25. Fatigue S-N plots of samples from GB batch 1......................................... 27

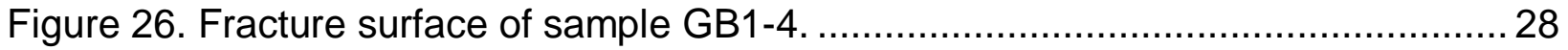

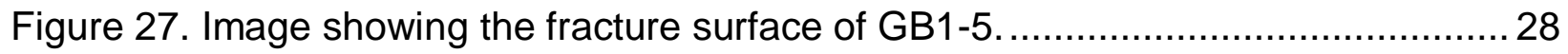

Figure 28. Images showing the fracture surfaces of (a) GB1-2 and (b) GB1-3........... 28

Figure 29. Images showing the fracture surfaces of (a) GB2-3 and (b) GB2-4 ............ 29

Figure 30. Images showing (a) the fracture surface of GB2-5 and (b) the crack

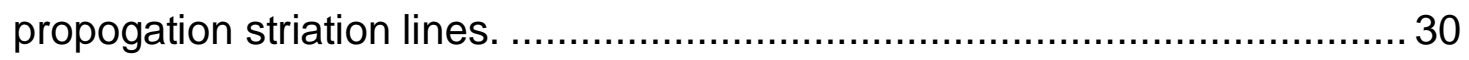

Figure 31. SEM image of the striation lines observed in GB2-5 .............................. 30

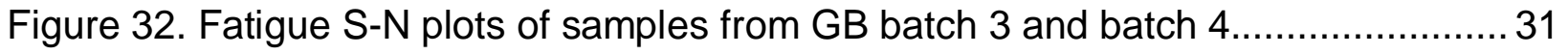

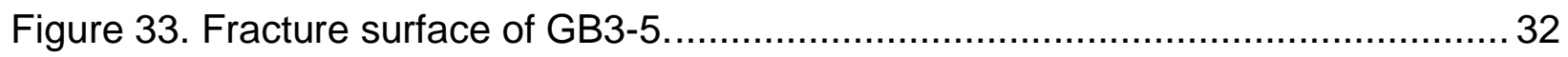

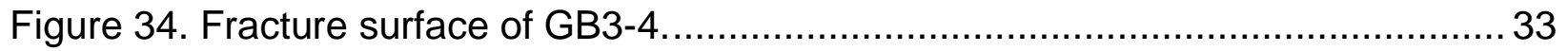

Figure 35. Images showing the fracture surfaces of GB4-5................................. 33

Figure 36. Images showing the radial markings along the groove line of GB3-2 …...... 34

Figure 37. Images showing the uniform crack growth along notch line of GB4-2 …...... 34

Figure 38. Effect of fatigue on stiffness of sample GB3-2 as measured from (a) load cell and RVDT, and (b) load cell and biaxial extensometer. ................................. 35

Figure 39. Images showing the fracture surface of MFG-2 ...................................... 36

Figure 40. Images showing the fracture surfaces of MFG-3................................... 36

Figure 41. Monotonic loading curves of GB1-6 and GB1-7 after fatigue. ..................... 37

Figure 42. Fracture surfaces of samples GB1-6 and GB1-7. ............................... 38

Figure 43. Comparison of the loading curves between GB2-1 and GB2-2 .................. 38

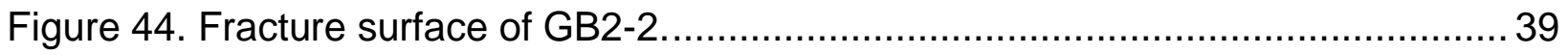

Figure 45. Comparison of the loading curves between GB4-4 and GB4-6 .................. 39

Figure 46. Images showing the fatigued crack growth on fracture surface of GB4-6. . 40 Figure 47. Comparison of the loading curves among GB3-1, GB3-3, GB4-1, and GB4-3.

Figure 48. Images showing the fracture surface of GB3-3 ….............................. 41

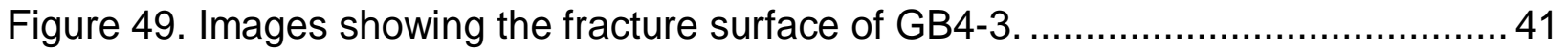

Figure 50. Effect of fatigue on stiffness of sample GB3-3 as measured from (a) load cell and RVDT, and (b) load cell and biaxial extensometer. ............................. 42 


\section{DRAFT}

Figure 51. Effect of fatigue on stiffness of sample GB4-3 as measured from (a) load cell and RVDT, and (b) load cell and biaxial extensometer. ............................... 42

Figure 52. Images showing the fracture surface of GB3-7 .................................... 43

Figure 53. Schematic diagram of SNTT mesh design that allows the crack propagation to be perpendicular to the central axis of the SNTT samples...................... 44

Figure 54. Schematic diagram of SNTT mesh design partition surfaces...................... 44

Figure 55. FEM mesh around crack front and crack tip, including the mesh boundary designed along the orientation of crack propagation.................................. 45

Figure 56. The FEM model designed for SNTT epoxy samples.................................. 45

Figure 57. The enlarged view of FEM model for SNTT epoxy sample, where the red lines indicates the crack seam region...................................................... 46 


\section{DRAFT}

\section{LIST OF TABLES}

Table 1. Processing and mechanical properties of the received epoxy materials ......... 10

Table 2. Chemical composition of the resins and hardeners used in the study............. 11

Table 3. Geometries of SNTT epoxy samples...................................................... 13

Table 4. Epoxy samples testing summary ....................................................... 17

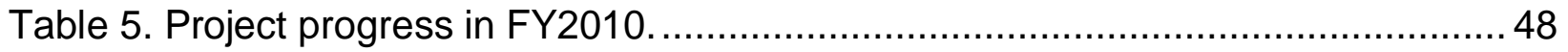


DRAFT 


\section{EXECUTIVE SUMMARY}

Wind turbine blades are subjected to complex multiaxial stress states during operation. A review of the literature suggests that mixed mode fracture toughness can be significantly less than that of the tensile opening mode (Mode I), implying that fracture failure can occur at a much lower load capacity if the structure is subject to mixed-mode loading. Thus, it will be necessary to identify the mechanisms that might lead to failure in blade materials under mixed-mode loading conditions.

Meanwhile, wind turbine blades are typically fabricated from fiber reinforced polymeric materials, e.g. fiber glass composites. Due to the large degree of anisotropy in mechanical properties that is usually associated with laminates, the fracture behavior of these composite materials is likely to be strongly dependent on the loading conditions. This may further strengthen the need to study the effect of mixed-mode loading on the integrity and durability of the wind turbine blade composites.

To quantify the fracture behavior of composite structures under mixed mode loading conditions, particularly under combined Mode I (flexural or normal tensile stress) and Mode III (torsional shear stress) loading, a new testing technique is proposed based on the spiral notch torsion test (SNTT). As a 2002 R\&D 100 Award winner, SNTT has been recognized as a novel fracture testing technology which should be suitable for analyzing the expected loading behaviors. SNTT has many advantages over conventional fracture toughness methods and has been used to determine fracture toughness values on a wide spectrum of materials. The current project is the first attempt to utilize SNTT on polymeric and polymer-based composite materials. It is expected that mixed-mode failure mechanisms of wind turbine blades induced by typical in-service loading conditions, such as delamination, matrix cracking, fiber pull-out and fracture, can be effectively and economically investigated by using this methodology.

This project consists of two phases. The Phase I (FY2010) effort includes (1) preparation of testing material and testing equipment set-up, including calibration of associated instruments/sensors, (2) development of design protocols for the proposed SNTT samples for both polymer and composite materials, such as sample geometries and fabrication techniques, (3) manufacture of SNTT samples, and (4) fracture toughness testing using the SNTT method. The major milestone achieved in Phase I is the understanding of fracture behaviors of polymeric matrix materials from testing numerous epoxy SNTT samples.

A total of 30 epoxy SNTT samples were fabricated from two types of epoxy materials provided by industrial partners Gougeon Brothers, Inc. and Molded Fiber Glass Companies. These samples were tested with SNTT in three groups: (1) fracture due to monotonic loading, (2) fracture due to fatigue cyclic loading, and (3) monotonic loading applied to fatigue-precracked samples. 
Brittle fractures were observed on all tested samples, implying linear elastic fracture mechanics analysis can be effectively used to estimate the fracture toughness of these materials with confidence. Appropriate fatigue precracking protocols were established to achieve controllable crack growth using the SNTT approach under pure torsion loading. These fatigue protocols provided significant insight in to the mechanical behavior of epoxy polymeric materials and their associated rate-dependent characteristics. Study of the effects of mixed-mode loading on the fracture behavior of epoxy materials found that all epoxy samples failed in brittle tensile failure mode; the fracture surfaces always follow a $45^{\circ}$ spiral plane that corresponded to Mode I tensile failure, even when the initial pitch angle of the machined spiral grooves was not at $45^{\circ}$. In addition, general observation from the fatigue experiments implied that loading rate played an important role determining the fracture behavior of epoxy materials, such that a higher loading rate resulted in a shorter fatigue life. A detailed study of loading rate effect will be performed in Phase II of the project.

Fracture toughness evaluation by analytical finite element analysis is also an integral part of the research program. In the report period this analysis was also initiated with preliminary progress resulting in the building of geometric models and designs with appropriate meshing protocols for epoxy polymeric samples.

Based on the experience learned from the Phase I study, in FY2011 we will carry out Phase II efforts to continue the finite element analysis to simulate the fracture process of both epoxy and composite materials. Experimental investigation will be focused on blade composite materials and the proposed SNTT composite samples will be jointly developed by the ORNL team and Prof. John Mandell's group at Montana State University. 


\section{Introduction and background}

Improvement of wind turbine performance depends upon enhancing the reliability of turbines and components. To increase the energy capture capability, future designs will utilize larger rotors with longer blades fabricated with advanced composite materials with high strength and stiffness-to-weight ratios [Hayman 2008]. This will require more thorough knowledge of materials and safety factors, as well as further investigation into new materials. In particular, the basic understanding of damage and failure mechanisms, the effects and interpretation of stochastic loadings, multiple stress states, environmental effects, size effects, and thickness effects shall be obtained [Kensche 2004].

\subsection{Mixed mode loading of wind turbine blades}

During operation wind turbine blades are subjected to complex multiaxial stress states. To ensure that the next generation of wind power systems operate safely and reliably it will be necessary to identify the mechanisms that might lead to failure in blade materials and to fully characterize their behavior under extreme conditions. This may further strengthen the need to study the mixed-mode loading effect on the integrity and durability of the wind turbine blade composites.

Fracture is one of the most dramatic failure modes of any engineering structure. A material's intrinsic capacity to resist fracture is known as fracture toughness. Although there are an extensive number of studies on fracture toughness under tensile loading (Mode I fracture), little information is available for fracture toughness under mixed loading conditions that involves sliding (Mode II) and/or tearing (Mode III). As mentioned previously, wind turbines are unfortunately subject to mixed mode loading. Literature data indicates that mixed mode (Mode I + Mode III) fracture toughness and dynamic tearing modulus values are reduced by $50 \%$ and $70 \%$, respectively from those under Mode I conditions [Li 1996].

\subsection{Mixed loading of polymeric composites}

Typical composite materials used in wind turbine blade manufactures are fiber (glass and/or carbon fibers) reinforced polymeric (especially thermosetting polymers) materials. Compared to fibers, the polymeric matrices possess a much lower stiffness. The toughness and especially failure strain is moderate for thermosets, $5-8 \%$, and the polymeric matrices thus induce toughness in the composites, in particular via energy absorbing mechanisms related to the fiber-matrix interface [Kelly 2000]. Thus, the mixed-mode failure mechanism of the resin matrix deserves attention.

Because the composite materials used for the manufacture of these components are laminated, fracture behavior of the interfacial region between layers in the lamina and between fibers and the polymeric matrix, tend to be the weakest elements in the 
composite. Therefore, this needs to be characterized to ensure the structural reliability of the composites. The availability of simplified test methods to characterize the fracture behavior of composite materials under mixed modes of fracture is essential to enable the qualification and use of these materials for the next generation of wind turbines.

\subsection{Spiral notch torsion test (SNTT)}

\subsubsection{SNTT approach and FEM analyses}

To quantify the fracture behavior of composites under combined Mode I (flexural tensile stress) and Mode III (torsion shear stress) loading, this project aims to develop novel methods to test polymeric composite materials, based on the spiral notch torsion test (SNTT), an ORNL patented [Wang 2003a] R\&D 100 Award winning technology [Wang 2002a].

The SNTT test method uses a round-rod specimen having a V-grooved spiral line at a $45^{\circ}$ pitch (Figure 1 ), subjected to pure torsion. When the grooved specimen is sectioned into segments perpendicular to the groove line, each of the segments can be viewed as a CT specimen with a notch. Since all the imaginary CT specimens are bonded side-by-side seamlessly, the compatibility condition is automatically satisfied, and remains in place before and after application of torsion loading. In the absence of the V-groove, the stress state of a generic element in a round bar under pure torsion can be depicted as tension (normal to the $45^{\circ}$ pitch) and compression (tangential to $45^{\circ}$ pitch) of equal magnitude. When a notch is introduced (Figure 1), a tri-axial tensile stress field will evolve in the neighborhood of the notch root area. This observation has been experimentally and analytically validated [Wang 2000, 2002b]. Therefore, when a $V$-grooved spiral line with a $45^{\circ}$ pitch is machined on the surface of the specimen, the grooved line effectively becomes a Mode I crack mouth opening.

Due to the 3-D non-coplanar crack front of the SNTT configuration and the lack of closed form solutions, $\mathrm{K}_{\mathrm{IC}}$ of the SNTT method was evaluated using 3-D finite element analysis and derived from minimum strain energy density criterion [Sih 1974] or JIntegral based on the domain integral method [Wang 2000, 2002b]. Typically, a finite element model shown in Figure $2 a$ is used for brittle SNTT specimens, such as concrete, with shallow crack fronts and while the model shown in Figure $2 b$ is used for ductile specimens. The SNTT FEM model normally contains about 8,000 20-node quadratic brick elements with reduced integration and 35,000 nodes. 


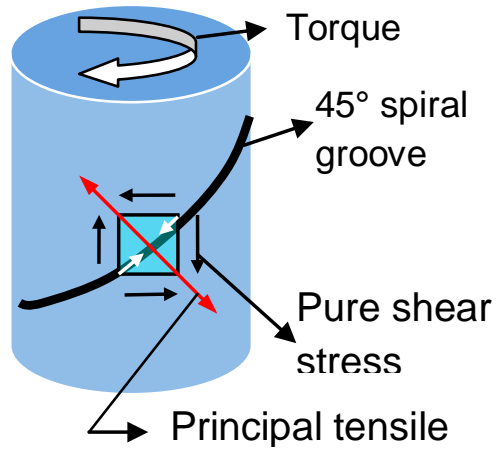

Figure 1. SNTT configuration.

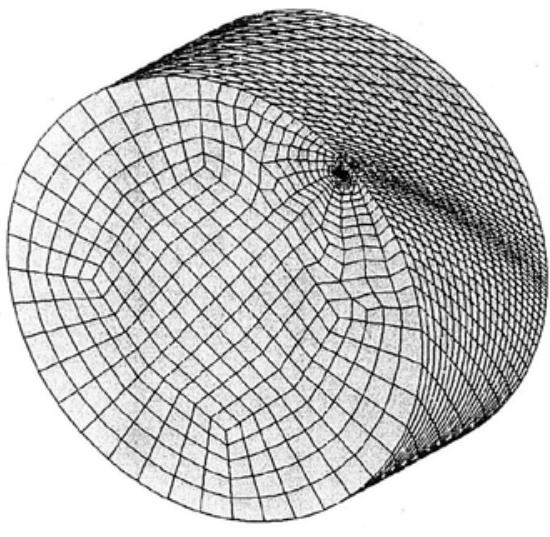

(a) Shallow notch crack

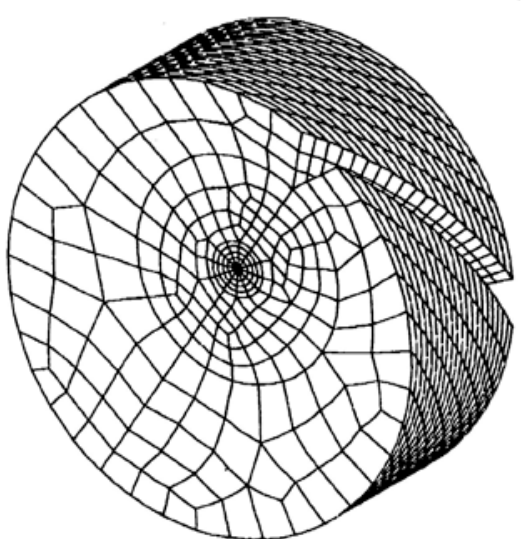

(b) Deep fatigue precrack

Figure 2. SNTT FEM Models.

\subsubsection{SNTT specimen size reduction}

The CT specimen, as shown in Figure 3, has been widely used in existing fracture toughness test methods because the general consensus indicates it is the nextbest basic configuration that nearly conforms to the strict requirements of the classical theory of fracture mechanics. Despite the simplification, the theoretical conditions (i.e., the conditions required to achieve uniformly distributed applied stress over the thickness and plane-strain condition) can never materialize as long as free surfaces exist at both ends of the specimen. The end effects will be further amplified when the thickness decreases to a thin plate, as shown in Figure 3. Another dilemma is that an increase in specimen thickness will automatically accompany an increase in specimen length and width in order to maintain specimen rigidity under load. Miniaturization is an important 
goal of the SNTT method. This is made possible because the $\mathrm{K}_{\mathrm{IC}}$ values determined by the SNTT method are virtually independent of specimen size. A cursory review of the stress and strain fields in a CT specimen indicates that the key information needed for determining the $\mathrm{K}_{\mathrm{IC}}$ values is manifested within a small region near the crack tip; therefore, the rod specimen can be miniaturized substantially without the loss of general validity (Figure 3). The purpose of the vast volume of the material outside the critical zone in conventional samples is to poise the ideal far field of stress and to provide a means to accommodate loading devices. This redundancy is eliminated to the optimum condition in the round rod specimen; therefore, specimen miniaturization is achievable.

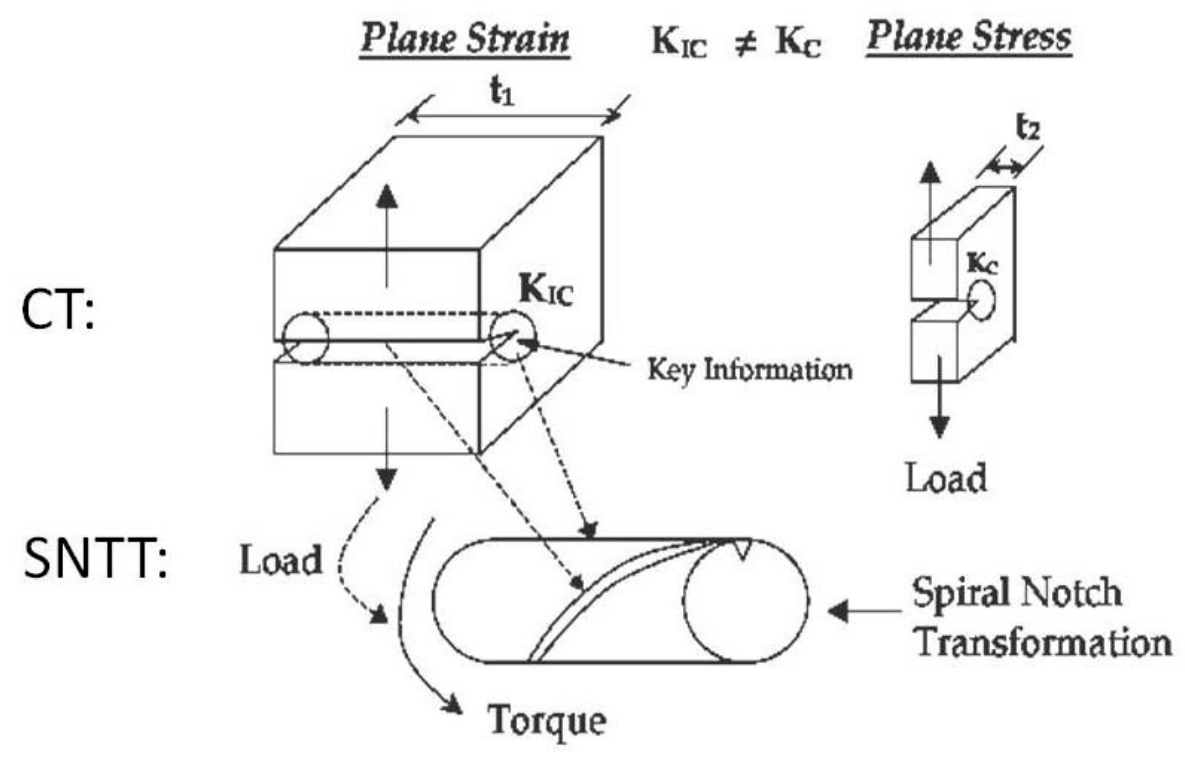

Figure 3. Specimen size effect.

Figure 4 illustrates the fracture toughness testing methods for brittle materials (such as graphite or carbon composite), which indicates that a test specimen machined with a deep notch is required. However, for the SNTT method only a shallow surface notch is required for testing of brittle materials. This will further reduce the specimen size as compared to a conventional test as shown in Figure 4. 


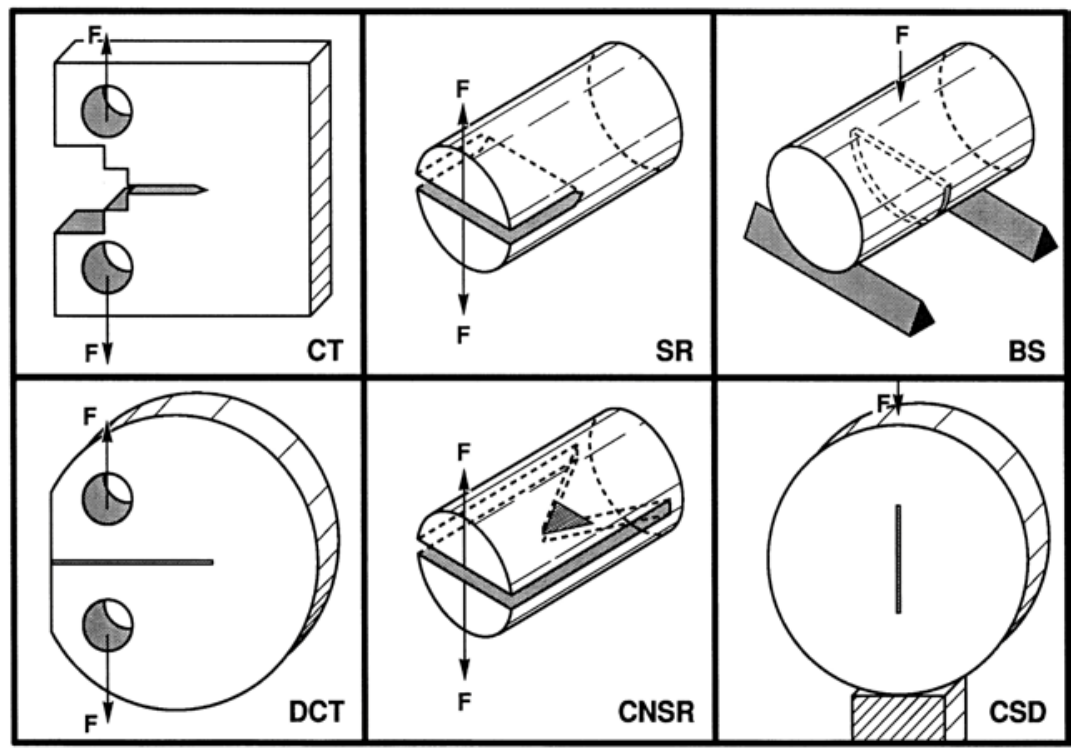

CT: Compact Tension; SR: Short Rod; BS: Bending Short Rod; DCT: Disk shape CT; CNSR: Chevron Notched Short Rod; CSD: Central loaded Short Disk.

Figure 4. Brittle material toughness testing methods.

Because of the plane strain and axisymmetric constraint and the uniformity in the stress and strain fields of the SNTT configuration, the crack front must propagate perpendicularly toward the specimen axis and along the conoids. Post-mortem examination verified such crack propagation behavior (see Figure 5) which was also verified from epoxy fatigue precracked samples.

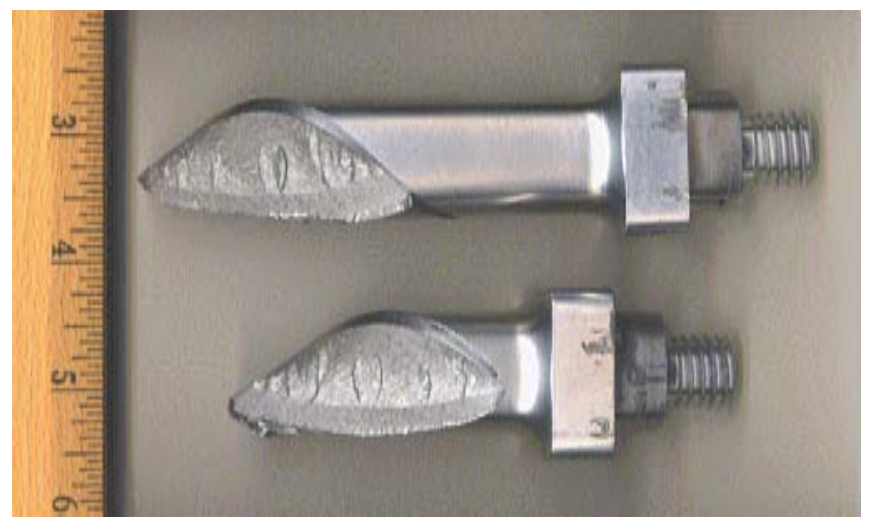

Figure 5. SNTT sample made from aluminum 7475-T7351 


\subsubsection{Mixed-mode fracture toughness}

In a recent study of mixed-mode fracture [Li 1996], utilizing a complex test set-up with a specially machined CT specimen, test results indicate that mixed-mode (Mode I + Mode III) toughness and tearing modulus reduced to $50 \%$ and $30 \%$, respectively, compared to those under Mode I only for the ductile materials. Therefore, the implication or the potential of the synergistic impact due to the combination of flexural normal stress (Mode I fracture) and the torsion shear stress (Mode III fracture) to the fracture toughness for the composite materials needs a close look. As for the brittle materials, the Mode I is still the dominate failure mode, such as for epoxy materials, as revealed from the current study on the epoxy materials. In applying the SNTT approach for the mixed Mode I + Mode III failure study, this can be achieved by simply varying the pitch angle of the spiral notch. A radiator hose was used to illustrate the SNTT approach under pure torsion loading Figure 6. As shown in Figure 6a, a slit was cut along the principal shear direction, i.e., along 0 or $180^{\circ}$, and the deformation appears to be pure shear Mode III failure. As shown in Figure $6 \mathrm{~b}$ if a slit was cut along $45^{\circ}$ angle, along the principal tensile stress orientation, the deformation appears to be opening Mode I failure. Therefore, by varying the pitch angle, Mode I and Mode III loading can be achieved with a SNTT sample under pure torsion loading.

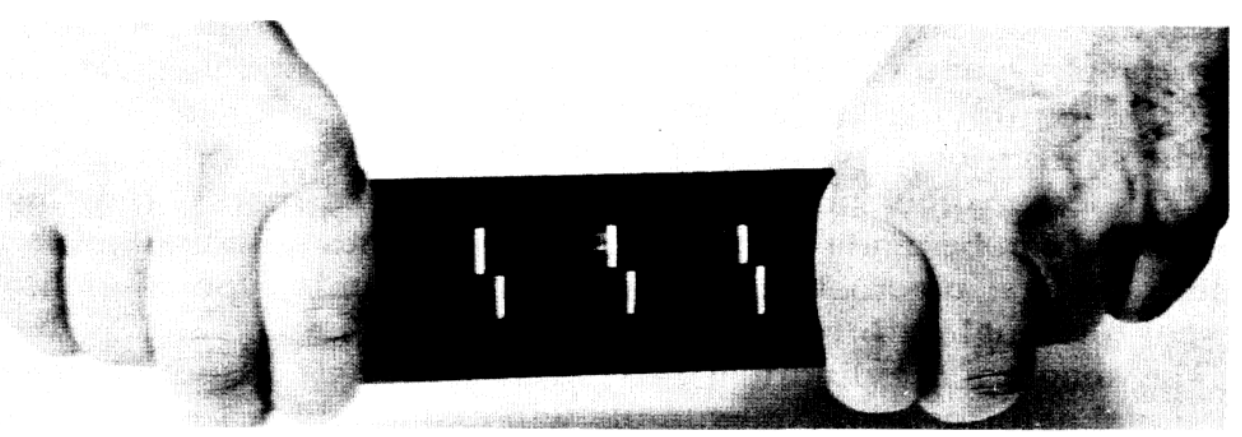

(a)

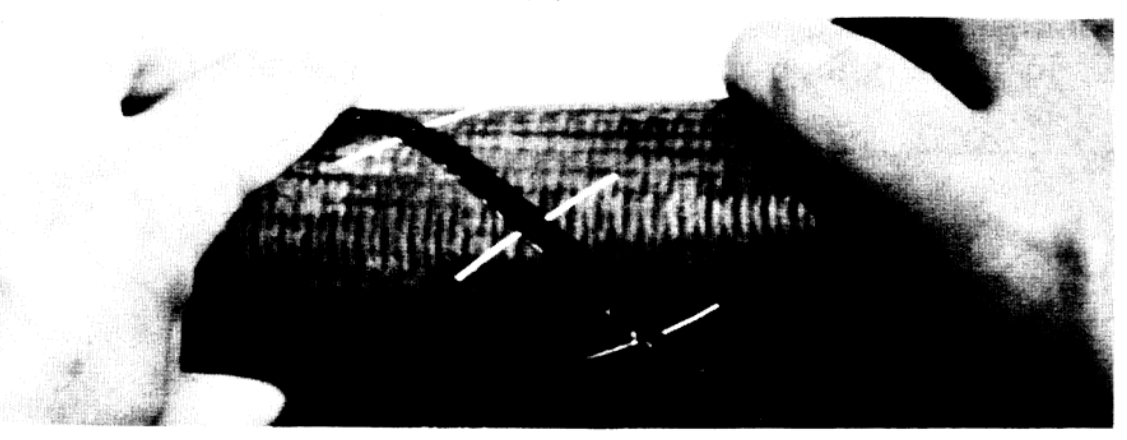

(b)

Figure 6. Illustration of SNTT approach using a radiator hose. 


\section{Scope of current research}

The objective of this research is to develop a mixed-mode SNTT methodology for evaluation of mixed-mode, static and dynamic fracture behaviors of composite materials used for wind turbine blades. The project is divided into the following steps:

1) Equipment and sample preparation;

2) SNTT testing and simulation of matrix polymeric materials;

3) SNTT testing and simulation of composite materials;

4) Study on the effects of loading rates and environmental factors

During FY2010 progress has been made in preparing the testing equipment, sample design and fabrication, testing of epoxy materials, and finite element modeling of epoxy SNTT samples. Specifically, the effects of sample geometry and loading conditions (Mode I vs. mixed mode) have been extensively studied. A great effort has also been put into characterization of the fracture surfaces of the test epoxy samples.

The first year accomplishment demonstrated the applicability of the SNTT technique for the evaluation of polymeric materials and provided understanding of the fracture behavior of these materials under tensile loading and mixed mode loading.

The encouraging results to date led to further exploration into the composite regime. The ORNL research team is currently working closely with Prof. John Mandell's group at Montana State University on designing and fabricating composite samples for SNTT experiments. 


\section{Equipment and sample preparation}

\subsection{Equipment preparation}

In this study, a biaxial (axial/torsional) hydraulic-servo testing machine (Model 809, MTS Systems Corp. Eden Prairie, MN, USA) is used to conduct the SNTT testing (Figure 7). The maximum load and torque of this test machine are $22,000 \mathrm{lbf}$ and 10,000 lbf-in, respectively. During the first quarter of 2010 , the loading frame was realigned, the filters for the hydraulic pump were replaced, and a hydraulic lock seal was replaced. A pair of sample grip fixtures were also designed and fabricated. Figure 7 shows the SNTT test set-up with an epoxy sample being tested under pure torsion loading.

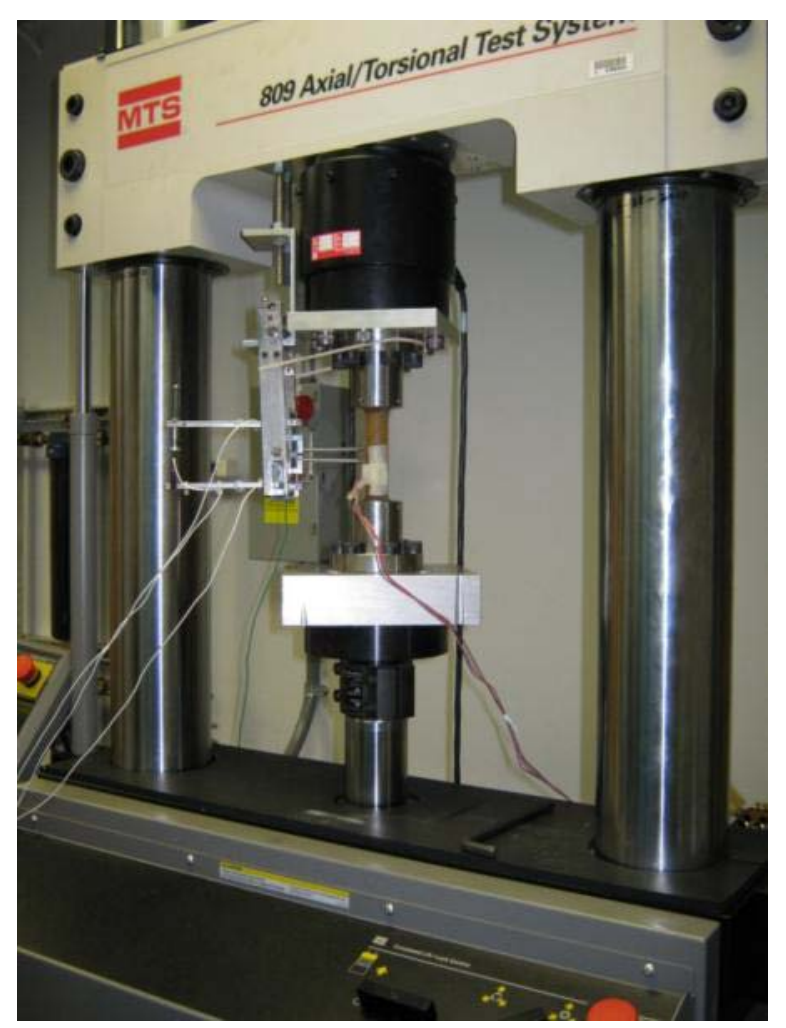

Figure 7. MTS 809 Axial/torsional test system used for SNTT.

An in-house built biaxial extensometer was utilized for displacement measurements (Figure 7). The extensometer consists of three pairs of capacitive sensors used to measure the relative displacement of the two probe pins both in the axial direction and torsional directions. Prior to testing, the extensometer was calibrated with a biaxial extensometer calibration block (Figure 8). 


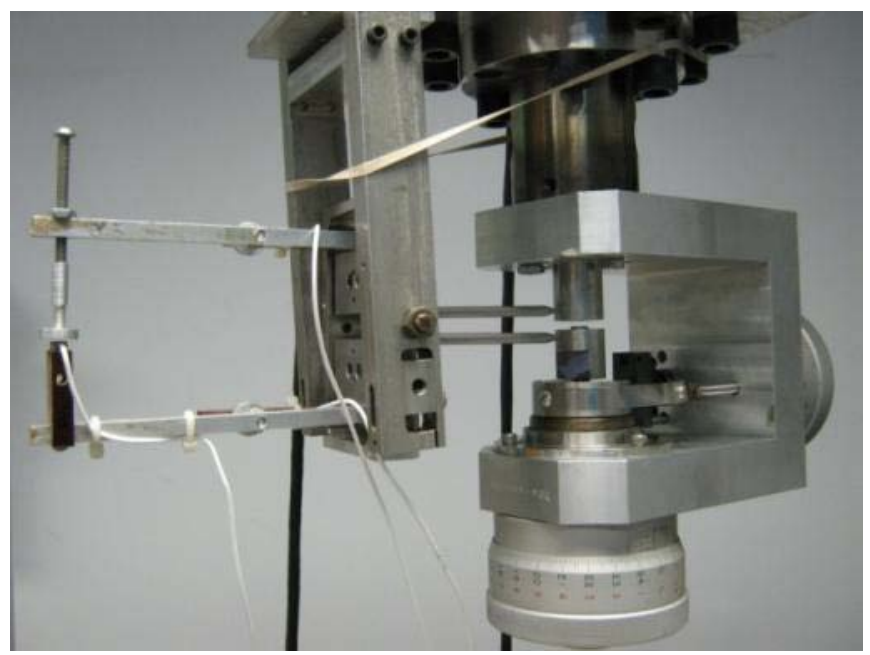

Figure 8. Calibration of the biaxial extensometer.

The data acquisition system consists of three capacitive amplifiers (Model 4100-L, Capacitec Inc. Ayer, MA, USA) and a clock drive with LED meter (Model 4100-CM4, Capacitec Inc. Ayer, MA, USA), all enclosed by a rack enclosure (Model 4016-C, Capacitec Inc. Ayer, MA, USA). The Capacitec system is connected to a computer by coaxial cables for data recording (Figure 9).

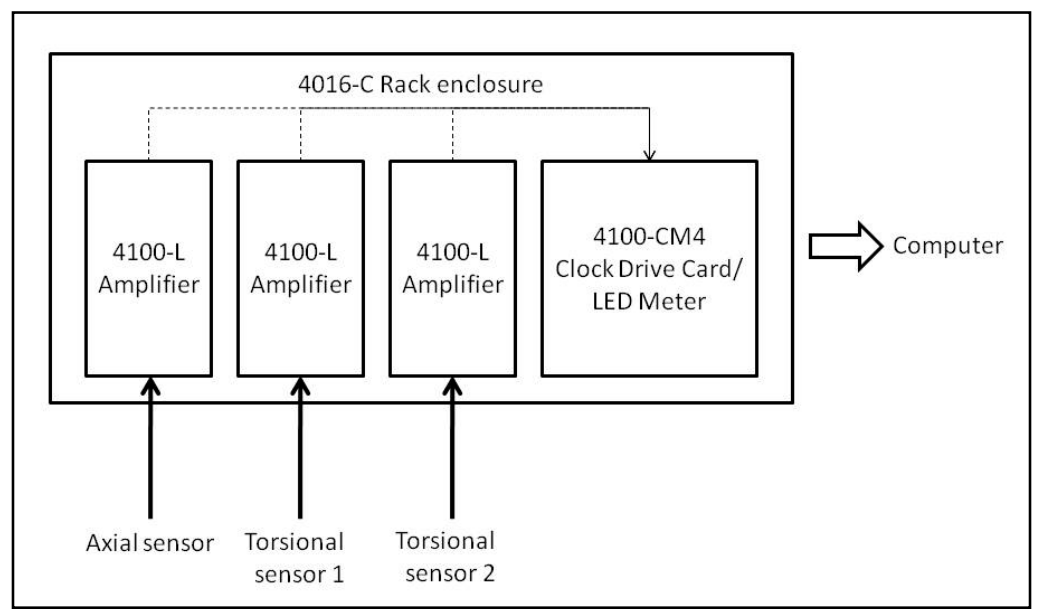

Figure 9. Block diagram of the capacitive data acquisition system.

In order to monitor and record the in-situ temperature on the sample surface during SNTT testing, an infrared imaging system (Model A325, FLIR Systems, Boston, MA, USA) has been set up (Figure 10). In addition, thin film thermocouples (CO1-K, Omega Engineering, Inc. Stamford, CT, USA) are also used as a temperature reference. 


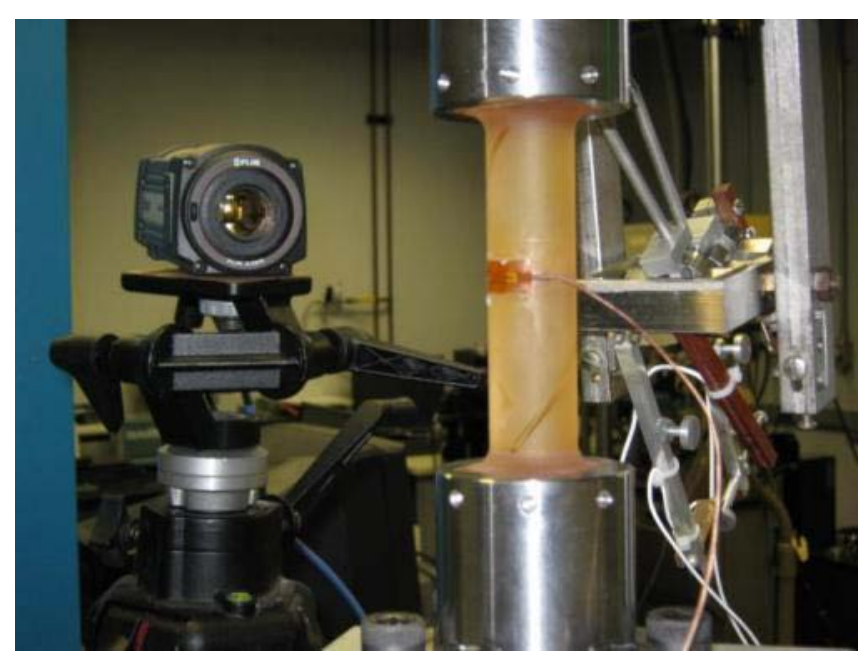

Figure 10. The IR imaging system used to monitor SNTT samples.

\subsection{Epoxy sample preparation}

Raw epoxy materials were obtained from two of our industrial partners: Pro-Set ${ }^{\circledR}$ epoxy, Gougeon Brothers (GB), Inc. Bay City, MI; and Hexion ${ }^{\circledR}$ EpikoteTM MGS $®$ epoxy, Molded Fiber Glass Companies (MFG), Ashtabula, OH (Table 1) (Figure 11). Basic mechanical properties, as provided by the vendors are summarized in Table 1and the chemical compositions for each epoxy system are listed in Table 2.

Table 1. Processing and mechanical properties of the received epoxy materials

\begin{tabular}{|l|l|l|l|}
\hline Mechanical properties & $117 \mathrm{LV} / 229$ & $117 \mathrm{LV} / \mathrm{XH} 10 \mathrm{~B}$ & RIM135/RIMH1366 \\
\hline Supplier & GB & GB & MFG \\
\hline Product family & Pro-Set ${ }^{\circledR}$ & Pro-Set ${ }^{\circledR}$ & Hexion ${ }^{\circledR}$ Epikote ${ }^{\mathrm{IM}}$ MGS $\AA$ \\
\hline Resin to hardener ratio & $100: 31$ & $100: 33.9$ & $100: 30$ \\
\hline Curing conditions & $\begin{array}{l}\text { Overnight at room temperature } \\
\text { followed by } 8 \text { hrs at } 60^{\circ} \mathrm{C}\end{array}$ & $\begin{array}{l}\text { Cured through the exotherm, and } \\
\text { post-cured for } 6.5 \text { hours at } 70^{\circ} \mathrm{C} .\end{array}$ \\
\hline Elastic modulus (GPa) & 3.4 & 3.1 & $2.7-3.2$ \\
\hline Tensile strength (MPa) & 70 & 66 & $60-75$ \\
\hline Tensile elongation (\%) & 3.2 & 4.3 & $8-16$ \\
\hline Compressive strength (MPa) & 102 & 104 & $80-90$ \\
\hline Impact strength & $28.3 \mathrm{~J} / \mathrm{m}$ & $57.6 \mathrm{~J} / \mathrm{m}$ & $70-80 \mathrm{KJ} / \mathrm{m}^{2}$ \\
\hline
\end{tabular}


Table 2. Chemical composition of the resins and hardeners used in the study.

\begin{tabular}{|c|c|c|}
\hline Epoxy component & Ingredient & concentration \\
\hline \multirow{3}{*}{ Pro-Set ${ }^{\circledR} 117 L V$ infusion resin } & Bisphenol-A type epoxy resin & \\
\hline & Bisphenol-F type epoxy resin & \\
\hline & Neopentyl glycol diglycidyl ether & $<25 \%$ \\
\hline \multirow[t]{5}{*}{ PRO-SET $® 229$ Hardener } & Polyoxypropylenediamine & $25-50 \%$ \\
\hline & $\begin{array}{l}\text { Reaction products of isophoronediamine } \\
\text { with phenol/formaldehyde }\end{array}$ & $<25 \%$ \\
\hline & Isophoronediamine & $<25 \%$ \\
\hline & Triethylenetetramine (TETA) & $<12 \%$ \\
\hline & Hydroxybenzene & $<7 \%$ \\
\hline \multirow{5}{*}{$\begin{array}{l}\text { Developmental Hardener XH 00- } \\
\text { 099-10B }\end{array}$} & Polyoxypropylenediamine & $25-50 \%$ \\
\hline & $\begin{array}{l}\text { Reaction products of isophoronediamine } \\
\text { with phenol/formaldehyde }\end{array}$ & $<25 \%$ \\
\hline & Isophoronediamine & $<25 \%$ \\
\hline & Triethylenetetramine (TETA) & $<10 \%$ \\
\hline & Hydroxybenzene & $<7 \%$ \\
\hline \multirow[t]{2}{*}{$\begin{array}{l}\text { EPIKOTE }{ }^{\text {In }} \text { Resin MGS RIMR } \\
135\end{array}$} & $\begin{array}{l}\text { 4,4'-Isopropylidenediphenol- } \\
\text { Epichlorohydrin Copolymer }\end{array}$ & $70-100 \%$ \\
\hline & 1,6-Hexanediol Diglycidyl Ether & $10-30 \%$ \\
\hline \multirow{3}{*}{$\begin{array}{l}\text { EPIKURE TM Curing Agent MGS } \\
\text { RIMH } 1366\end{array}$} & Alkyletheramine & $25-50 \%$ \\
\hline & Isophoronediamine & $20-25 \%$ \\
\hline & Aminoethylpiperazine & $<20 \%$ \\
\hline
\end{tabular}

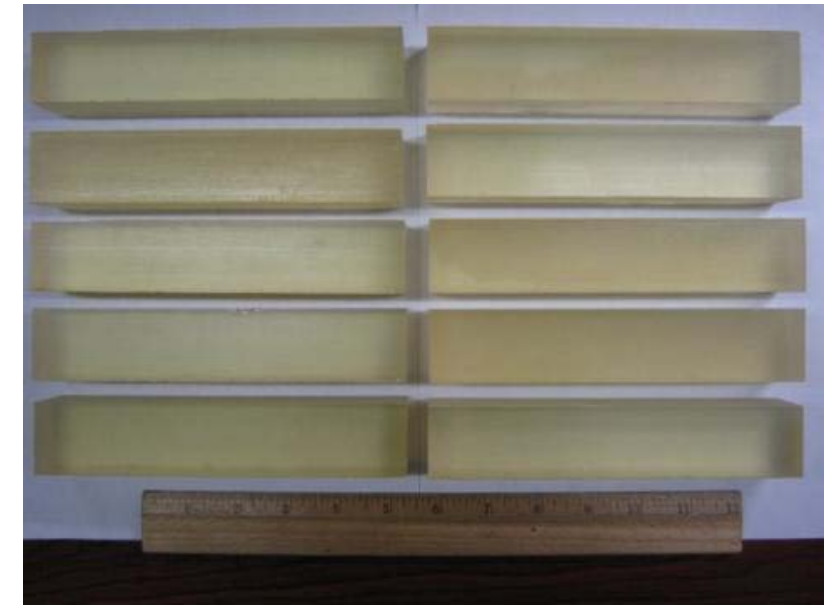

(a)

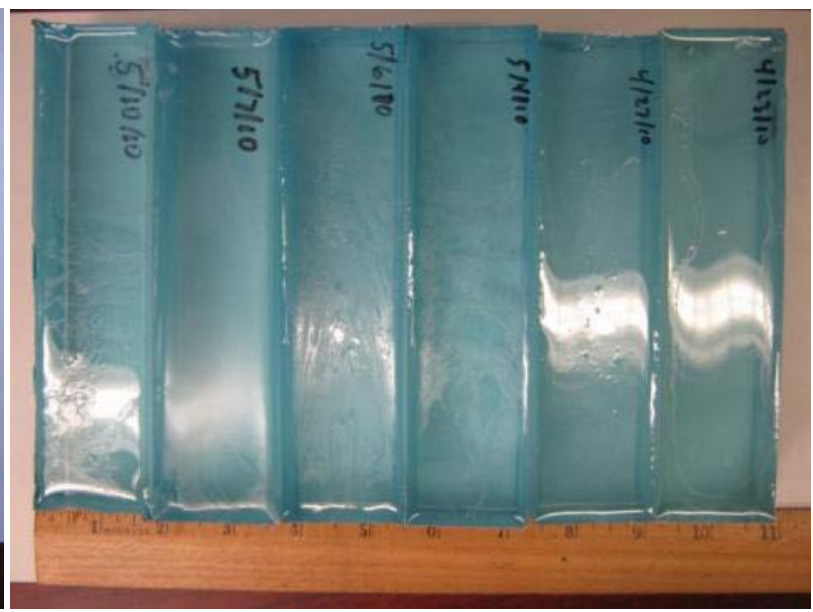

(b)

Figure 11. Pictures showing raw epoxy materials received from (a) Gougeon Brothers, Inc. and (b) Molded Fiber Glass Companies.

The geometry of the epoxy samples for SNTT testing is illustrated in Figure 12. The samples are 1" in diameter with a gauge length of 4"and a V-shaped spiral groove machined on the sample surface. Most samples have a V-groove with $\psi=45^{\circ}$ angle, while a few samples were made with $\psi=90^{\circ}$.Three depths of groove were used: $0.1 "$, $0.2^{\prime \prime}$, and $0.3^{\prime \prime}$ to simulate different crack lengths. The pitch angle $\theta$, varies between $45^{\circ}$ 
and $20^{\circ}$. When $\theta=45^{\circ}$, the principal stress $\sigma_{1}$ (tensile) is perpendicular to the notch, and the associated failure mode will be Mode I (tensile opening mode). When $\theta<45^{\circ}$, the notch is subject to a mixed loading of Mode I and Mode III (tearing mode, torsional shear mode). Figure 13 shows some pictures of SNTT epoxy samples. To date (by August. $24^{\text {th }}$ 2010), a total number of 31 epoxy samples were fabricated (Table 3 ).

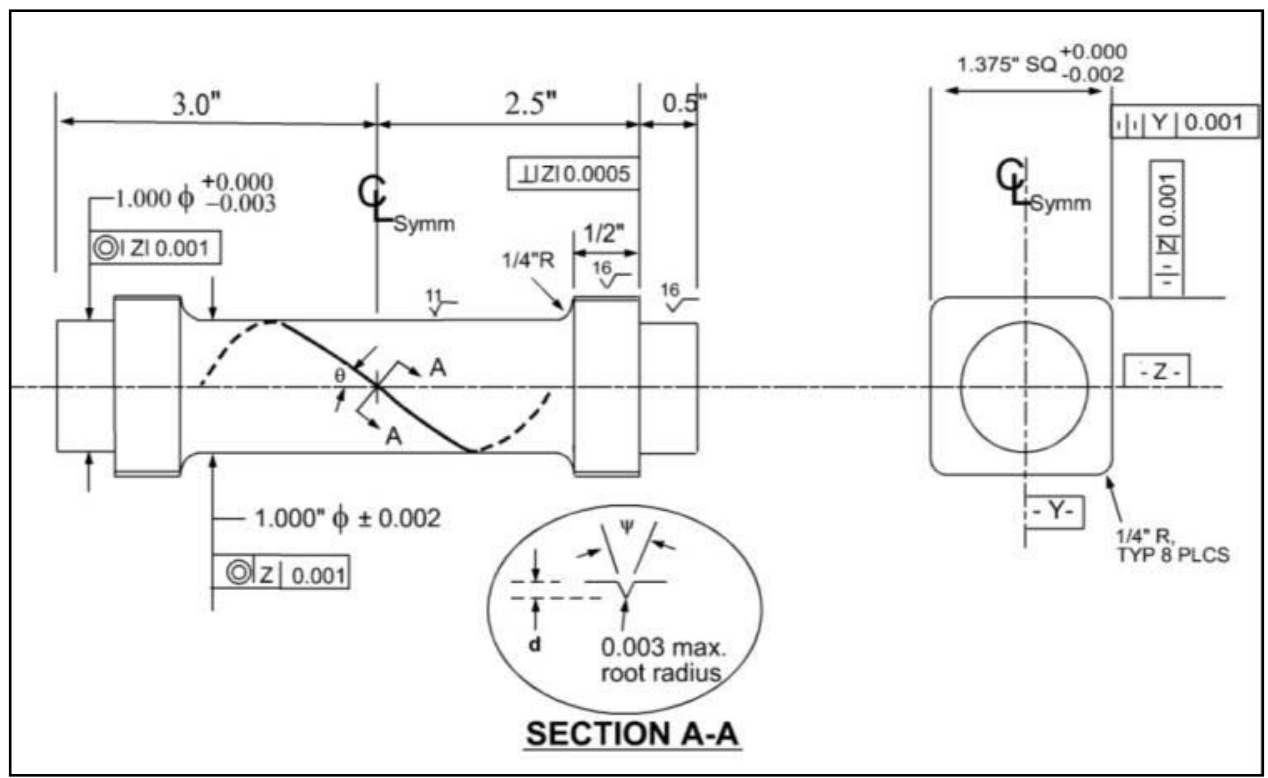

Figure 12. SNTT sample geometry.

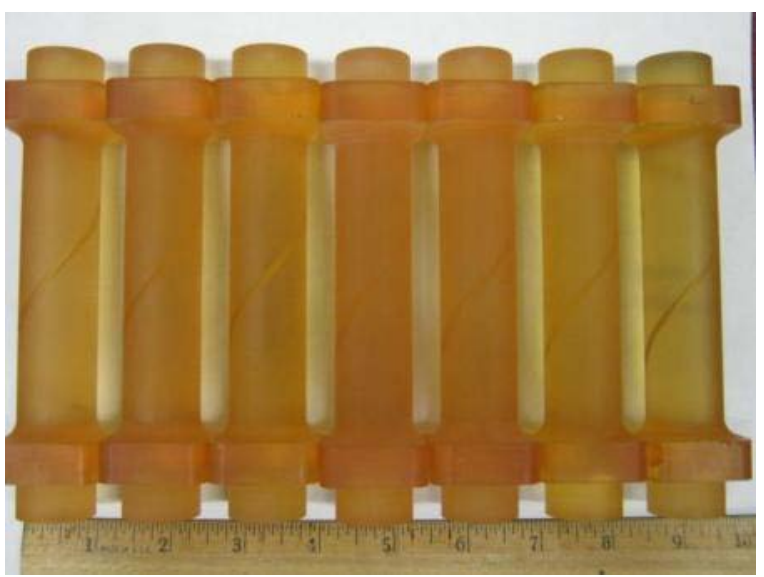

(a)

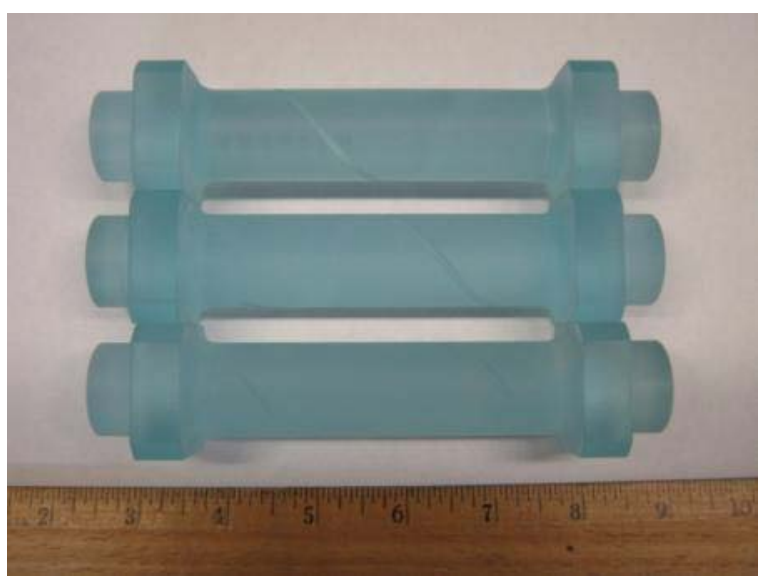

(b)

Figure 13. Pictures showing machined samples made from epoxy materials provided by (a) Gougeon Brothers, Inc. and (b) Molded Fiber Glass Companies. 
Table 3. Geometries of SNTT epoxy samples.

\begin{tabular}{|c|c|c|c|}
\hline Depth & & Pitch angle & Sample ID \\
\hline \multirow{5}{*}{$d=0.1 "$} & \multirow{5}{*}{$\psi=45^{\circ}$} & \multirow{3}{*}{$\theta=45^{\circ}$} & GB 3-4, 3-5, 3-6, 3-7 \\
\hline & & & GB 4-4, 4-5, 4-6 \\
\hline & & & MFG $1,2,3$ \\
\hline & & \multirow[t]{2}{*}{$\theta=36^{\circ}$} & $\begin{array}{l}\text { GB 1-1, GB 1-2, GB 1-3, GB 1-4, } \\
\text { GB 1-5, GB 1-6, GB 1-7 }\end{array}$ \\
\hline & & & GB 2-1, GB 2-2 \\
\hline \multirow[t]{2}{*}{$d=0.115 "$} & \multirow[t]{2}{*}{$\psi=90^{\circ}$} & \multirow[t]{2}{*}{$\theta=45^{\circ}$} & GB 3-1, 3-2, 3-3 \\
\hline & & & GB 4-1, 4-2, 4-3 \\
\hline \multirow[t]{2}{*}{$d=0.2^{\prime \prime}$} & \multirow[t]{2}{*}{$\psi=45^{\circ}$} & $\theta=28^{\circ}$ & GB 2-3, GB 2-4 \\
\hline & & $\theta=45^{\circ}$ & GB 3-8 \\
\hline \multirow[t]{2}{*}{$\boldsymbol{d}=0.3^{\prime \prime}$} & \multirow[t]{2}{*}{$\psi=45^{\circ}$} & $\theta=20^{\circ}$ & GB 2-5, GB 2-6 \\
\hline & & $\theta=45^{\circ}$ & GB 3-9 \\
\hline
\end{tabular}

Note on sample ID: GB = Gougeon Brothers, Inc., MFG = Molded Fiber Glass Companies, the first number denotes the batch number; the second number denotes the sample number in a given batch.

\subsection{Composite sample design}

To date, more than 30 epoxy samples have been successfully fabricated through machining based on the geometry shown in Figure 12. However, making composite samples presents many challenges. One of the challenges is related to the anisotropic nature of composite materials used in turbine blades, such as fiber glass composites. Epoxies can be treated as isotropic materials. In contrast, reinforcement fibers not only possess different mechanical properties, such as higher stiffness, but also exhibit large anisotropy such that the properties in the axial direction can vary significantly from transverse direction. In addition, the composites may exhibit increased toughness when fiber is added.

Thus, different approaches are proposed to fabricate composite samples. One approach is to build composite structures on top of epoxy bars, by either filling in a machined groove with epoxy/fiber (Figure 14a) or gluing fiber layers on to the epoxy surface (Figure 14b). In these configurations, the epoxy bar functions as a mandrel. In a different approach sandwich structures will first be made from epoxy and fiberglass layers, followed by core-drilling to form cylindrical samples (Figure $14 \mathrm{c}-\mathrm{d}$ ). Depending on the relative orientation of the sample axis after core-drilling of the original sandwich structure, a spiral notch may (Figure 14c) or may not (Figure 14d) be needed.

Further improvements in sample design and composite sample fabrication are in progress as a joint effort between the ORNL team and the MSU group. 


\section{DRAFT}

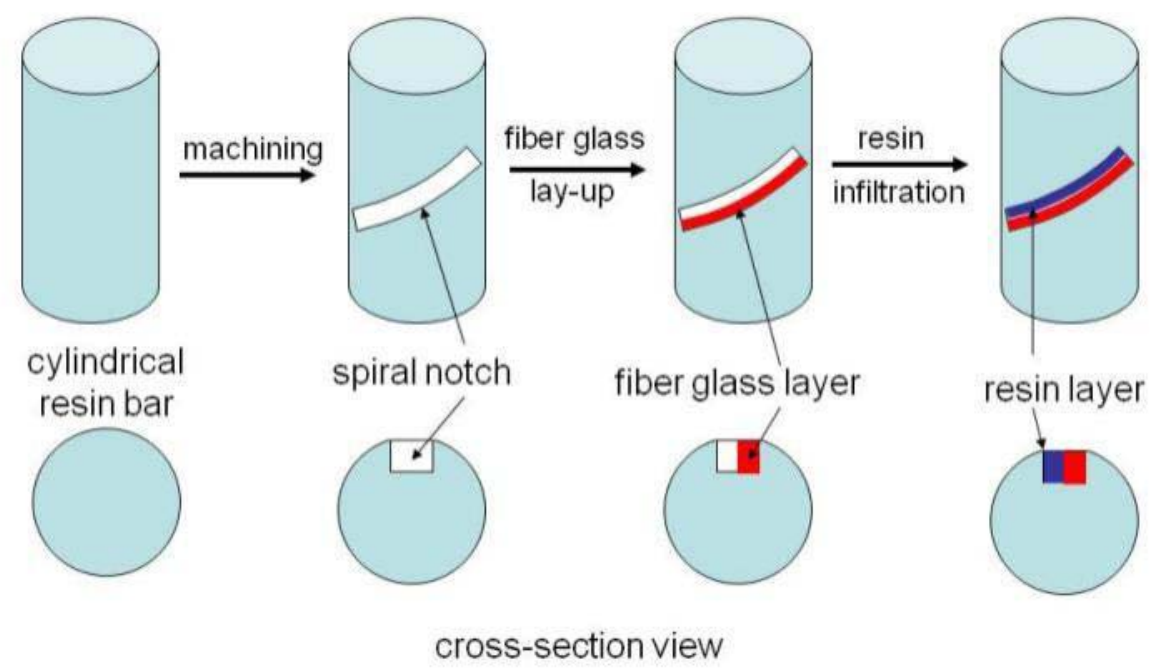

(a)

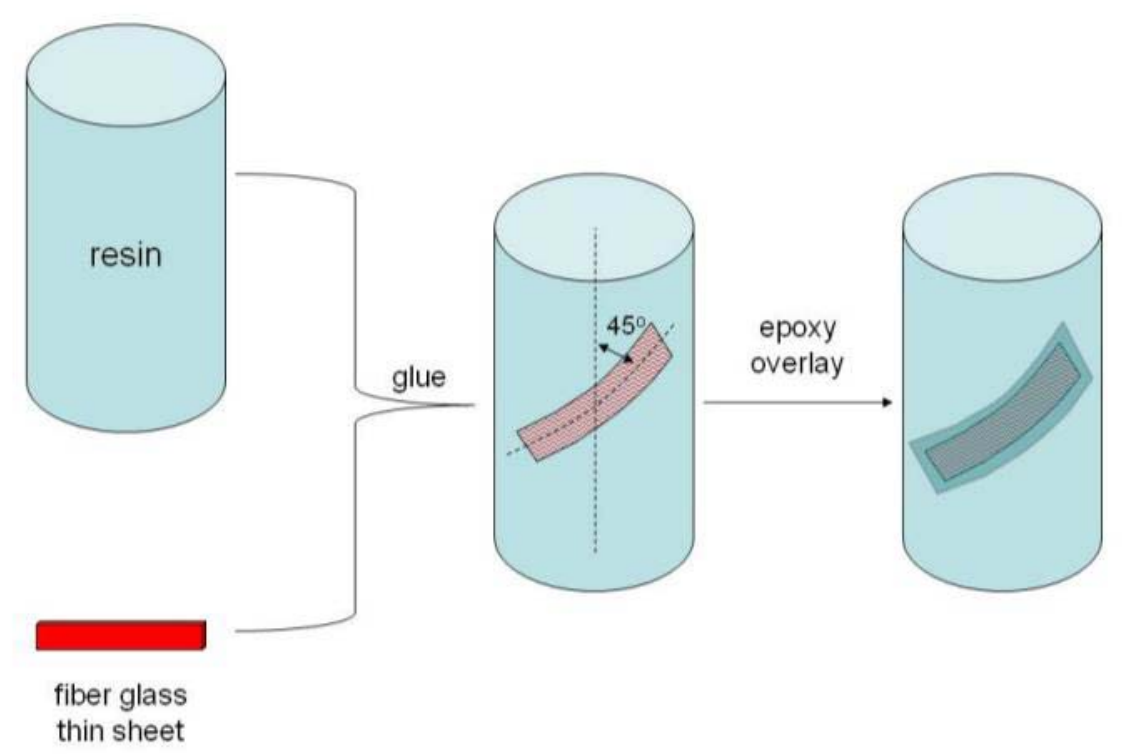

(b) 


\section{DRAFT}

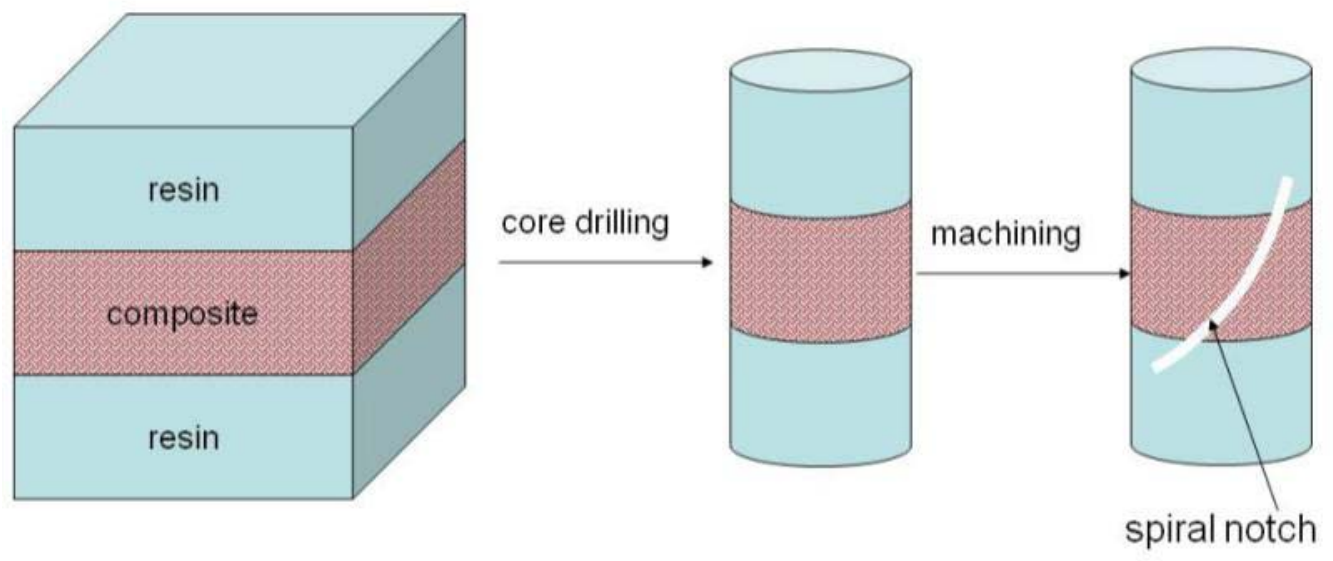

(c)
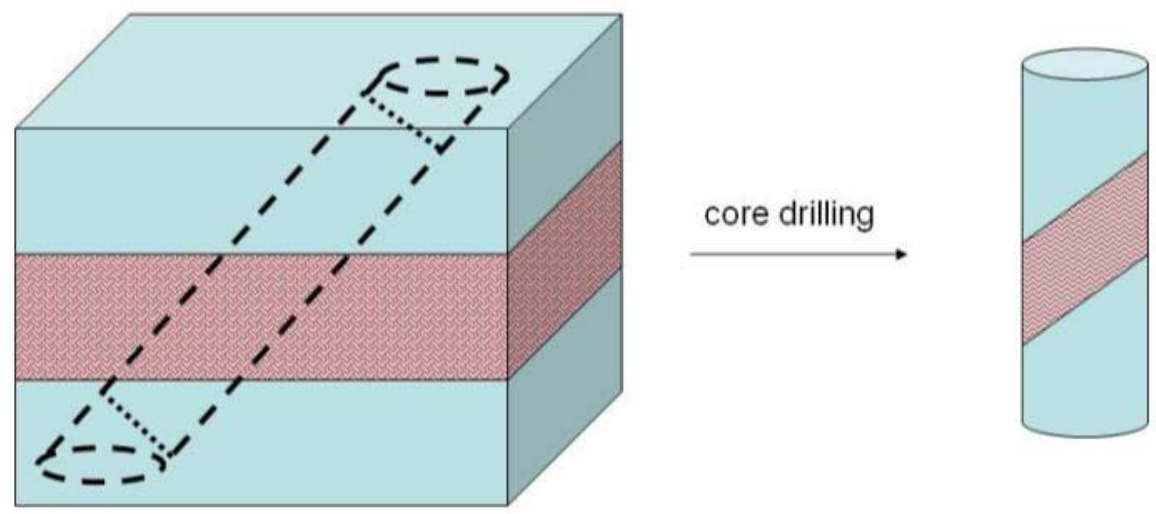

(d)

Figure 14. Proposed methods for fabricating composite SNTT samples. 


\section{SNTT testing of epoxy samples}

Three types of torsional testing were performed on epoxy samples:

1) Monotonic loading;

2) Fatigue;

3) Monotonic loading of fatigued samples;

For monotonic loading, pure torsion loading was applied to the samples with axial loading maintained as close to zero as possible. For a SNTT sample, the tensile principal stress is normal to the groove line with a $45^{\circ}$ pitch angle. Torque was monotonically increased until the sample fractured at a constant loading rate of $40 \mathrm{lbf}-$ in/sec. Meanwhile, a small compression force of $5 \mathrm{lbf}$ was maintained along the sample axis to prevent the sample from dropping off the grips.

For fatigue testing, various loading conditions have been explored. Two controlling modes were used: angle control (A control) by cycling between two selected rotation angles registered by RVDT, and torque control ( $T$ control) by cycling between two selected torque values ( $T_{\max }$ and $T_{\min }$ ). Table 4 summarizes SNTT tests performed on Aug. $16^{\text {th }}$ 2010. $R=T_{\min } / T_{\max } . N=$ number of fatigue cycles. The first sample tested, GB1-1, is not included in Table 4 because it was fractured accidentally when tuning the testing machine.

\subsection{SNTT deformation process via IR imaging}

Using an infrared camera, the in-situ fracture process of epoxy samples during SNTT was examined. Figure 15 shows IR images and temperature profiles across the notch, as marked with blue line in Fig. 14, obtained from sample GB2-6 during monotonic loading.

Without loading, the temperature was uniform on the sample surface (Figure 15a). When torque was applied, the vicinity of the notch root region was subject to a tri-axial tensile stress state. In general, under IR imaging material at peak (or principal) tri-axial tensile stress (or at a localized material stretched state) region will show a relatively lower temperature compared to nearby lower tensile stress regions [Wang, H. 2002]. The temperature profile shown in Figure $15 \mathrm{~b}$ exhibits this behavior where a relatively small temperature drop was observed in the vicinity of the notch region. It is noted that due to increase in strain energy in the sample, the overall temperature profile was increased as also shown in Fig. 14b. At the moment of the SNTT sample fracture, surface temperatures peaked at the notch location (Figure 15c) due to the release of surface energy upon fracture. 
DRAFT

Table 4. Epoxy samples testing summary

\begin{tabular}{|c|c|c|c|c|c|c|c|c|c|}
\hline \multicolumn{10}{|c|}{ Monotonic loading } \\
\hline Sample & Material & Nominal geometry & Fracture Torque & \multicolumn{6}{|l|}{ Note } \\
\hline GB2-1 & 2 & $d=0.1^{\prime \prime}, \psi=45^{\circ}, \theta=36^{\circ}$ & 774 lbf-in & \multicolumn{6}{|l|}{ 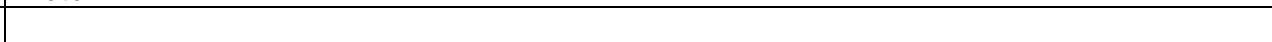 } \\
\hline GB2-6 & 2 & $d=0.3^{\prime \prime}, \psi=45^{\circ}, \theta=20^{\circ}$ & 447 lbf-in & \\
\hline GB3-1 & 1 & $d=0.115^{\prime \prime}, \psi=90^{\circ}, \theta=45^{\circ}$ & 338 lbf-in & \\
\hline GB3-6 & 1 & $d=0.1^{\prime \prime}, \psi=45^{\circ}, \theta=45^{\circ}$ & 384 lbf-in & \multirow{2}{*}{\multicolumn{6}{|c|}{ Blunt notch root; root sharpened with razor blade }} \\
\hline GB3-8 & 1 & $d=0.2^{\prime \prime}, \psi=45^{\circ}, \theta=45^{\circ}$ & 343 lbf-in & & & & & & \\
\hline GB3-9 & 1 & $d=0.3^{\prime \prime}, \psi=45^{\circ}, \theta=45^{\circ}$ & 430 lbf-in & \multicolumn{6}{|c|}{ Blunt notch root } \\
\hline GB4-1 & 1 & $d=0.115^{\prime \prime}, \psi=90^{\circ}, \theta=45^{\circ}$ & $305 \mathrm{lbf}-\mathrm{in}$ & \\
\hline GB4-4 & 1 & $d=0.1^{\prime \prime}, \psi=45^{\circ}, \theta=45^{\circ}$ & 404 lbf-in & \\
\hline MFG-1 & 3 & $d=0.1^{\prime \prime}, \psi=45^{\circ}, \theta=45^{\circ}$ & 1013 lbf-in & & & & & & \\
\hline \multicolumn{10}{|l|}{ Fatigue } \\
\hline \multirow{2}{*}{ Sample } & \multirow{2}{*}{ Material } & \multirow[t]{2}{*}{ Nominal geometry } & \multicolumn{6}{|l|}{ Fatigue conditions } & \multirow[t]{2}{*}{ Note } \\
\hline & & & Fatigue mode & $T_{\max }$ (lbf-in) & $T_{\min }(\mathrm{lbf}-\mathrm{in})$ & $\mathbf{R}$ & Freq $(\mathrm{Hz})$ & $\mathbf{N}$ & \\
\hline \multirow[t]{3}{*}{ GB1-2 } & \multirow[t]{3}{*}{1} & \multirow[t]{3}{*}{$d=0.1^{\prime \prime}, \psi=45^{\circ}, \theta=36^{\circ}$} & A control $\left(5.17^{0}-6.43^{\circ}\right)$ & $400^{*}$ & $300^{*}$ & $0.75^{*}$ & 1 & $100 \mathrm{~K}$ & *Values at fatigue start \\
\hline & & & $\mathrm{T}$ control & 450 & 350 & 0.78 & 1 & 3000 & \\
\hline & & & A control $\left(7.50^{\circ}-8.75^{\circ}\right)$ & $500^{*}$ & $400^{*}$ & $0.8^{*}$ & 2 & $\sim 2 \mathrm{Ks}$ & ${ }^{*}$ Values at fatigue start \\
\hline \multirow[t]{9}{*}{ GB1-3 } & \multirow[t]{9}{*}{1} & \multirow[t]{9}{*}{$d=0.1^{\prime \prime}, \psi=45^{\circ}, \theta=36^{\circ}$} & T control & 200 & 150 & 0.75 & 1 & $70 \mathrm{~K}$ & \\
\hline & & & $\mathrm{T}$ control & 250 & 200 & 0.8 & 1 & $90 \mathrm{~K}$ & \\
\hline & & & T control & 300 & 250 & 0.83 & 1 & $50 \mathrm{~K}$ & \\
\hline & & & T control & 400 & 350 & 0.88 & 1 & $30 \mathrm{~K}$ & \\
\hline & & & $\mathrm{T}$ control & 450 & 400 & 0.89 & 1 & $100 \mathrm{~K}$ & \\
\hline & & & T control & 550 & 500 & 0.91 & 2 & $50 \mathrm{~K}$ & \\
\hline & & & $\mathrm{T}$ control & 650 & 600 & 0.92 & 2 & $50 \mathrm{~K}$ & \\
\hline & & & A control $\left(0.5^{\circ}-6.1^{\circ}\right)$ & $400^{*}$ & $0^{*}$ & $0^{*}$ & 0.1 & 1000 & ${ }^{*}$ Values at fatigue start \\
\hline & & & A control $\left(0.4^{\circ}-6.0^{\circ}\right)$ & $400^{*}$ & $0^{*}$ & $0^{*}$ & 2 & 2700 & *Values at fatigue start \\
\hline GB1-4 & 1 & $d=0.1^{\prime \prime}, \psi=45^{\circ}, \theta=36^{\circ}$ & A control $\left(1.2^{\circ}-4.8^{\circ}\right)$ & $300^{*}$ & $30^{*}$ & $0.1^{*}$ & 1 & 16164 & *Values at fatigue start \\
\hline \multirow[t]{2}{*}{ GB1-5 } & \multirow[t]{2}{*}{1} & $d=0.1^{\prime \prime}, \psi=45^{\circ}, \theta=36^{\circ}$ & T control & 200 & 20 & 0.1 & 1 & $50 \mathrm{~K}$ & \\
\hline & & & T control & 300 & 30 & 0.1 & 1 & 6316 & \\
\hline GB2-3 & 2 & $d=0.2^{\prime \prime}, \psi=45^{\circ}, \theta=28^{\circ}$ & $\mathrm{T}$ control & 300 & 30 & 0.1 & 2 & 100 & root sharpened with razor blade \\
\hline GB2-4 & 2 & $d=0.2^{\prime \prime}, \psi=45^{\circ}, \theta=28^{\circ}$ & T control & 300 & 30 & 0.1 & 1 & 1660 & root sharpened with razor blade \\
\hline GB2-5 & 2 & $d=0.3^{\prime \prime}, \psi=45^{\circ}, \theta=20^{\circ}$ & T control & 100 & 10 & 0.1 & 1 & $60 \mathrm{~K}$ & \\
\hline & & & T control & 100 & 10 & 0.1 & 2 & $1.2 \mathrm{M}$ & \\
\hline & & & T control & 100 & 10 & 0.1 & 2 & $0.7 \mathrm{M}$ & \\
\hline & & & T control & 100 & 10 & 0.1 & 2 & $1 \mathrm{M}$ & \\
\hline & & & T control & 150 & 15 & 0.1 & 1 & 41795 & root sharpened with razor blade \\
\hline GB3-2 & 1 & $d=0.115^{\prime \prime}, \psi=90^{\circ}, \theta=45^{\circ}$ & T control & 200 & 20 & 0.1 & 1 & 5139 & \\
\hline GB3-4 & 1 & $d=0.1^{\prime \prime}, \psi=45^{\circ}, \theta=45^{\circ}$ & T control & 300 & 30 & 0.1 & 1 & 2369 & \\
\hline GB3-5 & 1 & $d=0.1^{\prime \prime}, \psi=45^{\circ}, \theta=45^{\circ}$ & T control & 300 & 30 & 0.1 & 1 & 220 & \\
\hline GB4-2 & 1 & $d=0.115^{\prime \prime}, \psi=90^{\circ}, \theta=45^{\circ}$ & T control & 200 & 20 & 0.1 & 1 & 3308 & \\
\hline GB4-5 & 1 & $d=0.1^{\prime \prime}, \psi=45^{\circ}, \theta=45^{\circ}$ & T control & 200 & 20 & 0.1 & 1 & $\sim 10 \mathrm{~K}$ & $\begin{array}{l}\text { Fractured after another } 80 \\
\text { cycles between } 25 \text { and } 250 \mathrm{lbf}-\mathrm{in}\end{array}$ \\
\hline MFG-2 & 3 & $d=0.1^{\prime \prime}, \psi=45^{\circ}, \theta=45^{\circ}$ & T control & 600 & 60 & 0.1 & 1 & 500 & \\
\hline MFG-3 & 3 & $d=0.1^{\prime \prime}, \psi=45^{\circ}, \theta=45^{\circ}$ & T control & 300 & 30 & 0.1 & 1 & 7084 & \\
\hline
\end{tabular}




\section{DRAFT}

\begin{tabular}{|c|c|c|c|c|c|c|c|c|c|c|}
\hline \multicolumn{11}{|c|}{ Monotonic loading of fatigued samples } \\
\hline \multirow[t]{2}{*}{ Sample } & \multirow[t]{2}{*}{ Material } & \multirow[t]{2}{*}{ Nominal geometry } & \multicolumn{6}{|c|}{ Fatigue conditions } & \multirow{2}{*}{$\begin{array}{l}\text { Fracture } \\
\text { Torque (lbf-in) }\end{array}$} & \multirow[t]{2}{*}{ Note } \\
\hline & & & Fatique mode & $T_{\max }$ (lbf-in) & $T_{\min }$ (lbf-in) & $\mathbf{R}$ & Freq $(\mathrm{Hz})$ & $\mathbf{N}$ & & \\
\hline GB1-6 & 1 & $d=0.1^{\prime \prime}, \psi=45^{\circ}, \theta=36^{\circ}$ & T control & 300 & 30 & 0.1 & 1 & 5500 & 596 & \\
\hline GB1-7 & 1 & $d=0.1^{\prime \prime}, \psi=45^{\circ}, \theta=36^{\circ}$ & T control & 200 & 20 & 0.1 & 1 & $260 \mathrm{~K}$ & 357 & \\
\hline GB2-2 & 2 & $d=0.1^{\prime \prime}, \psi=45^{\circ}, \theta=36^{\circ}$ & T control & 200 & 20 & 0.1 & 1 & $150 \mathrm{~K}$ & 865 & \\
\hline GB3-3 & 1 & $d=0.115^{\prime \prime}, \psi=90^{\circ}, \theta=45^{\circ}$ & T control & 200 & 20 & 0.1 & 1 & 3000 & 244 & \\
\hline GB3-7 & 1 & $d=0.1^{\prime \prime}, \psi=45^{\circ}, \theta=45^{\circ}$ & T control & 200 & 20 & 0.1 & 1 & 9000 & 618 & $\begin{array}{l}\text { Blunt notch root; } \\
\text { root sharpened with razor blade }\end{array}$ \\
\hline GB4-3 & 1 & $d=0.115^{\prime \prime}, \psi=90^{\circ}, \theta=45^{\circ}$ & T control & 200 & 20 & 0.1 & 1 & 4000 & 235 & \\
\hline GB4-6 & 1 & $d=0.1^{\prime \prime}, \psi=45^{\circ}, \theta=45^{\circ}$ & T control & 200 & 20 & 0.1 & 1 & 9000 & 281 & \\
\hline
\end{tabular}

Material type: 1 - 117LV/229; 2 - 117LV/XH10B; 3 - RIM135/RIMH1366 
The qualitative and quantitative measurement of temperature profiles obtained from this study proved to be very useful in SNTT failure characterization. However, accurate measurements require knowledge of surface emissivity, which is not only dependent on the material itself, but also on the surface roughness and the local curvature.

Nevertheless, the preliminary IR results verified that the notch groove was subject to tensile states while under SNTT pure torsion loading (Figure 15b).

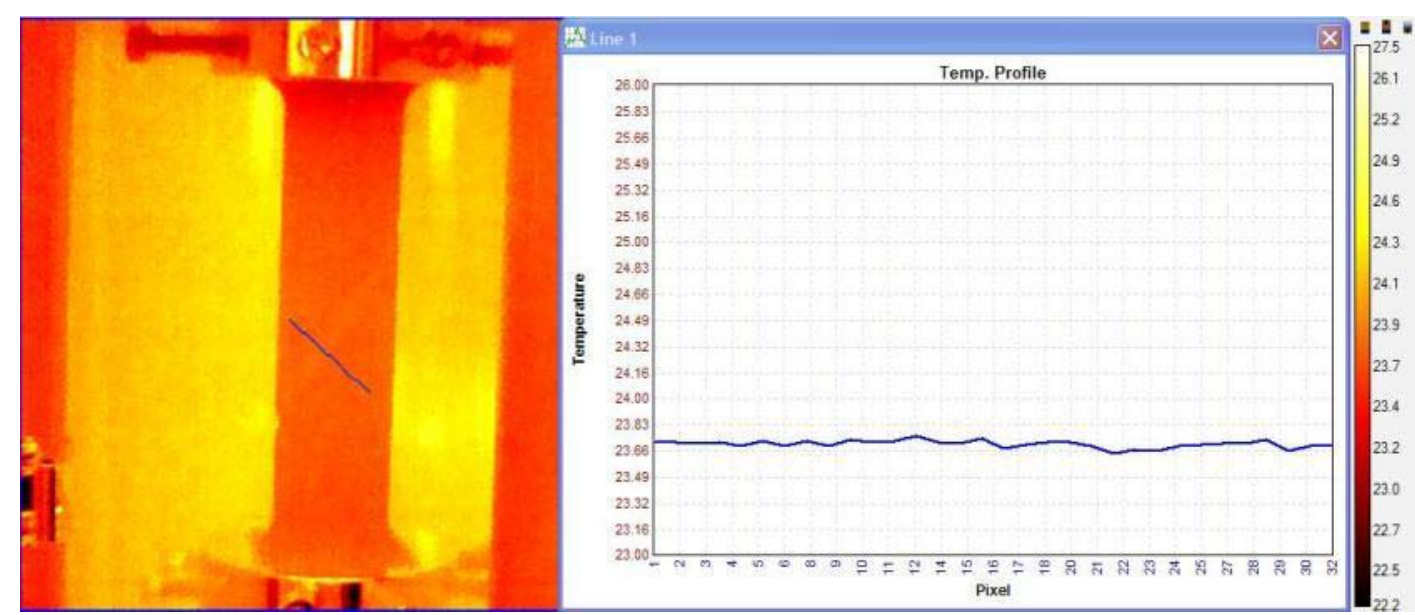

(a)
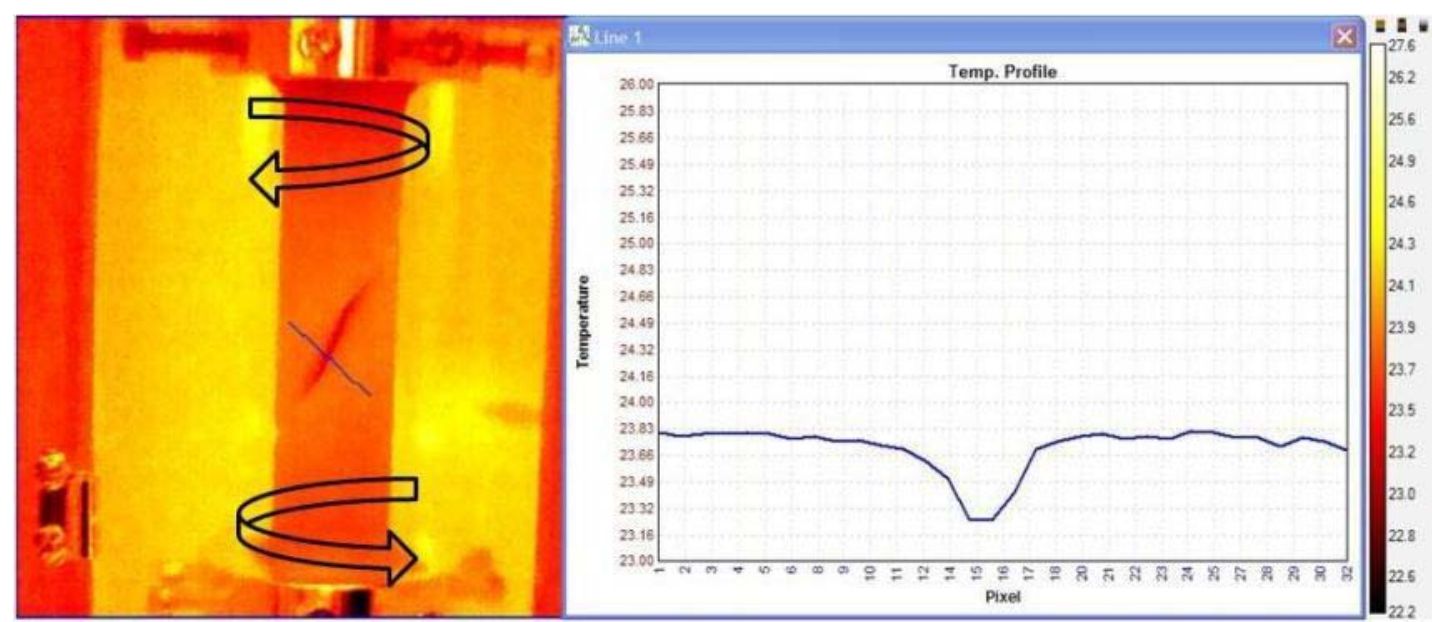

(b) 


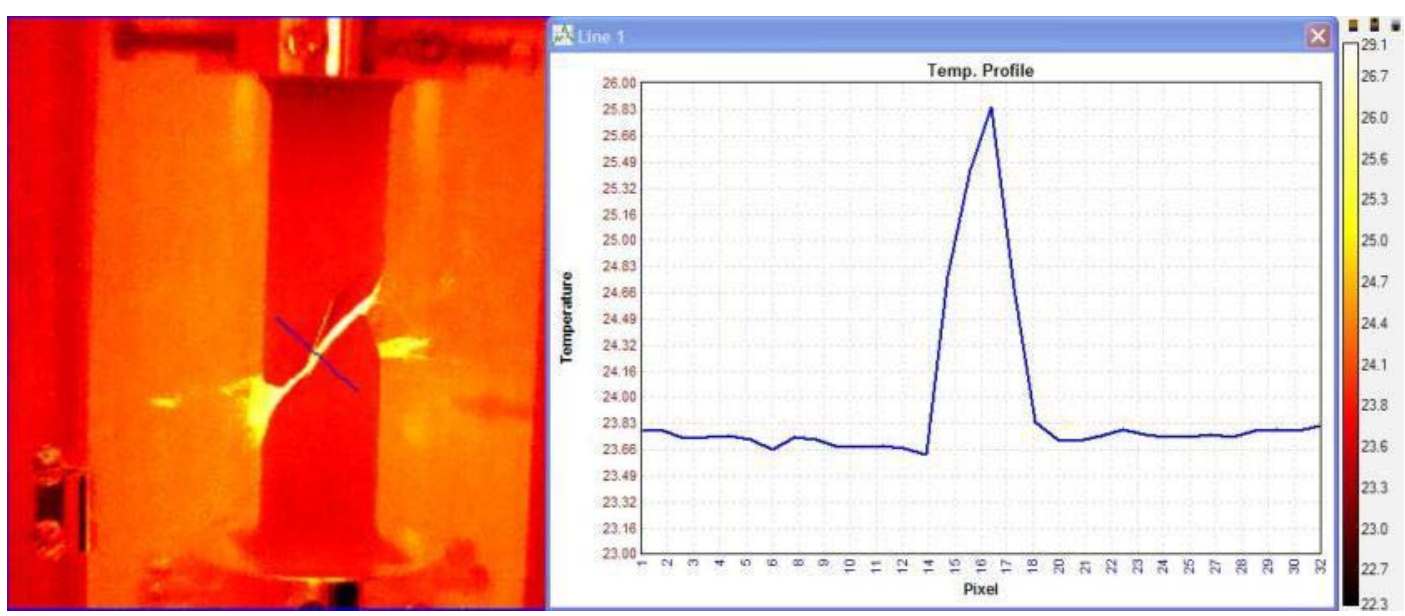

(c)

Figure 15. IR images of an epoxy sample during SNTT testing: (a) before testing, (b) during monotonic loading, and (3) at fracture instance.

\subsection{Fracture due to monotonic loading}

For tested epoxy samples, torque versus rotation angle curves showed typical brittle fracture behaviors with nearly linear load-displacement relationships (Figure 16). All samples failed near or below 400 lbf-in, except for the MFG-1 sample and two samples GB2-1 and GB2-6 that were made from toughened epoxies.

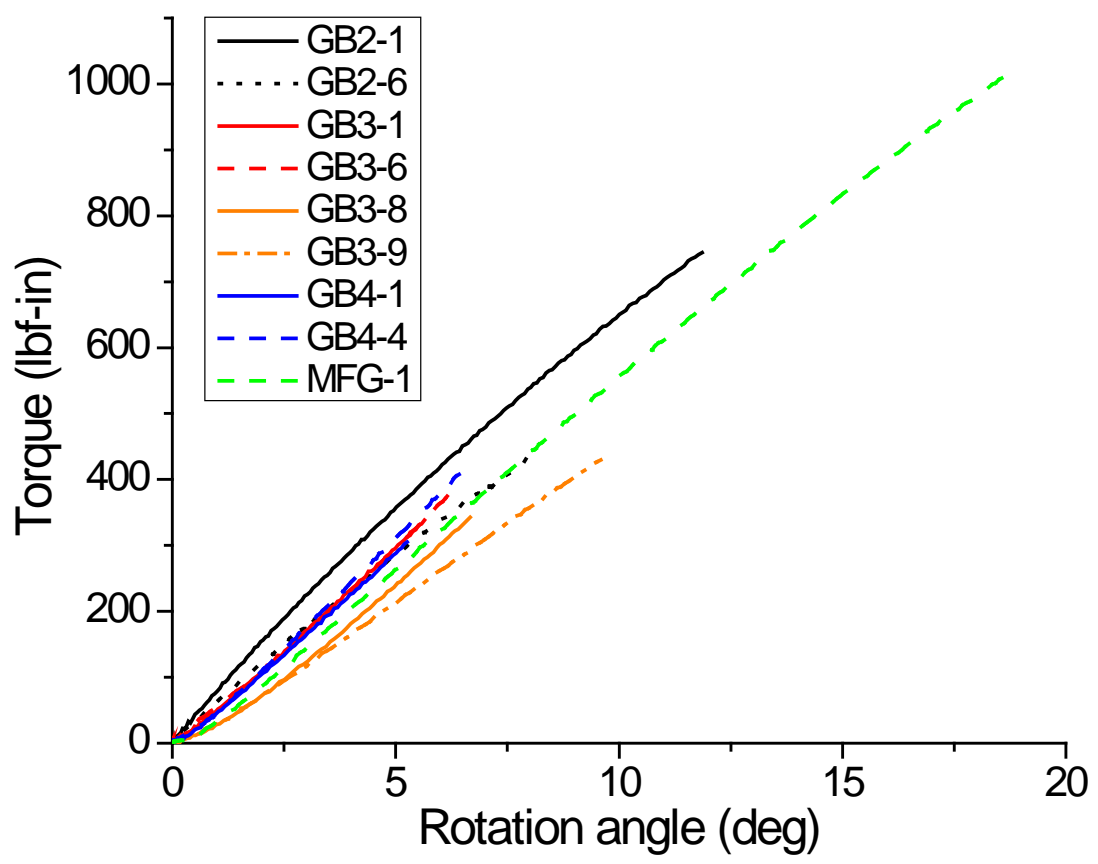

Figure 16. The torque-rotation plots of tested SNTT samples 
Due to the geometric constraint and pure torsion loading, sample MFG-1 fractured into two halves along the spiral line (Figure 17a). However, the fracture surface showed a significant degree of roughness (Figure 17b). There were two distinct regions on the fracture surface: a quasi-circular region that had a smooth morphology and a rough region that surrounded the smooth region (Figure 17b). In contrast to the smooth region, which was relatively featureless, the rough region consisted of ridges and furrows that radiated from the border between the two regions and ran parallel along the crack propagation directions (indicated by arrows) (Figure 17b).

The smooth region, sometimes called "mirror" [Araki 2002], was likely formed as a result of slow unstable crack growth, this subsequently transformed to a rough region due to fast unstable crack growth [Owen 1975]. The rough region was sometimes termed as hackle [Phillips 1978, Yamini 1979] similar to those observed in glassy materials [Quinn 2007]. The ridged features in the rough region could be caused by secondary fractures as a result of the increased propagation speed of the primary crack [Owen 1975].

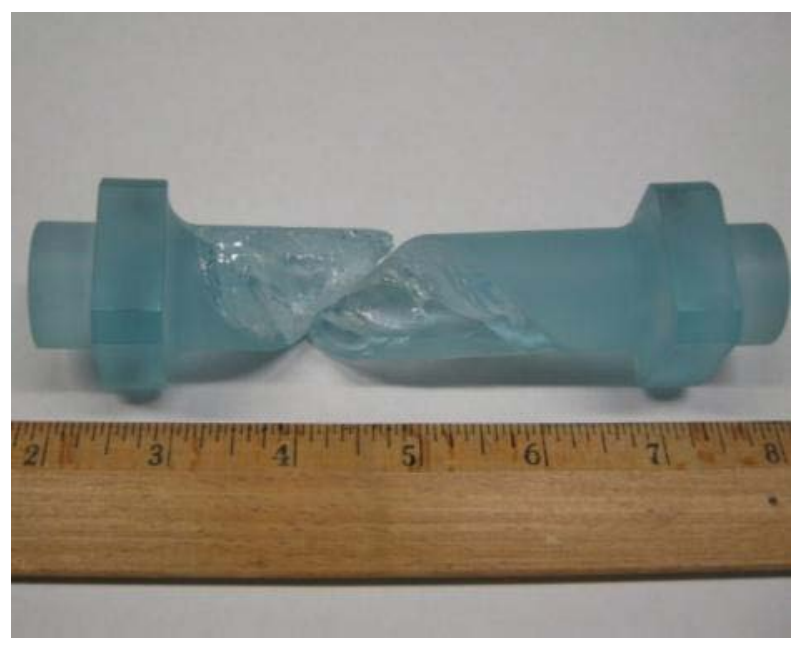

(a)

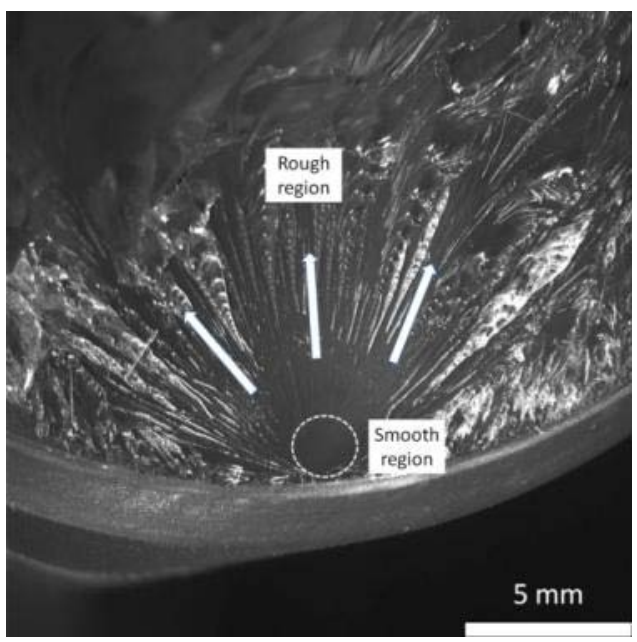

(b)

Figure 17. Pictures showing (a) the fractured MFG-1 sample, and (b) its fracture surface.

The fracture surfaces of samples GB2-1 and GB2-6 showed similar features as those observed on MFG-1 (Figure 18). However, the size of the smooth region on GB21 and GB2-6 is larger than on MFG-1. In addition, some detached fibers were observed in the rough regions on samples GB2-1 and GB2-6 (Figure 18). These fibers could be formed by brittle cleavage from the ridges [Cherry 1981].

It is noted that both GB2-1 and GB2-6 were mixed-mode samples, because the pitch angles of the spiral notches were away from $45^{\circ}$ (Table 3 ). As mentioned in Section 3.2, when $\theta \neq 45^{\circ}$, the groove line region is subjected to Mode I + Mode III 
stresses while under pure torsion loading. However, for both GB2-1 and GB2-6, the actual final brittle fracture still took place at a $45^{\circ}$ pitch angle with respect to the sample axis, rather than along the notch line (Figure 19).

The fracture torque of GB2- 6 was $447 \mathrm{lbf}$-in, about $42 \%$ lower than the fracture torque of GB2-1 (774 lbf-in) because the notch depth of GB2-6 was nominally 0.3 " while that of GB2-1 was 0.1" nominally (Table 4).

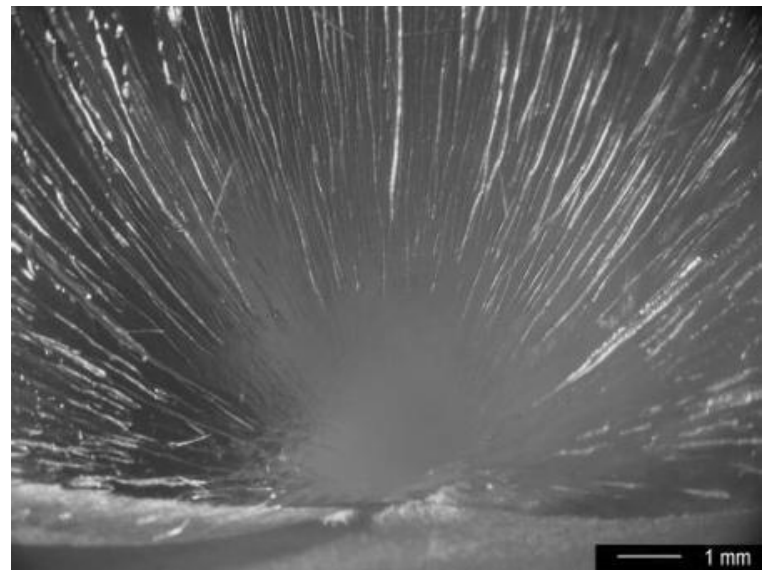

(a)

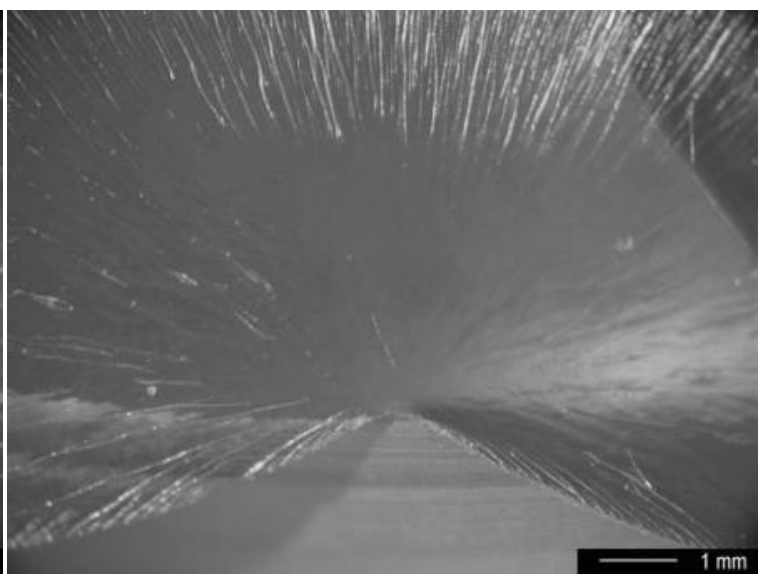

(b)

Figure 18. Images showing the fracture surfaces of (a) GB2-1 and (b) GB2-6.

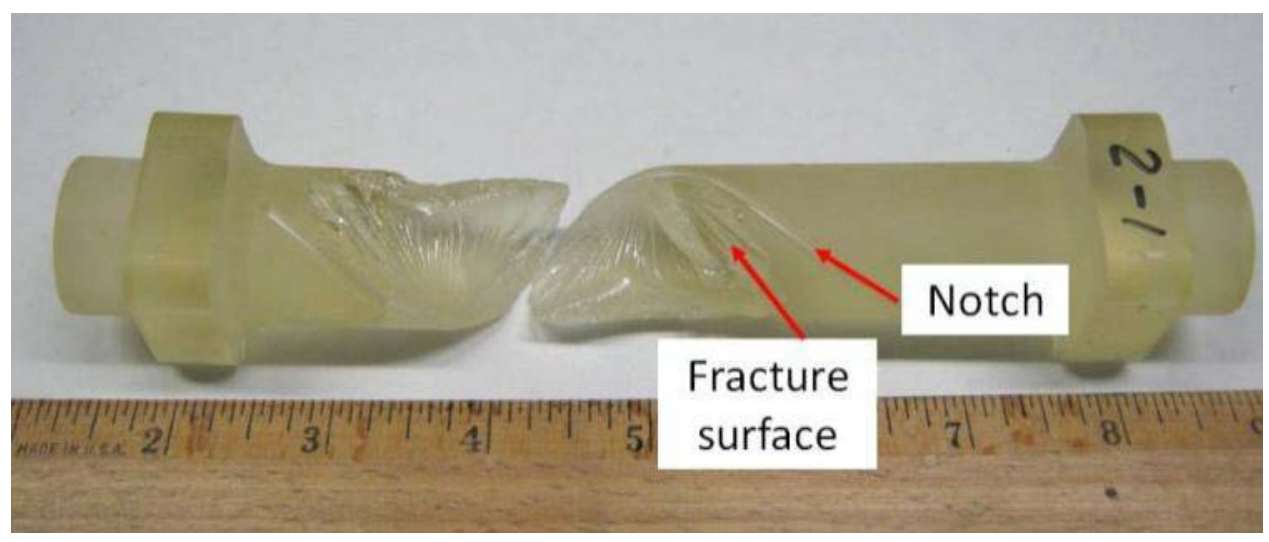

Figure 19. Sample GB2-1 after fracture.

Samples GB3-1, GB3-6, GB4-1, and GB4-4 all had a pitch angle of $45^{\circ}$ (Table 3), and their fracture surfaces resemble the " $45^{\circ}$ spiral planes". In another good example, Figure 20 shows the fracture surface of GB3-1, which initiated exactly along $45^{\circ}$ spiral notch line.

The fracture surface of GB3-1 also contained both the smooth region and the rough region that was caused by slow and fast unstable crack propagations respectively (Figure 21a). A higher magnification image further revealed some fine river lines near the notch root (indicated by an arrow in Figure 21b). These river lines were characteristics of stable crack growth [Owen 1975]. The stable crack growth was a 
small fraction of the entire fracture surface (Figure 21a), implying that under monotonic loading a crack would grow unstably shortly after its formation.

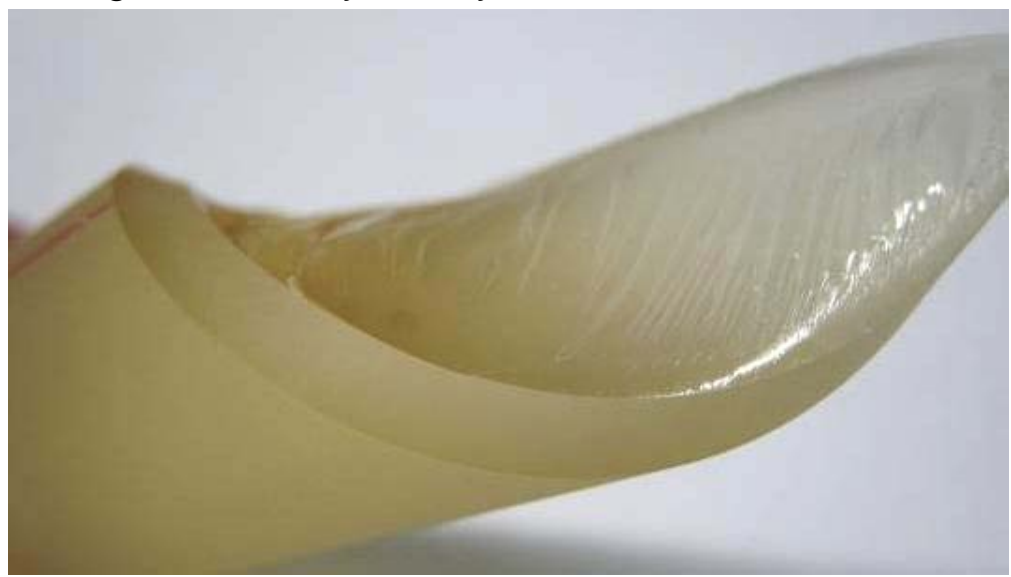

Figure 20. Picture showing one fractured half of sample GB3-1.

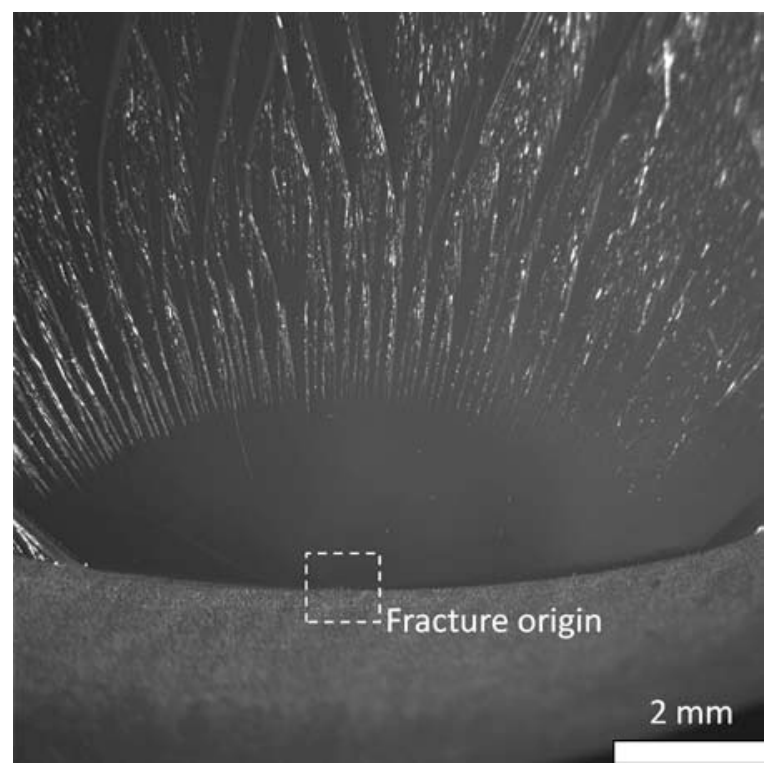

(a)

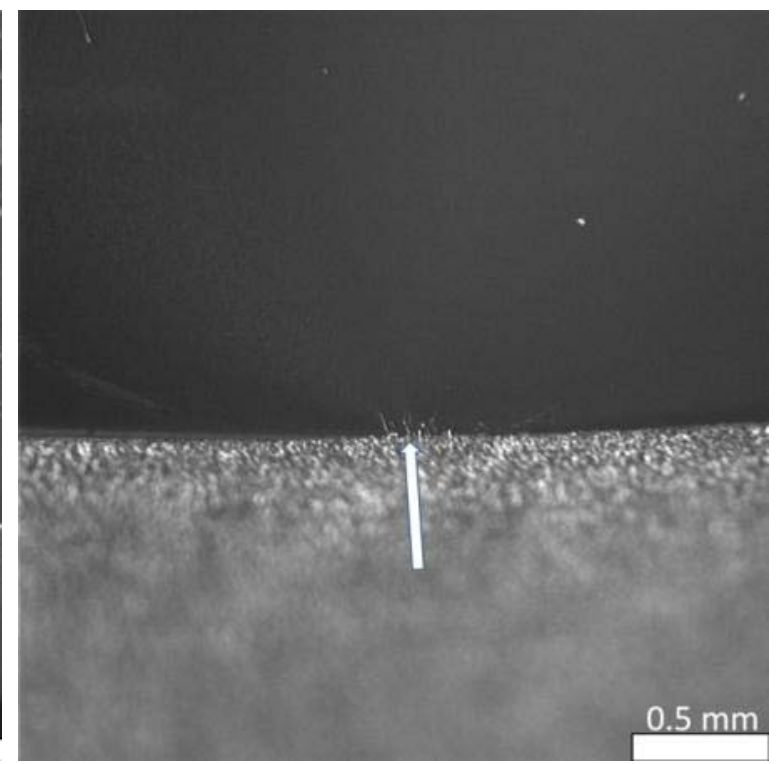

(b)

Figure 21. Images showing (a) the fracture surface and (b) the fracture origin of sample GB3-1.

The fracture surfaces of GB3-6, GB4-1, and GB4-4 showed similar morphology to that of GB3-1 (Figure 22). GB3-1 and GB4-1 had comparable fracture torques (Table 4) due to their similar geometry. GB3-6 and GB4-4 exhibited higher fracture torques due to their smaller notch depth (0.1") than that of GB3-1 and GB4-1 (0.115") (Table 3). It is noted that the notch opening angles were different as well $\left(45^{\circ}\right.$ versus $90^{\circ}$, see Table 3 ) and that the effect of the notch opening angle on fractures will be explored in the future. 


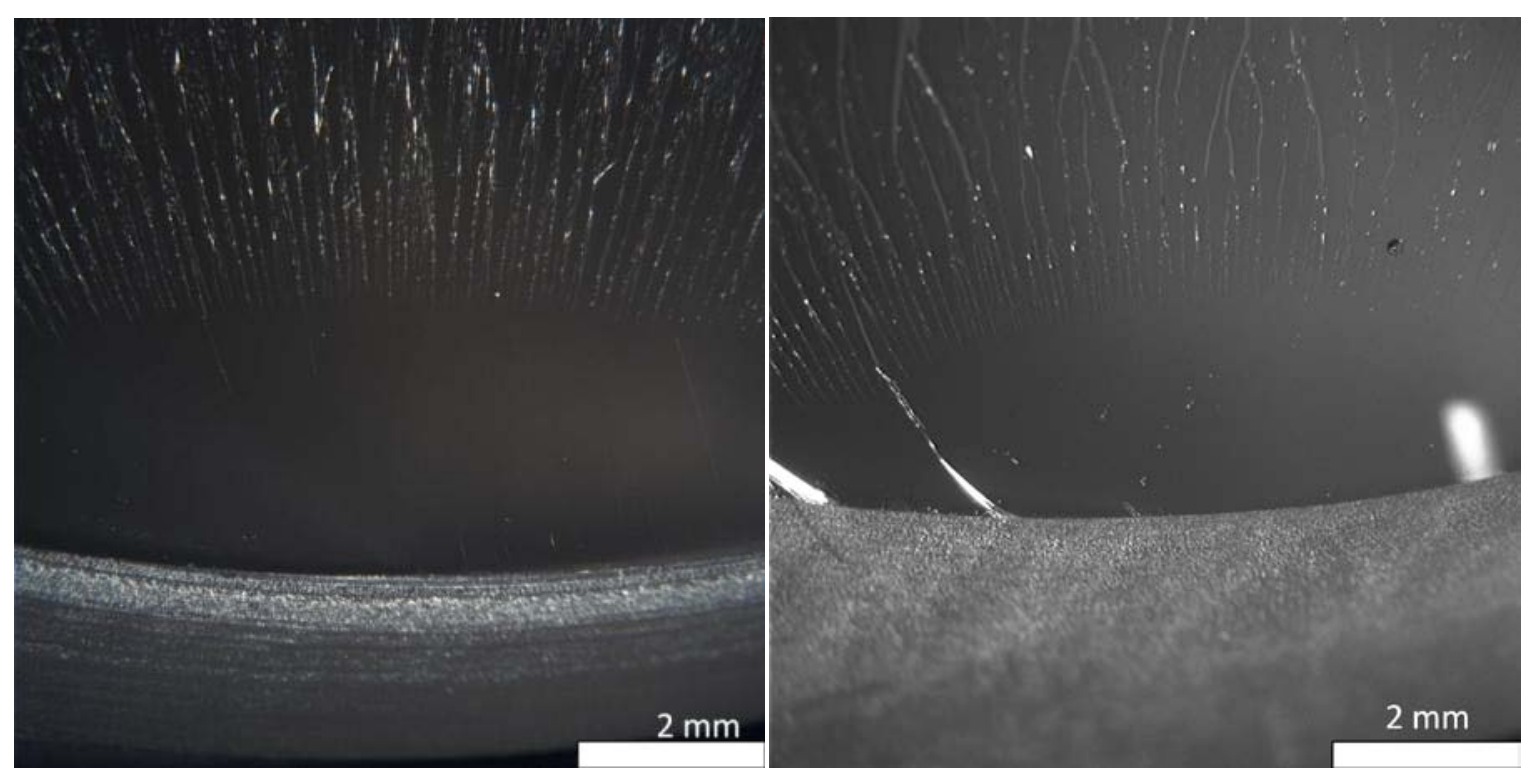

(a)

(b)

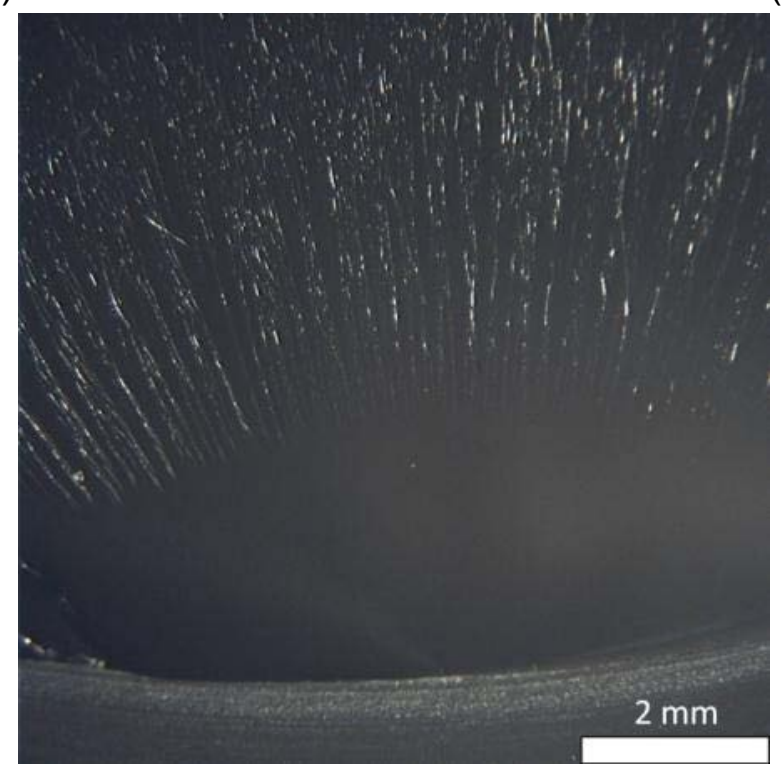

(c)

Figure 22. Images showing fracture surfaces of (a) GB3-6, (b) GB4-1, and (c) GB4-4.

Samples GB3-8 and GB3-9 had similar geometry to samples GB3-6 and GB4-4, except that the notch depth was 0.2" for GB3-8 and 0.3" for GB3-9, while both GB3-6 and GB4-4 had a notch depth of 0.1" (Table 3). However, GB3-9 showed a higher fracture load (430 lbf-in) than GB3-6 (384 lbf-in) and GB4-4 (404 lbf-in). The fracture surface of sample GB3-9 consisted of a very smooth region away from the notch surrounded by a very rough region (Figure $23 b$ ).

Samples GB3-9, GB3-8, and GB3-7 were machined by a different company and it was found that their notch roots were $U$-shaped (or a dull notch root radius) rather than a sharp V-shaped. Thus, the GB3-9 sample presents a typical dull/blunt crack tip scenario with the observed fracture origin found to be inside the bulk material, rather 
than on the surface (Figure 23b). Based on this finding, the notch root of GB3-8 was sharpened using a razor blade prior to testing. The resulting fracture surface of GB3-8 showed a similar appearance to those with V-shaped grooves (Figure 23a)with a fracture torque of $343 \mathrm{lbf}-$ in (Table 4).

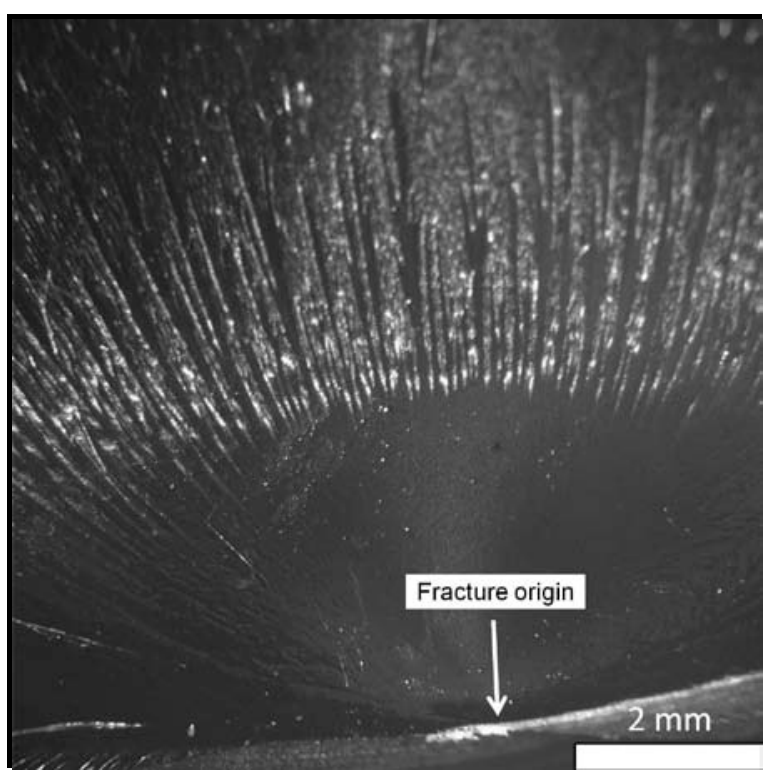

(a)

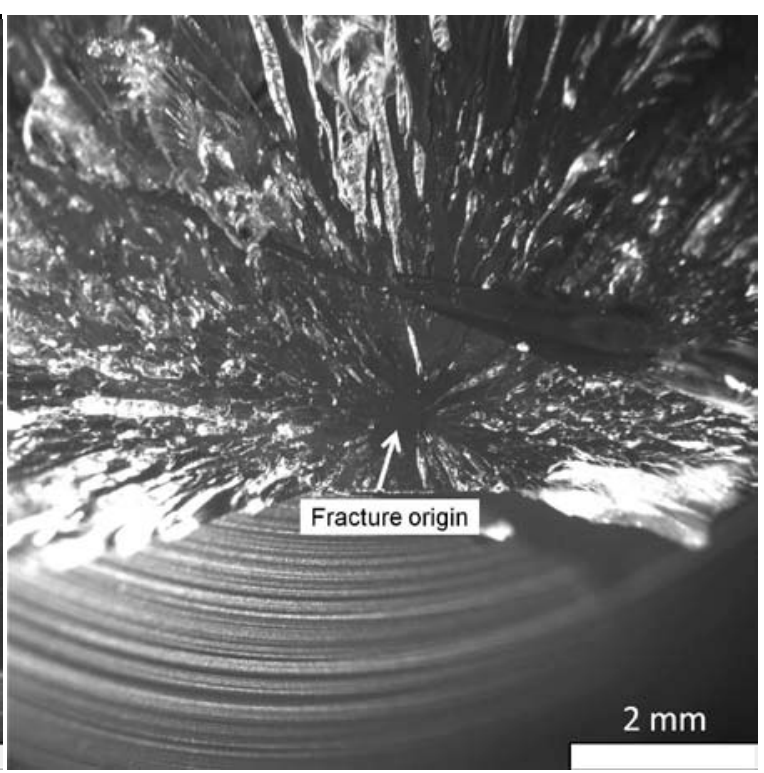

(b)

Figure 23. Images showing the fracture surfaces of (a) GB3-8 and (b) GB3-9.

\subsection{Fracture due to fatigue}

In addition to the intrinsic material properties, the fatigue behavior of polymeric materials is also influenced by loading conditions, such as stress amplitude $\left(\Delta \sigma=\sigma_{\max }\right.$ $\left.\sigma_{\min }\right)$, stress ratio $\left(R=\sigma_{\min } / \sigma_{\max }\right)$ and thus the mean stress, and loading rate $\left(\sigma^{\prime}=\mathrm{d} \sigma / \mathrm{dt}\right)$ (Figure 24). In order to develop an effective protocol to induce a controllable crack growth, pilot testing was carried out where the epoxy samples were tested under different fatigue loading conditions (Table 4). 


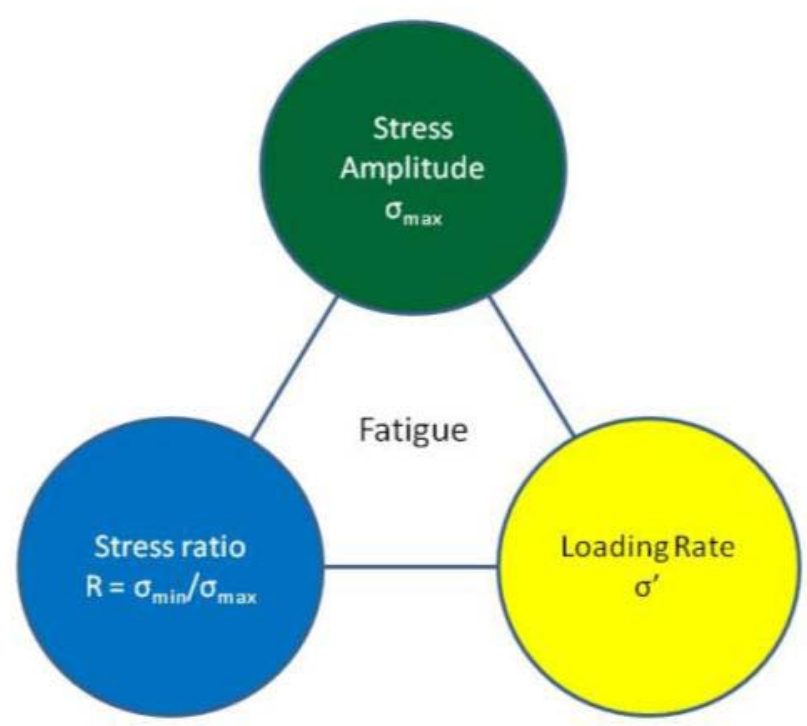

Figure 24. External factors influencing the fatigue behavior of materials.

Sample GB1-2 was fatigued with an angle (or displacement) control approach. The initial test was carried out under a fixed rotation angle range corresponding to a torque range between 300 and $400 \mathrm{lbf}-i n$. The sample did not show fatigue crack growth after 100,000 cycles, based on the observed unchanged specimen stiffness, at a fatigue frequency of $1 \mathrm{~Hz}$. In contrast, when the frequency was increased to $2 \mathrm{~Hz}$ with a torque range between 400 and $500 \mathrm{lbf}-\mathrm{in}$, the sample fractured after a few thousand cycles (Figure 25). Thus, it seems that the fatigue life of epoxy materials can be shortened significantly by increasing the loading rate. On the other hand, sample GB1-5 survived 50,000 cycles when fatigued between 20 and $200 \mathrm{lbf}$-in, but failed after 6316 cycles when the torque range was changed from 30 to $300 \mathrm{lbf}-$ in (Figure 25). Thus, increasing the stress amplitude could also decrease the fatigue life.

Sample GB1-3 survived more than 440,000 cycles under a variety of fatigue conditions (Table 4), where the maximum load reached 650 lbf-in for 50,000 cycles, without obvious stiffness change. However, GB1-3 fractured after 2700 cycles when $\Delta T$ $\left(=\mathrm{T}_{\max }-\mathrm{T}_{\min }\right)$ was increased from $50 \mathrm{lbf}$-in to $400 \mathrm{lbf}$-in while the maximum torque was reduced from $650 \mathrm{lbf}$-in to $400 \mathrm{lbf}-i n$ and the fatigue frequency was increased from $1 \mathrm{~Hz}$ to $2 \mathrm{~Hz}$ (Figure 25). This may also imply that the synergistic effect of loading rate and stress amplitude can significantly reduce the fatigue life. It is noted that $R>0.75$ for the first 440, 000 cycles while $R=0$ for the last 2700 cycles. The fatigue loading rate effect observed from this pilot study presents a unique characteristic of polymeric material, which is not normally observed in a cycle fatigued metallic material. This may also imply that the polymeric material failure is likely to be loading rate dependent. In general the higher loading rate will decrease the ductility; thus, reducing the fracture toughness. Furthermore, as observed from IR images, the notch region appears to have a lower temperature profile compared to the rest of the sample. Since polymeric material 
normally has lower thermal conductivity (compared to that of metallic materials, higher rate loading will further increase the temperature gradient near the crack tip region. The lower localized temperature profile at the crack front will certainly increase the localized constraint leading to lower fracture toughness and thus less fracture resistance.

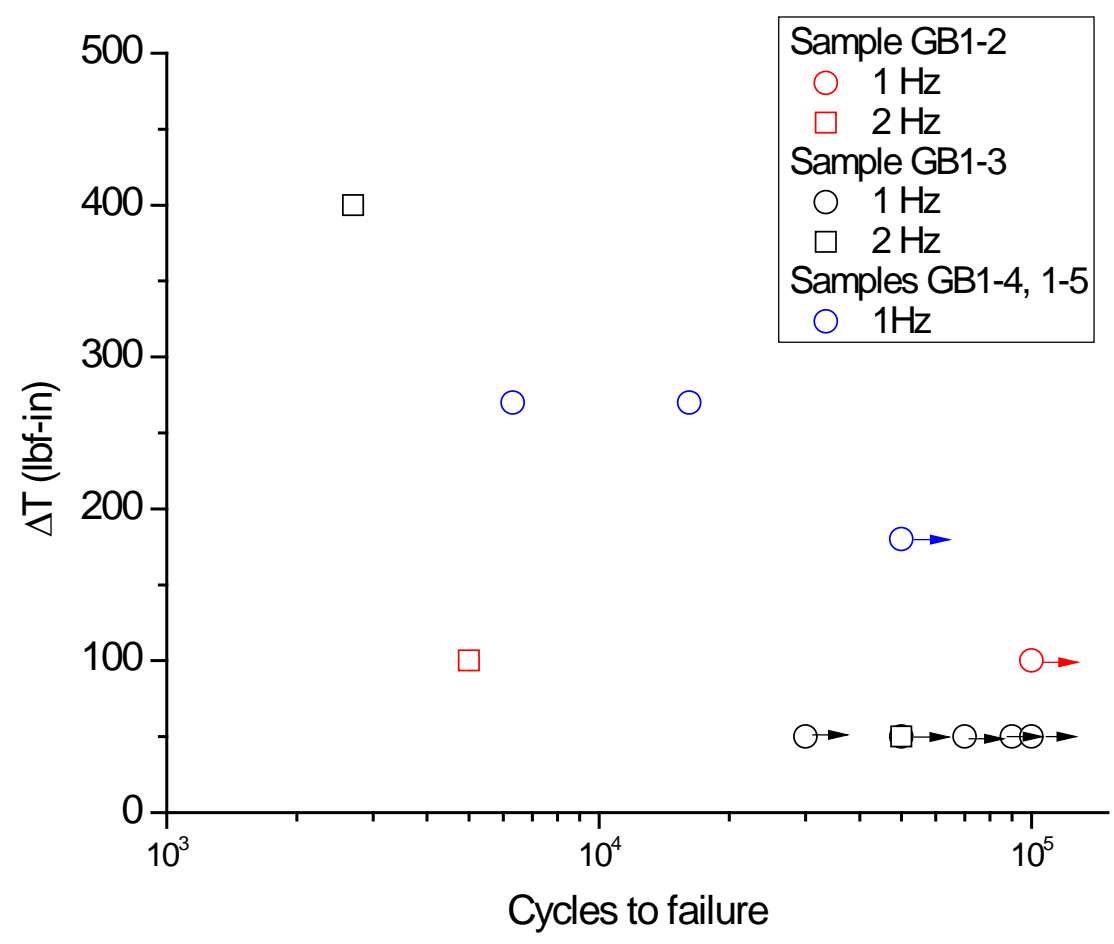

Figure 25. Fatigue S-N plots of samples from GB batch 1.

Based on lessons learned from GB1-2 and GB1-3 fatigue testing, levels of $\Delta T \cong 300$ $\mathrm{lbf}-\mathrm{in}$ and a maximum Torque of $300 \mathrm{lbf}-$ in were chosen as fatigue loading conditions for the following fatigue test. Sample GB1-4 was fatigued between 30 and 300 lbf-in with a frequency of $1 \mathrm{~Hz}$ and failed after 16,164 cycles (Figure 25). Three distinct regions were observed on the fracture surface: 1) a clam-shell shaped region, 2) a smooth region surrounding the clam-shell region, 3 ) and a rough region with ridges and furrows (Figure 26). The clam-shell region was probably formed during the fatigue phase, where the crack grew stably. The smooth region probably was created by slow unstable crack growth while the rough region was formed when crack propagation accelerated. Similar features were observed on the fracture surface of sample GB1-5: with the stable fatigue crack growth region, the slow unstable crack growth region, and the fast unstable crack growth region all visible (Figure 27).

In contrast, no fatigue region was observed on samples GB1-2 or GB1-3, where only the unstable crack growth regions were visible (Figure 28). The lack of fatigue region implies that no significant fatigue crack growth took place in these two samples 


\section{DRAFT}

even though they were fatigued for more than 100,000 and 440,000 cycles, respectively.

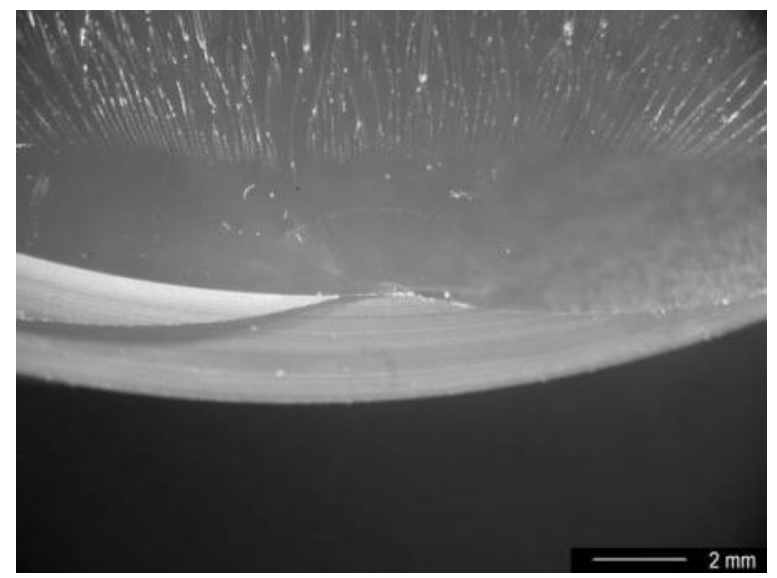

Figure 26. Fracture surface of sample GB1-4.

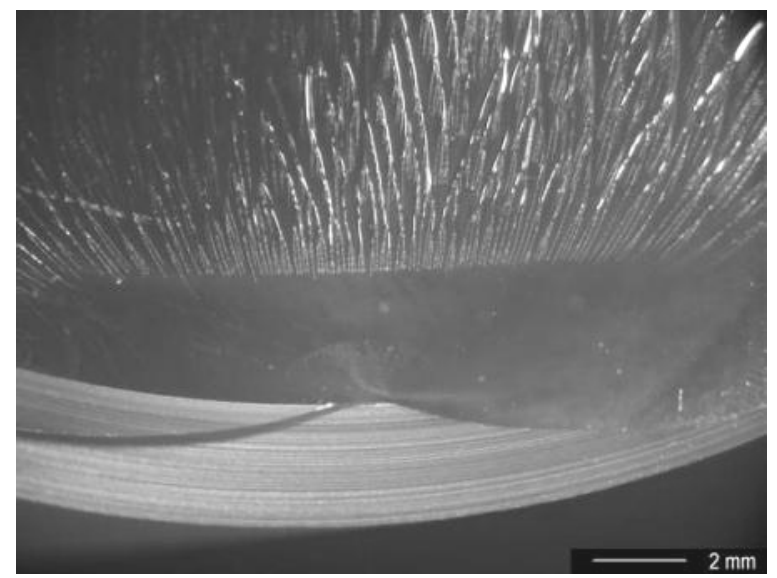

Figure 27. Image showing the fracture surface of GB1-5.

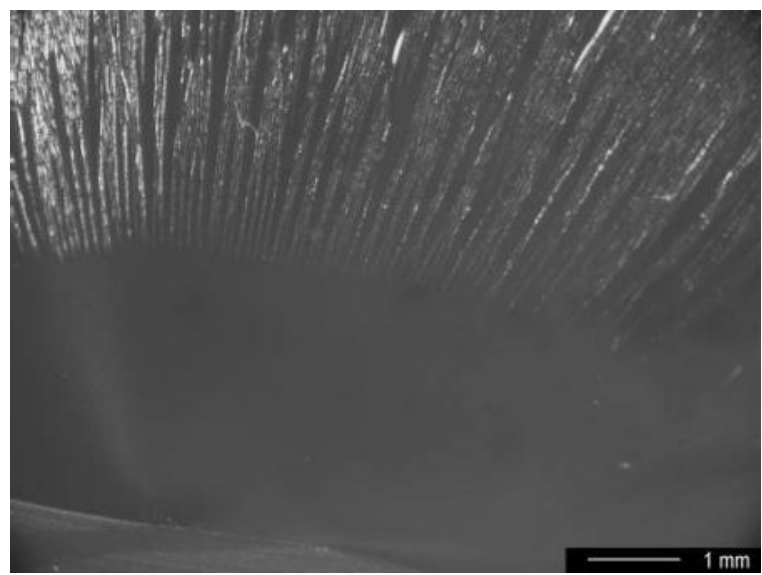

(a)

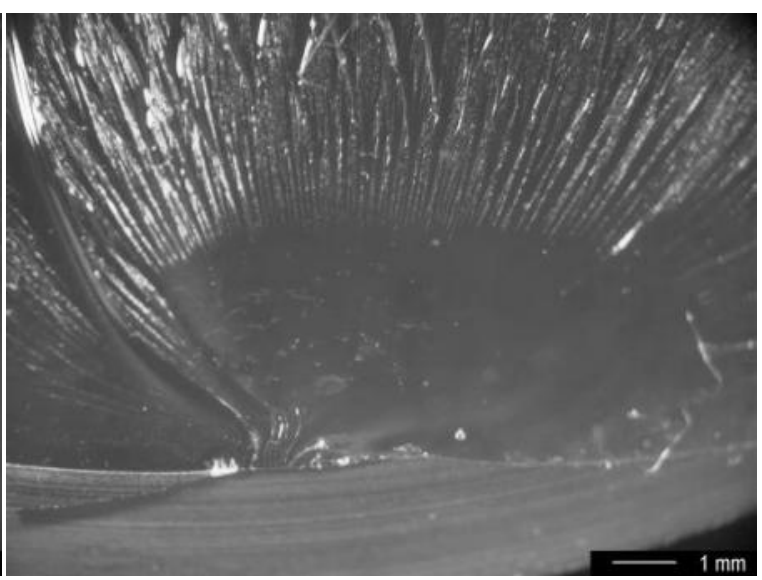

(b)

Figure 28. Images showing the fracture surfaces of (a) GB1-2 and (b) GB1-3. 
Samples GB1-2, GB1-3, GB1-4 and GB1-5 were all mixed mode samples with a pitch angle of $36^{\circ}$ (Table 3). However, both the stable crack growth (fatigue) and the unstable crack growth revealed that the fracture surface and crack growth occurred on a plane with a $45^{\circ}$ pitch angle with respect to the SNTT sample axis. Thus, the spiral plane corresponding to Mode I loading with a $45^{\circ}$ pitch angle is the preferred crack growth plane for these epoxy materials. Adams and Odom [Adams 1992] studied the fatigue failure of several brittle polymers including an epoxy resin, and discovered that they all failed in tensile mode even when they were subject to torsional fatigue.

Samples of the second batch from Gougeon Brothers were made from toughened epoxies (Table 1). Prior to fatigue testing, the notch roots of GB2-3, GB2-4, and GB2-5 were sharpened with a razor blade by manually sliding the blade along the spiral notch. GB2-3 fractured after 100 cycles between 30 and $300 \mathrm{lbf}$-in with a frequency of $2 \mathrm{~Hz}$; while GB2-4 fractured after 1660 cycles between 30 and $300 \mathrm{lbf}-i n$ with a frequency of 1 $\mathrm{Hz}$ (Table 4). The short fatigue life of these two samples was perhaps a result of increasing constraint due to notch root sharpening. No fatigue region was observed on samples GB2-3 or GB2-4 (Figure 29).

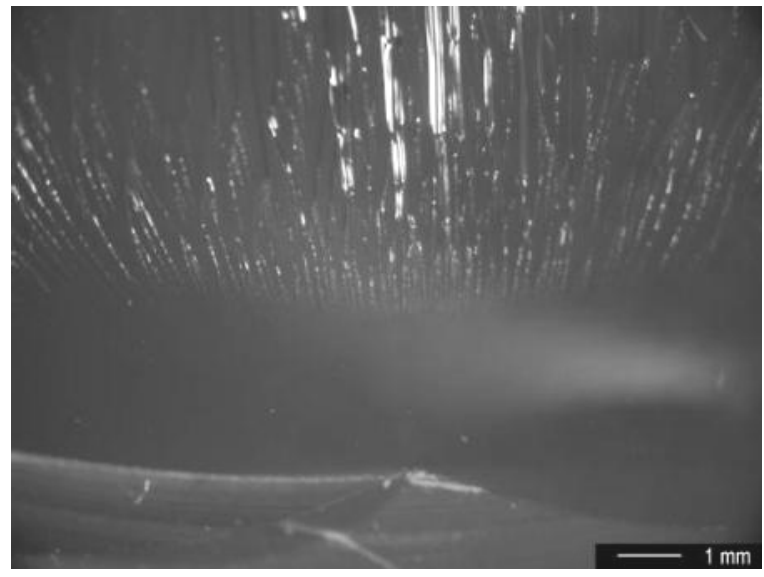

(a)

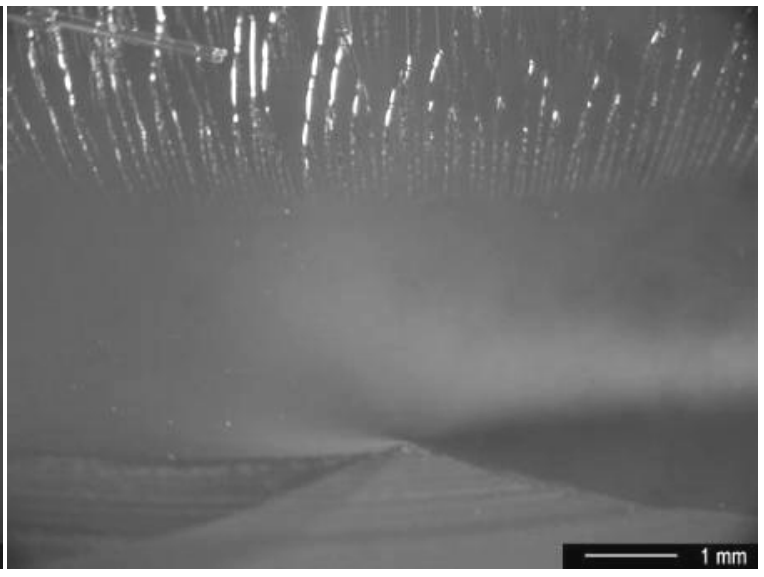

(b)

Figure 29. Images showing the fracture surfaces of (a) GB2-3 and (b) GB2-4.

Sample GB2-5 survived more than three million fatigue cycles, because of the small $\mathrm{T}_{\max }$ value (<100 lbf-in, Table 4$)$ and $\Delta \mathrm{T}=90 \mathrm{lbf}$-in. The sample finally fractured at 41,975 cycle with $\Delta T=90 \mathrm{lbf}$-in and $\mathrm{T}_{\max }=150 \mathrm{lbf}-\mathrm{in}$. On the fracture surface, a clamshell shaped fatigue region was clearly identified (Figure 30a). In this region, river lines radiated along the direction of the crack propagation, and concentric semi-elliptical lines perpendicular to the river lines were also visible at a higher magnification (Figure 30b). These concentric lines could be striation lines [Yamani 1979, 1980, Cherry 1981] generated during fatigue loading. Using the optical microscope, the spacing between adjacent striation lines measured approximately $0.1 \mathrm{~mm}$ (Figure 30b), while the SEM 
image showed striation lines on a much finer scale with a spacing around 10 microns (Figure 31a). Thus, the striation lines observed in Figure 30b are believed to represent the unique crack growth cycles of polymeric materials with fatigue aging.

The semi-elliptical region, similar to Figure 30 , was also observed by other researchers on fracture surfaces subject to rotary-bending fatigue [Nagasawa 1995] and uniaxial fatigue [Tao 2007] of epoxy materials. In addition, Tao et al. observed striation lines with a spacing of a few microns on the stable fatigue crack propagation zone in uniaxially fatigued epoxies [Tao 2007]. The boundary between the fatigue crack growth region and the smooth region (Figure 31b) corresponds to the transition from stable crack growth to unstable crack propagation.

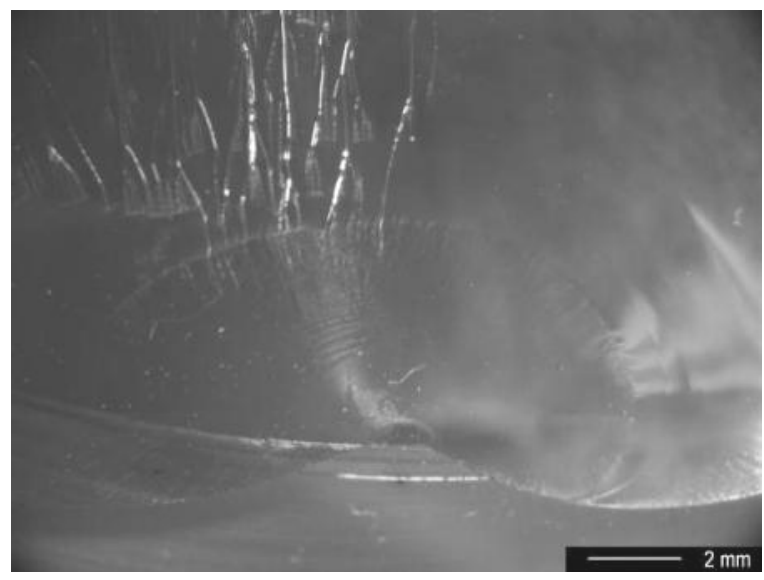

(a)

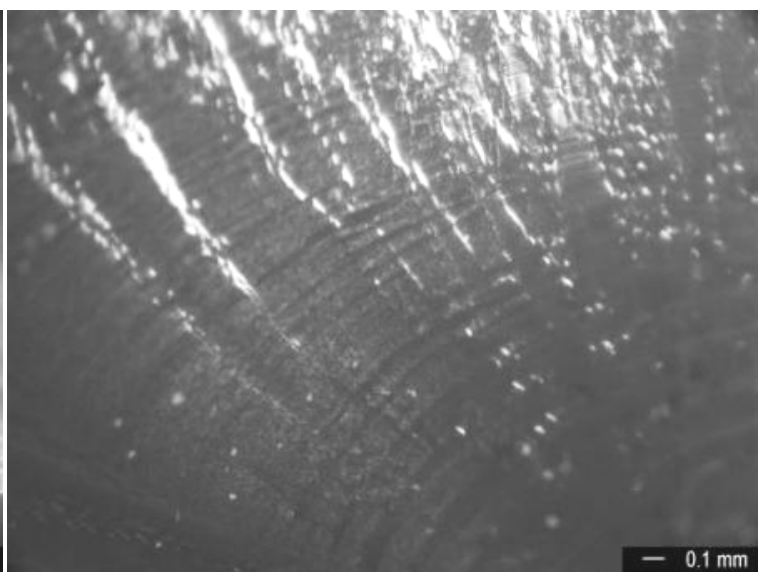

(b)

Figure 30. Images showing (a) the fracture surface of GB2-5 and (b) the crack propogation striation lines.

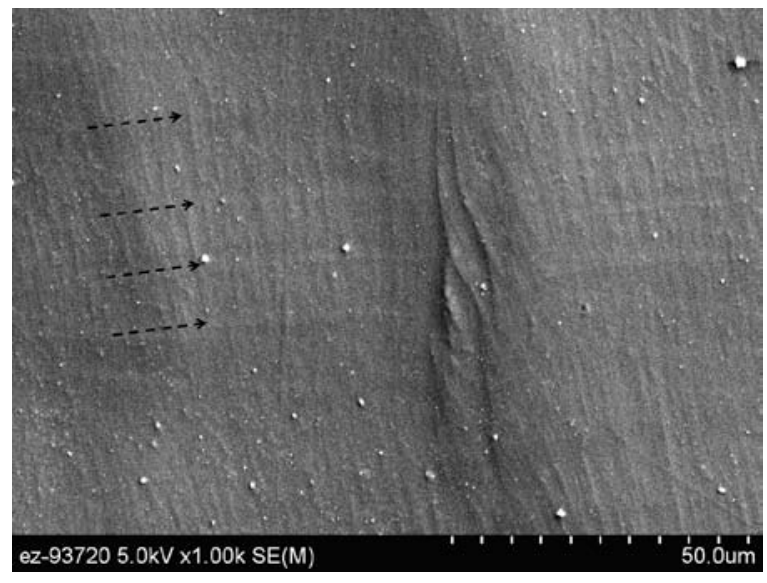

(a)

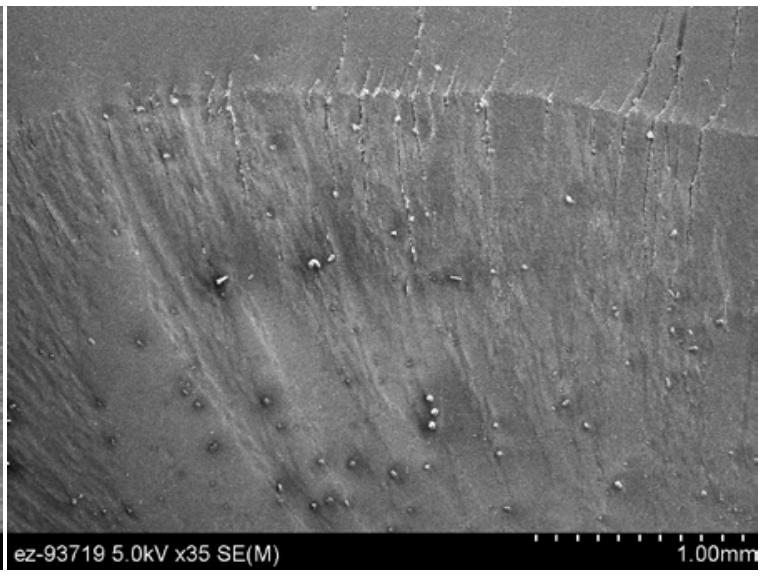

(b)

Figure 31. SEM image of the striation lines observed in GB2-5.

The pitch angles of the notches on samples GB2-3, GB2-4, and GB2-5 were all smaller than $45^{\circ}$ (Table 3), however they fractured along the $45^{\circ}$ plane rather than the 
notch plane. This observation agreed with the conclusion obtained from the first batch of samples: epoxy samples prefer to fracture in tensile opening mode, i.e., Mode I fracture.

Lessons learned from the early samples indicate that small $\mathrm{R}$, small $\Delta T$, and low fatigue frequency do not favor fatigue crack growth or controllable crack advance. In addition, it was difficult to maintain a constant $R$ value using the angle control mode. The Haver function was used in fatigue cycle control with $\mathrm{R}>0$. Under displacement control, the $\mathrm{R}$ ratio will reduce progressively with increasing fatigue cycles, due to increased specimen compliance induced by fatigue crack growth. Thus, all subsequent fatigue tests were performed using torque (or load) control mode with an $\mathrm{R}$ value of 0.1 and a frequency of $1 \mathrm{~Hz}$. $T_{\max }$ was selected to be approximately $60 \%$ of the torque that generated the maximum allowable shear stress on the surface of a SNTT sample.

Samples from batch 3 and batch 4 all had a $45^{\circ}$ pitch angle. GB3-4, GB3-5 and GB4-5 had a nominal notch depth of 0.1" and a notch opening angle of $45^{\circ}$. GB3-2 and GB4-2 had a nominal notch depth of $0.115^{\prime \prime}$ and a notch opening angle of $90^{\circ}$. All were fatigued at $1 \mathrm{~Hz}$ with an $\mathrm{R}$ value of 0.1 , and $\mathrm{T}_{\max }=200$ or $300 \mathrm{lbf}$-in (Table 4).

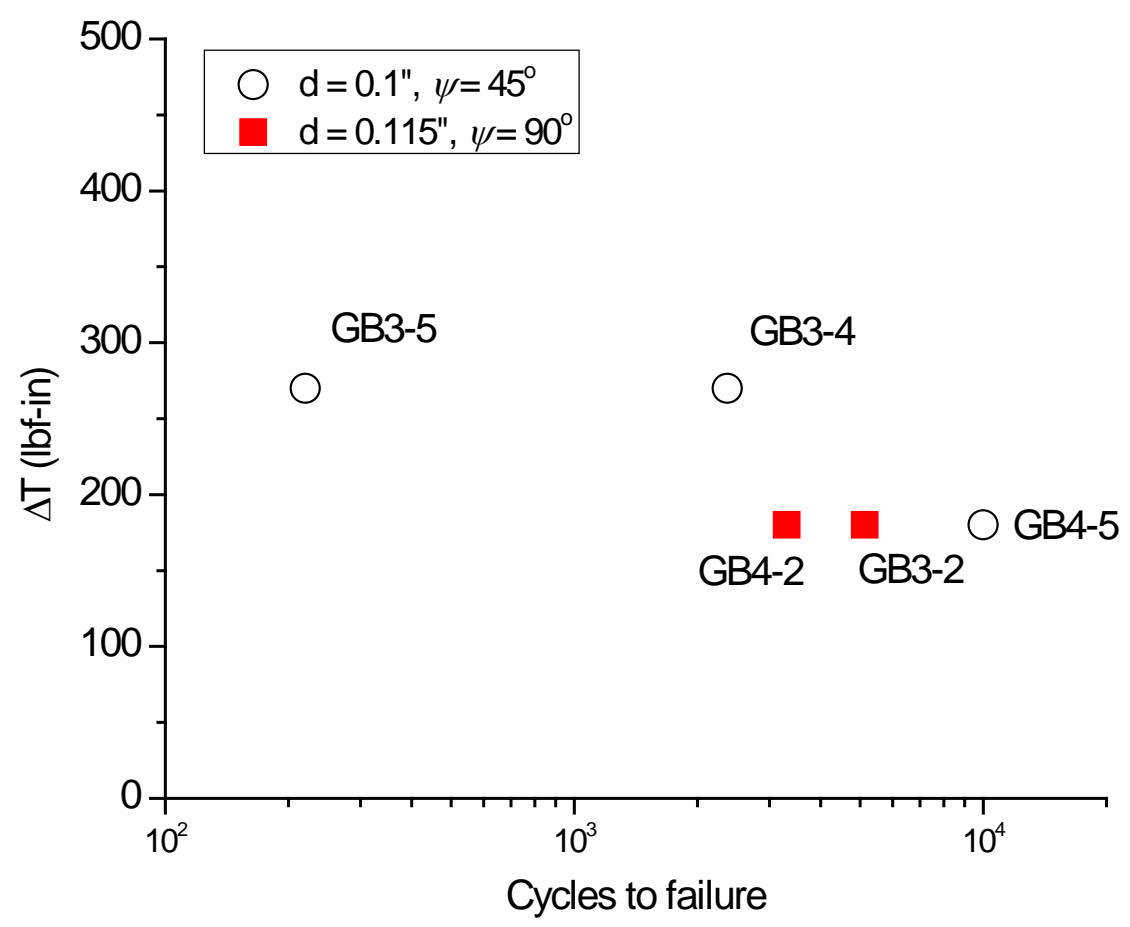

Figure 32. Fatigue S-N plots of samples from GB batch 3 and batch 4.

Compared to GB4-5, which failed after about 10,000 cycles, GB3-4 fractured after 2,369 cycles (Figure 32) because of a higher $\Delta \mathrm{T}$ (270 lbf-in versus $180 \mathrm{lbf}-\mathrm{in})$. GB4-2 and GB3-2 were both fatigued between 20 and $200 \mathrm{lbf}-i n$ with a frequency of $1 \mathrm{~Hz}$. They exhibited comparable fatigue life: 5,139 cycles for GB3-2 and 3,308 for GB 4-2 (Figure 
32). When compared to GB4-5, both GB3-2 and GB4-2 had shorter fatigue life (Figure 32), likely due to increased constraint induced by their deeper notches. GB3-5 was fatigued between 30 and $300 \mathrm{lbf}-i n$ with a frequency of $1 \mathrm{~Hz}$. However, it is not clear why it fractured after only 220 cycles (Figure 32) while GB3-4 fractured after 2369 cycles when subjected to identical fatigue conditions. One possible explanation is that a surface flaw due to machining existed near the notch line region in the sample prior to fatigue. In fact, no crack growth region could be identified on the fracture surface of GB3-5 (Figure 33). In any event, the fatigue life difference between 220 cycles and 2369 cycles may well due to material inhomogeneity or anisotropy.

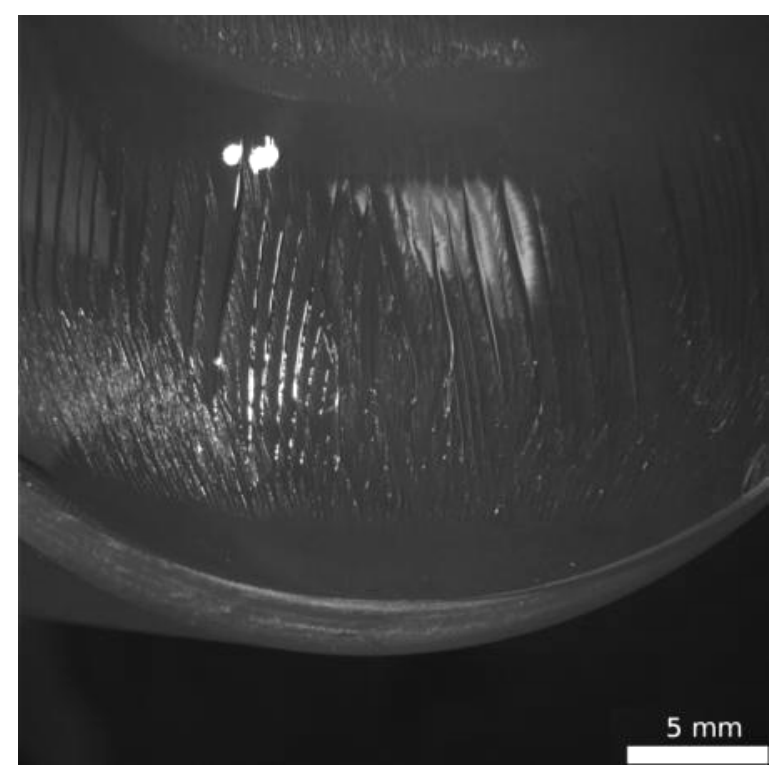

Figure 33. Fracture surface of GB3-5.

The fatigue regions on Mode I samples were expected to be a uniform band along the notch groove. However, the fatigue regions observed on the fracture surfaces of GB3-4 (Figure 34) and GB4-5 (Figure 35) were both long semi-ellipses. This deviation could be attributed to machining errors resulting in a pitch angle which deviated from $45^{\circ}$. It is interesting to point out that a broad striation line was observed on sample GB4-5 (Figure 35b). It is unclear the cause of this striation band, therefore it will require further investigation. 
DRAFT

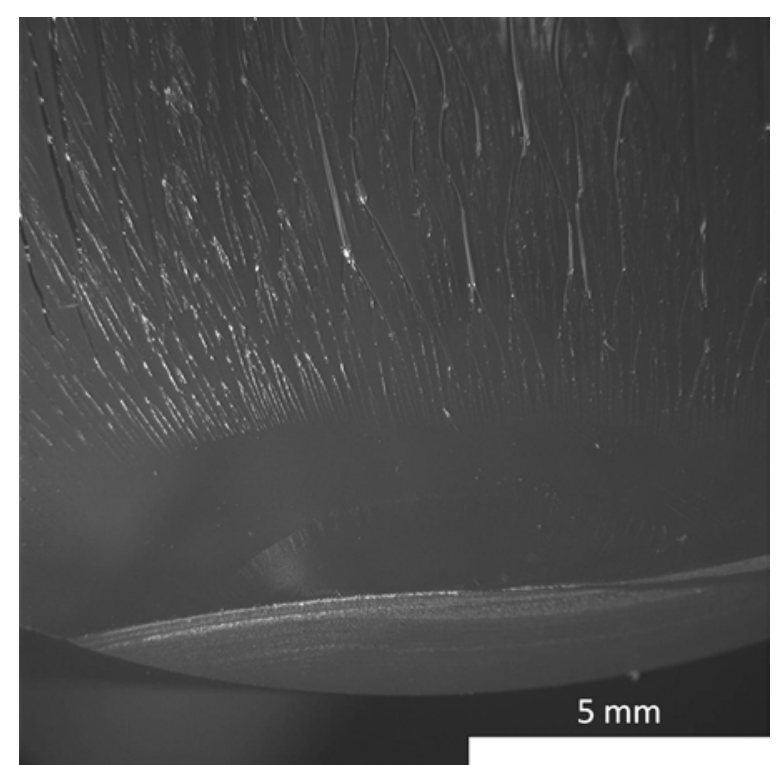

Figure 34. Fracture surface of GB3-4.

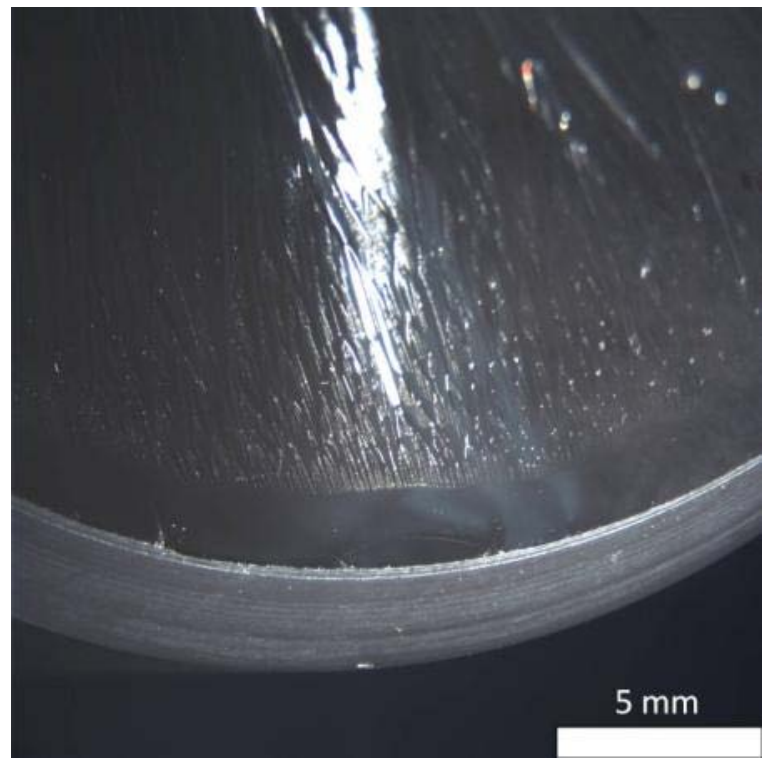

(a)

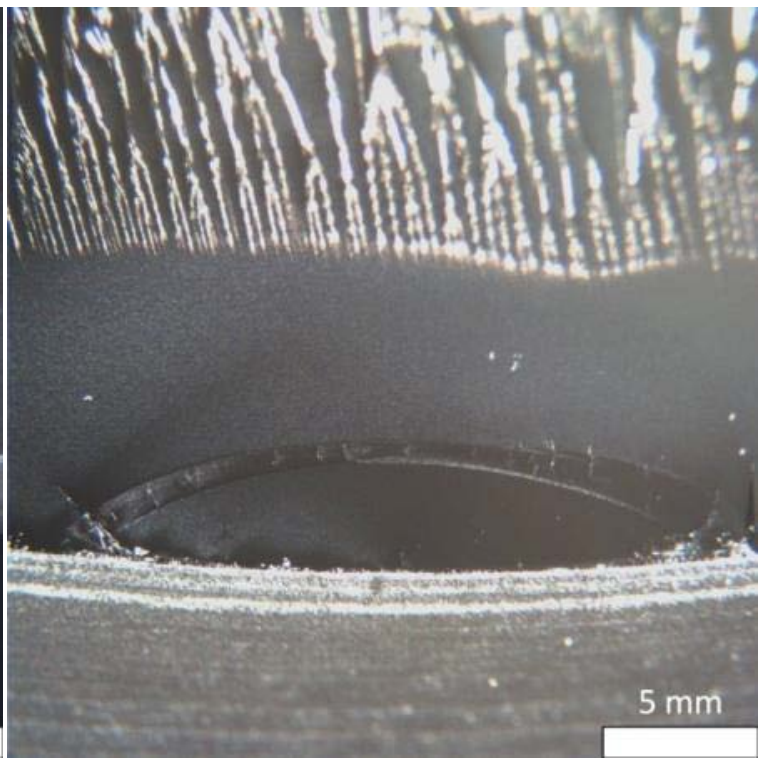

(b)

Figure 35. Images showing the fracture surfaces of GB4-5.

In contrast, uniform smooth bands (the smooth regions) were clearly seen on samples GB 3-2 and GB4-2 (Figure 36 and Figure 37). Higher magnification images of the smooth regions showed parallel markings with comparable lengths formed at a right angle to the notch roots which extended into the smooth regions (Figure 36b). These markings were observed in fatigued polyester resins and were attributed to stable fatigue crack growth [Owen 1975]. The fatigue regions on GB3-2 and GB4-2 agreed well with the expectation that a uniform fatigue growth occurs on a Mode I sample. 


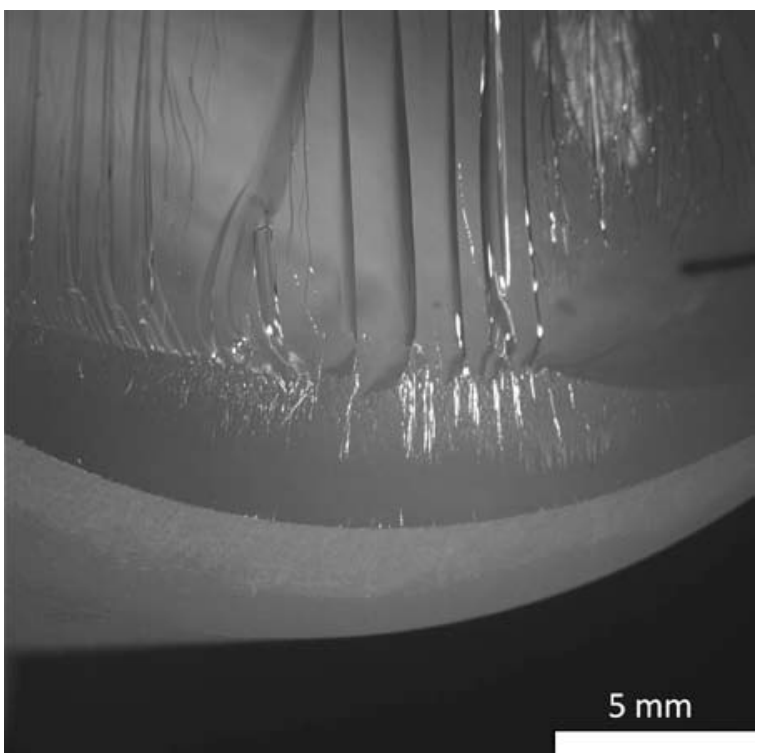

(a)

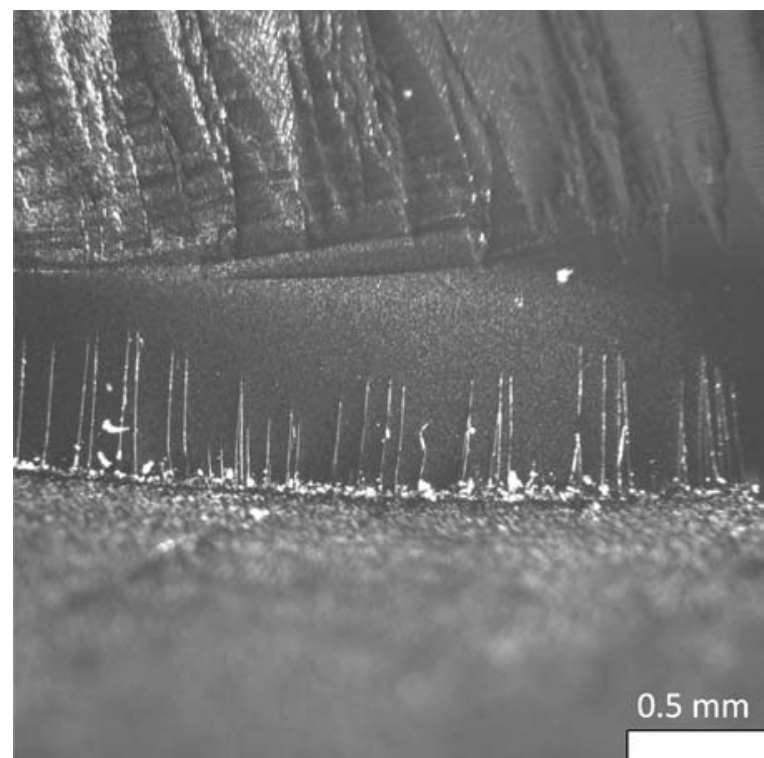

(b)

Figure 36. Images showing the radial markings along the groove line of GB3-2.

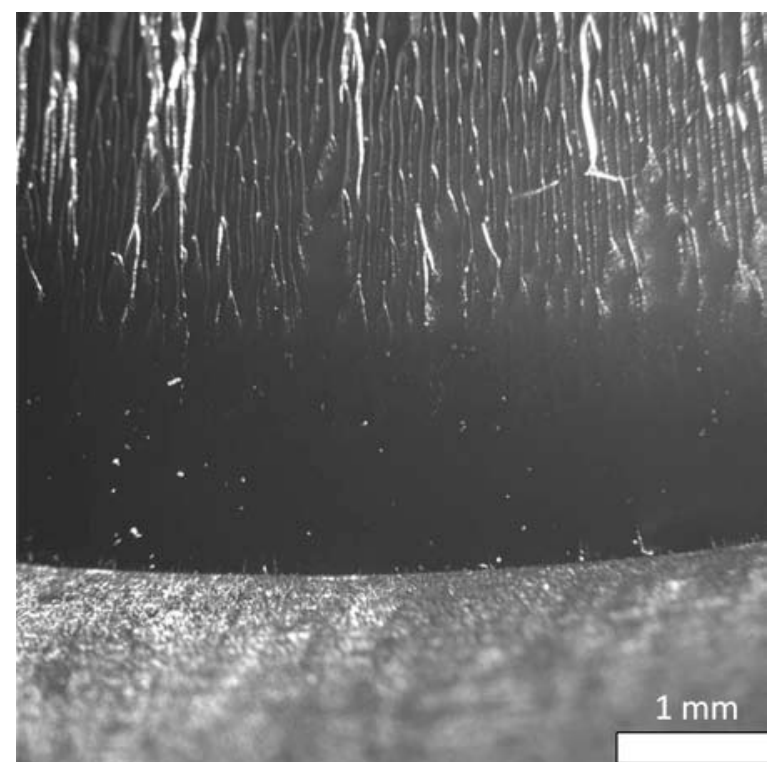

Figure 37. Images showing the uniform crack growth along notch line of GB4-2.

For GB3-2, the compliance change due to fatigue crack growth was monitored using both a rotary variable differential transformer (RVDT) and a biaxial extensometer (see Section 3.1). The extensometer measurements were taken every 1000 cycles. The torque versus rotation angle and shear strain were plotted in Figure 38a and Figure 38b, respectively.

For the rotation angle data measured from RVDT, the slope increased as a function of fatigue cycles, indicating an increase in sample stiffness or a decrease in sample compliance(Figure 38a). Strain accumulation could occur during cyclic loading 


\section{DRAFT}

[Nagasawa 1995], which might lead to strain hardening. A similar stiffness increase was observed by Tao et al. [Tao 2007] in an epoxy material fabricated from Epon 826 Resin and Epi-Cure Curing Agent 9551. Tao and coworkers [Tao 2007] showed that the stress range increased with increasing fatigue cycles when the sample was cycled between a strain range of $0.02 \%$ to $3.68 \%$; meanwhile, the stress range decreased with increasing cycles when the strain range involved both positive and negative strain values.

In contrast, a decrease in slope was observed in the extensometer measured data (Figure 38b). This seemed contradictory to the RVDT data. The RVDT measured the overall rotation of the entire sample, including the notched and un-notched regions; while the extensometer recorded the relative gage length displacement between the two probe pins across the notch. Therefore, the data measured by the extensometer is thought to give a more accurate estimate regarding localized deformation due to crack growth. Thus, the slope decrease in Figure 38b was a combined result from both crack growth induced compliance increases and hardening induced compliance decreases.

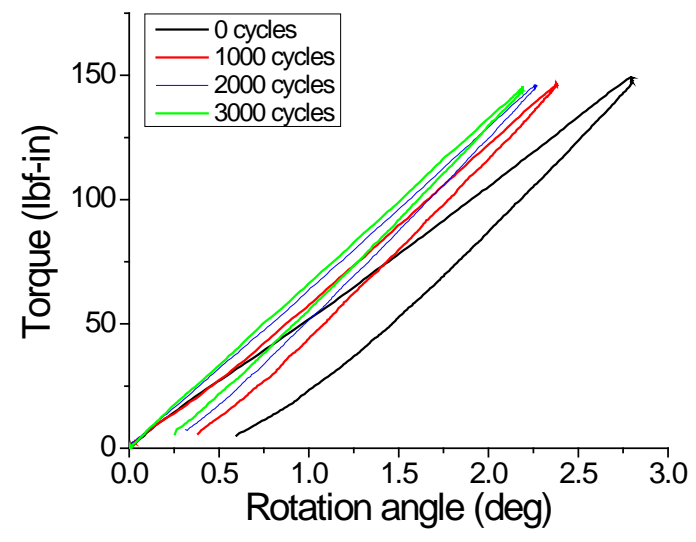

(a)

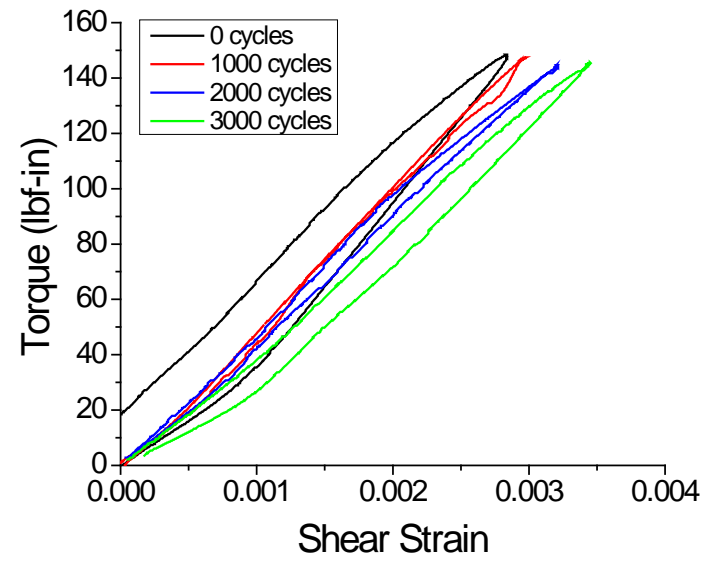

(b)

Figure 38. Effect of fatigue on stiffness of sample GB3-2 as measured from (a) load cell and RVDT, and (b) load cell and biaxial extensometer.

Due to the limited number of samples, only two MFG epoxy samples were tested under fatigue: MFG-2 and MFG-3. MFG-2 was cycle fatigued between 60 and $600 \mathrm{lbf}-\mathrm{in}$ with a frequency of $1 \mathrm{~Hz}$. However, the mechanical response of the testing machine was not fast enough to perform such test. The actual torque range was approximately 100 to 560 lbf-in. After about 500 cycles, MFG-2 fractured showing no obvious fatigue region on the fracture surface (Figure 39a). Some river lines were observed at the fracture origin (Figure 39b) indicating some fatigue crack growth.

In contrast to MFG-2, MFG-3 was fatigued between 30 and $300 \mathrm{lbf}-\mathrm{in}$ at $1 \mathrm{~Hz}$ and failed after 7084 cycles (Table 4). On the fracture surface, a uniform smooth band (Figure 40a), striation line, and unstable initiation line (Figure 40b) were all observed. In 


\section{DRAFT}

addition, parallel river markings, characteristic of stable crack growth were also seen (Figure 40b). The river markings initially grew perpendicular to the notch root, but then deflected at approximately $0.7 \mathrm{~mm}$ into the sample at two different angles (Figure 40b). This interesting behavior perhaps was related to some preferred stress directions and will be further investigated in the future.

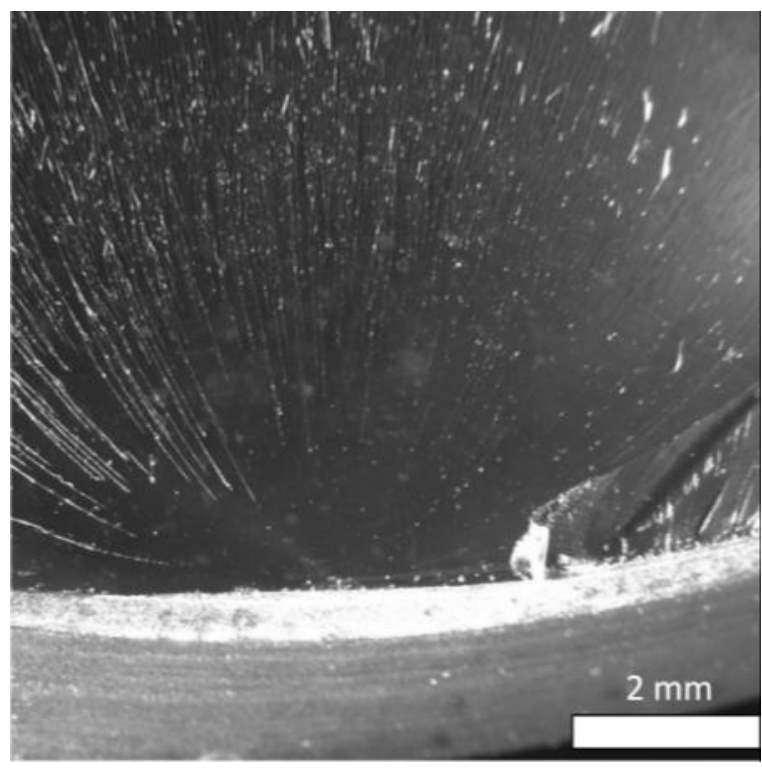

(a)

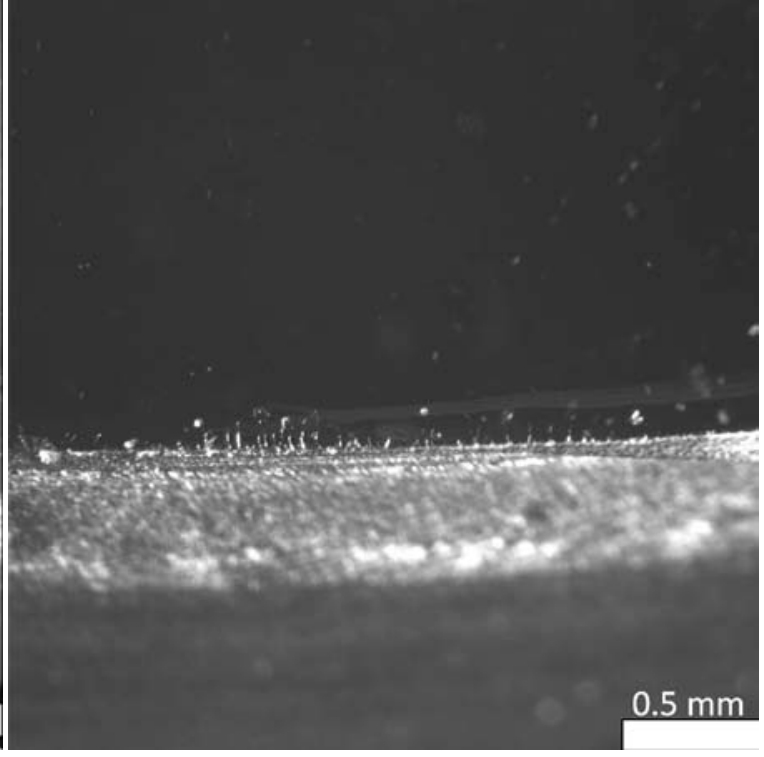

(b)

Figure 39. Images showing the fracture surface of MFG-2.

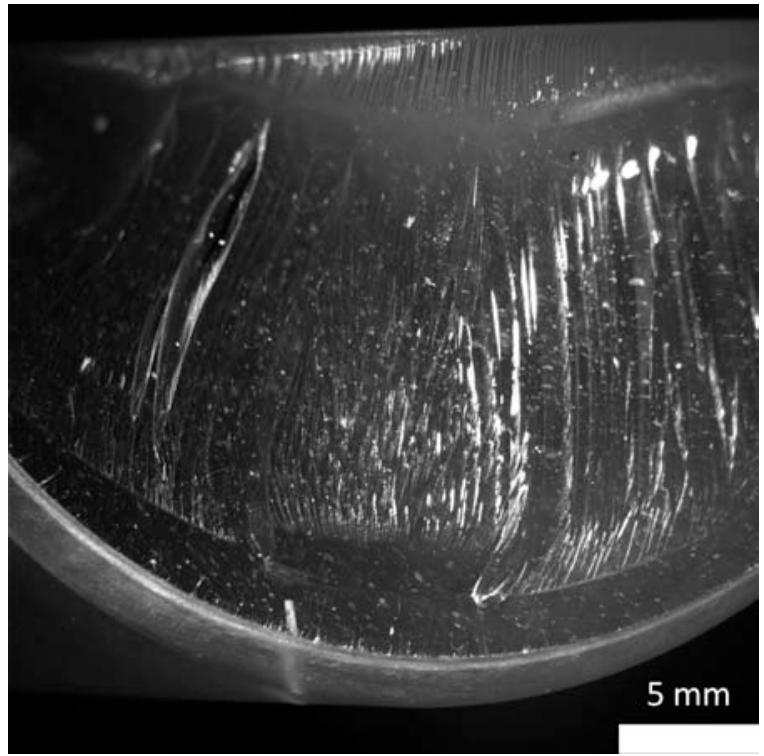

(a)

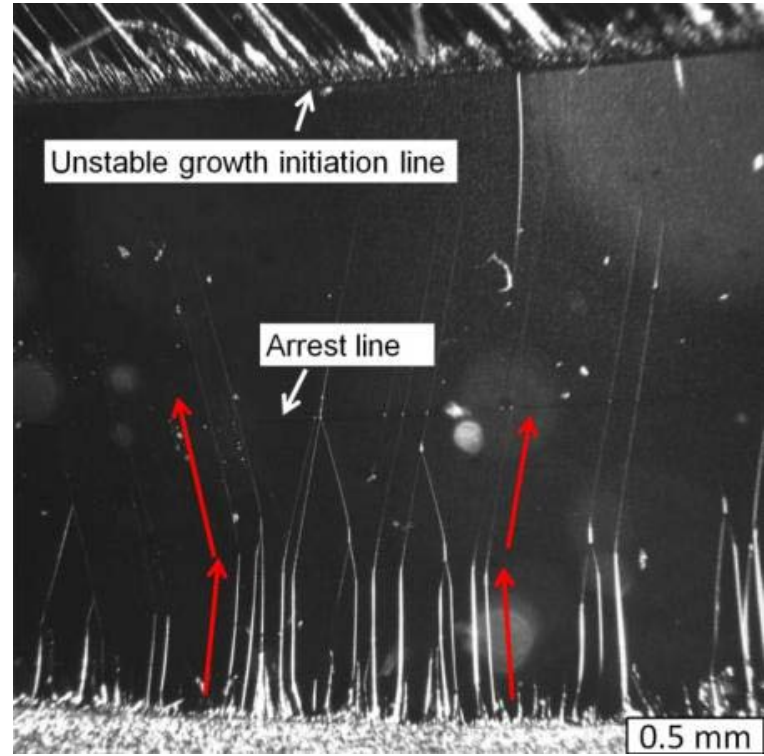

(b)

Figure 40. Images showing the fracture surfaces of MFG-3.

\subsection{Fatigue and monotonic loading}


Creation of sharp pre-cracks is essential for accurate fracture toughness measurements in order to minimize the energy associated with plastic deformation. In this study, fatigue procedures described in the previous section (Section 4.3) were used to create pre-cracks in epoxy samples. The fatigued samples were then loaded monotonically to failure (Section 4.2).

Samples GB1-6 and GB1-7 were fatigued for 5500 cycles and 260,000 cycles, respectively. Their final monotonic loading curves are compared in Figure 41. Both samples showed linear elastic behavior and almost identical slopes (Figure 41). However, the fracture torque of GB1-6 was $596 \mathrm{lbf}$-in, approximately $67 \%$ higher than that of GB1-7, which fractured at $357 \mathrm{lbf}$-in (Table 4). It was probable that the lower fracture torque of GB1-7 was due to a deep pre-crack as a result of longer fatigue cycles.

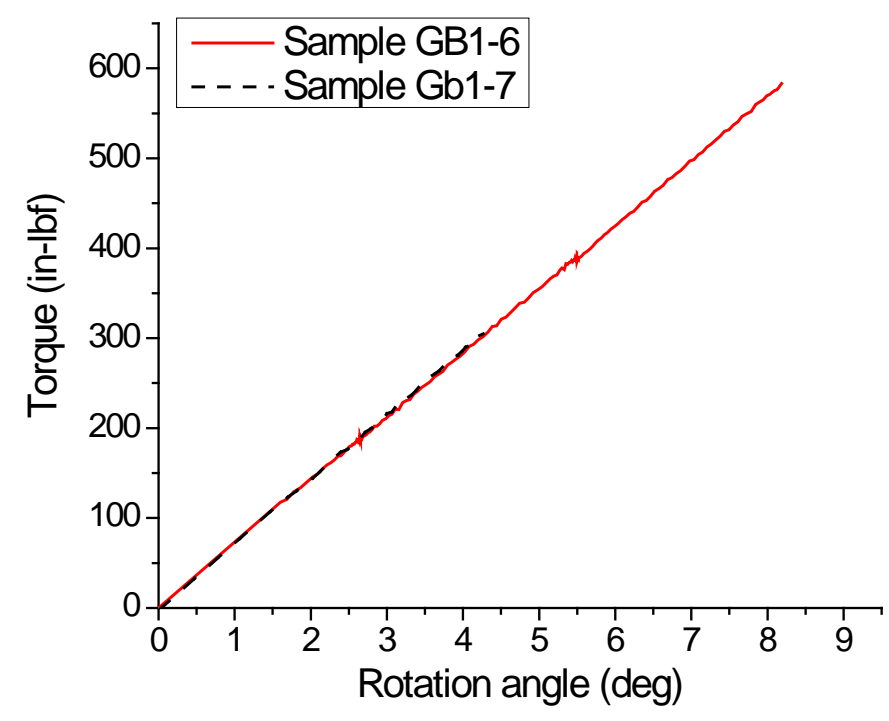

Figure 41. Monotonic loading curves of GB1-6 and GB1-7 after fatigue.

Fractographic analysis showed that no significant fatigue region could be identified on sample GB1-6 (Figure 42a); while in contrast a clam-shell fatigue region was observed on GB1-7, which could explain its lower fracture torque compared to GB1-6. 


\section{DRAFT}

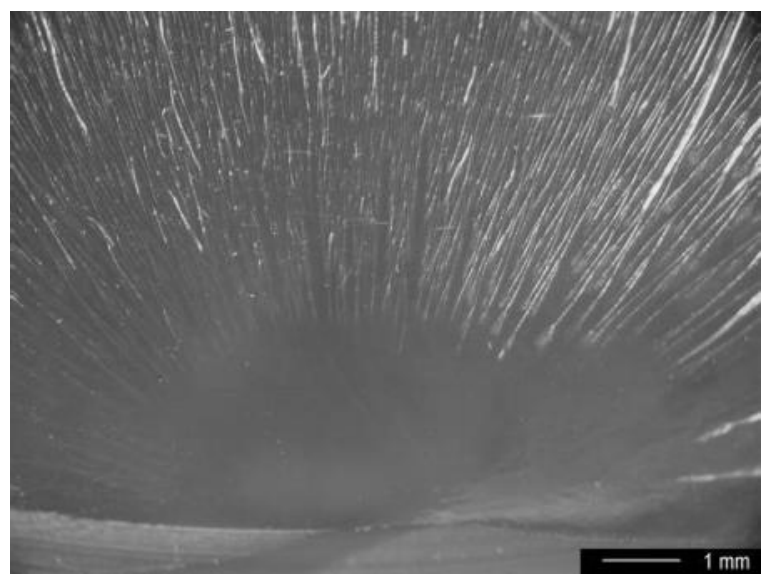

(a)

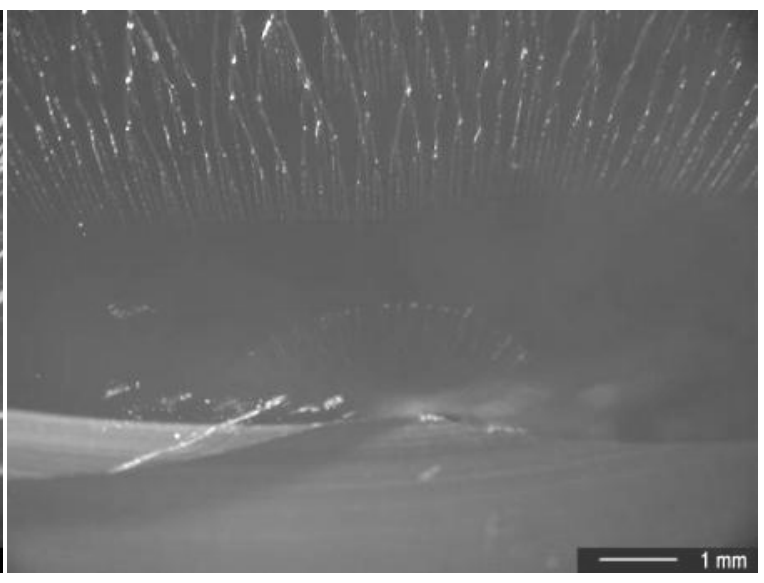

(b)

Figure 42. Fracture surfaces of samples GB1-6 and GB1-7.

Sample GB2-2 was initially fatigued between 20 and $200 \mathrm{lbf}$-in for 150,000 cycles. Upon monotonic loading, GB2-2 fractured at 865 lbf-in, which was comparable to (in fact slightly higher than) sample GB2-1 without fatigue (Figure 43). This was due to a small peak loading torque being used in fatigue (200 lbf-in) so no pre-crack was generated in the fatigue stage. Microscopic examination also confirms that no significant fatigue crack growth developed in GB2-2 (Figure 44). The fracture surface of GB2-2 looked very similar to GB2-1 and GB2-6 (Figure 18), which were not fatigued prior to monotonic loading.

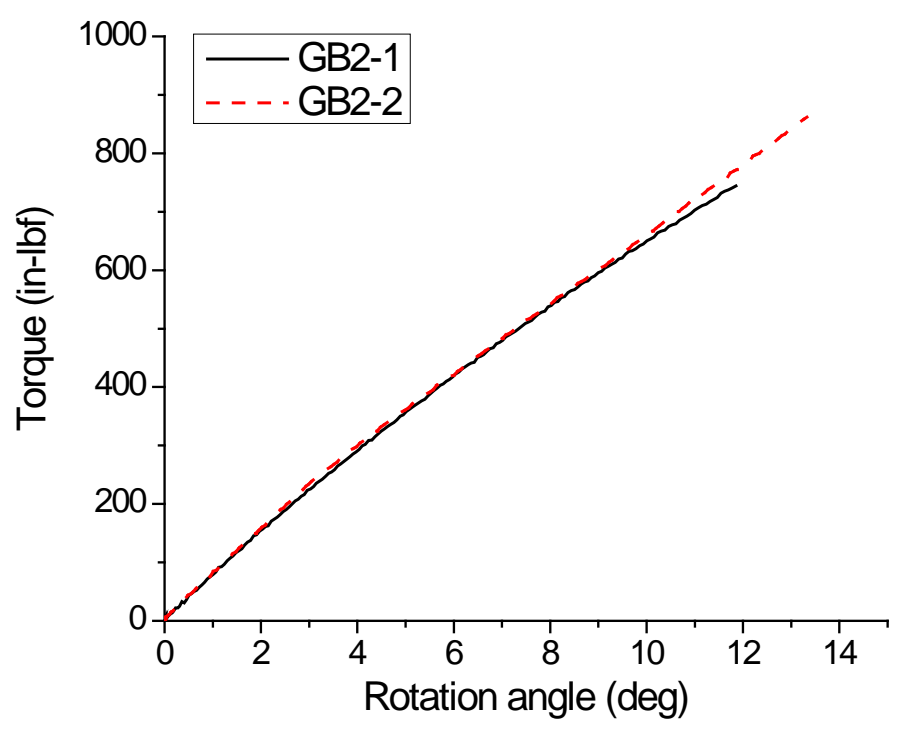

Figure 43. Comparison of the loading curves between GB2-1 and GB2-2. 


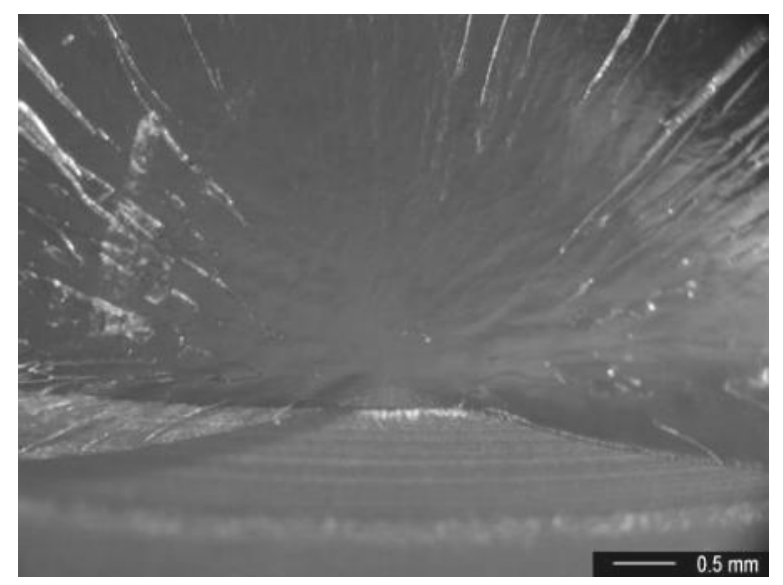

Figure 44. Fracture surface of GB2-2.

Sample GB4-6 was first fatigued between 20 and $200 \mathrm{lbf}-\mathrm{in}$ for 9000 cycles and then fractured at $281 \mathrm{lbf}$-in during monotonic loading. Compared to the fracture load of sample GB4-4 without fatigue (404 lbf-in), GB4-6 exhibited a 30\% decrease (Figure 45). This was due to the introduction of fatigue cracks, which were clearly seen on the fracture surface of GB4-6 (Figure 46). However, a slight increase in the slope was observed on the loading curve of GB4-6 as compared to GB4-4 (Figure 45), which might be explained by strain hardening [Tao 2007] as seen in sample GB3-2 (Figure 38a).

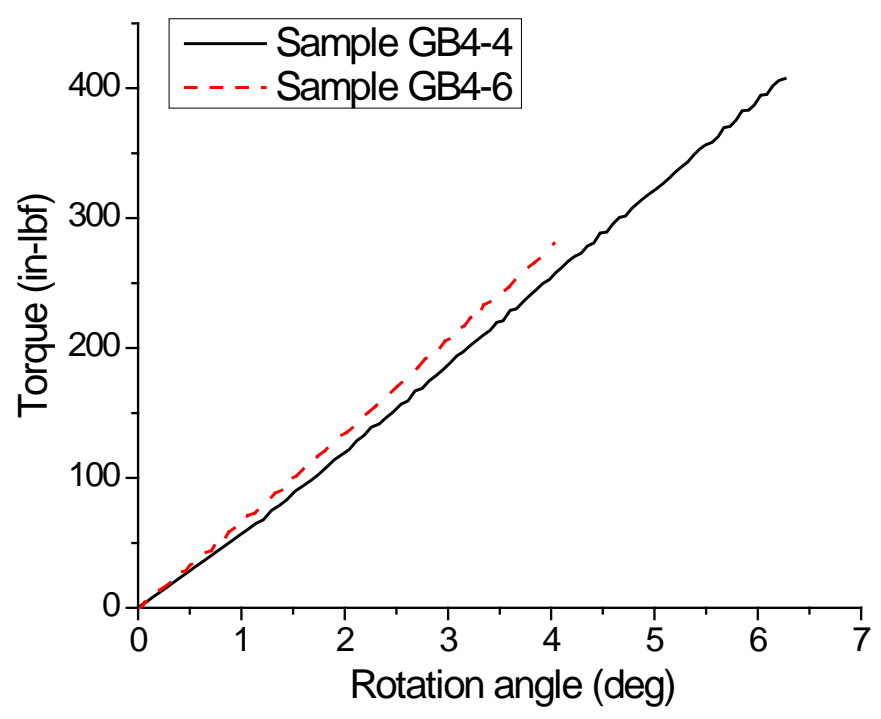

Figure 45. Comparison of the loading curves between GB4-4 and GB4-6. 


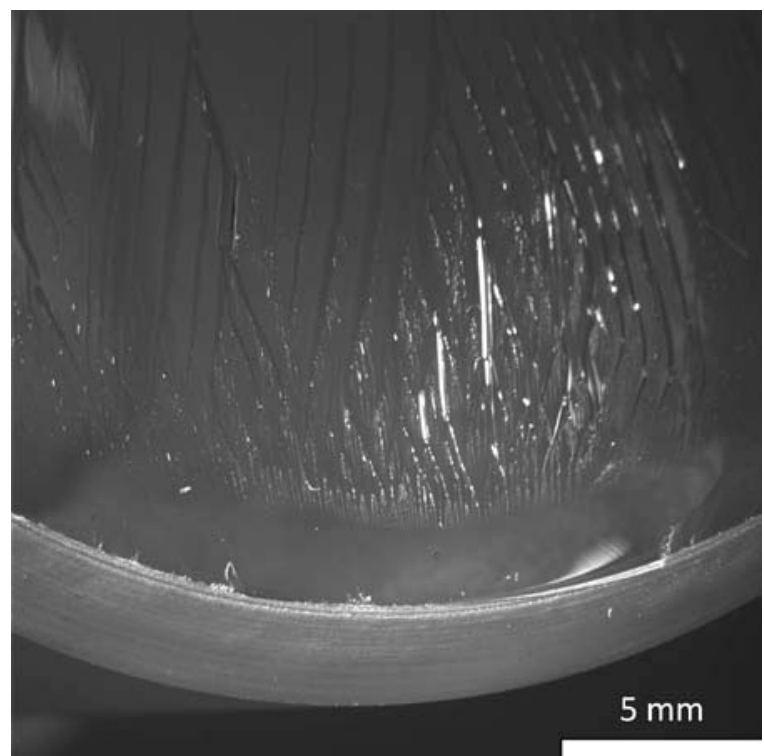

(a)

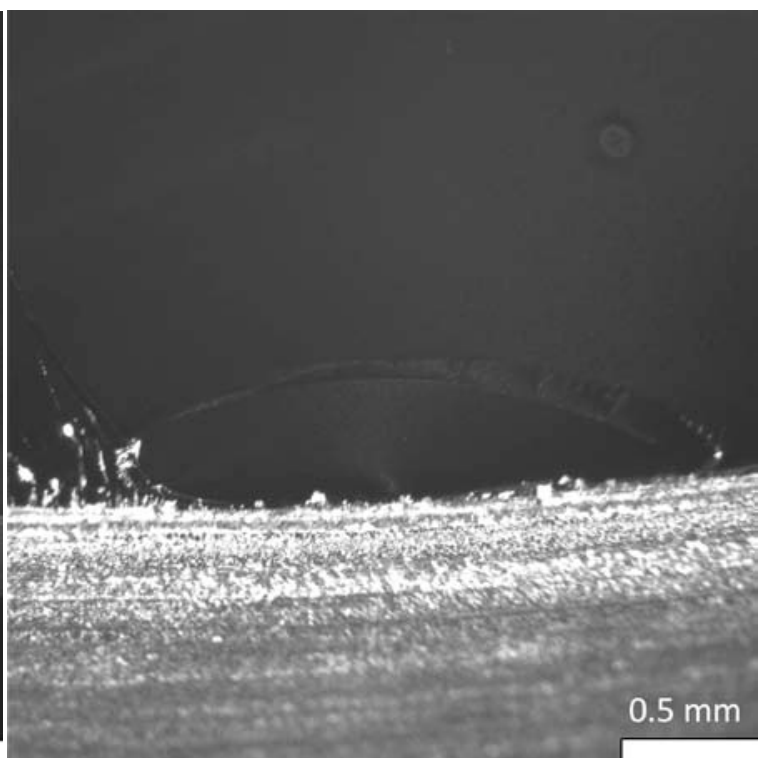

(b)

Figure 46. Images showing the fatigued crack growth on fracture surface of GB4-6.

Samples GB3-1, GB3-3, GB4-1, and GB4-3 were nominally identical (Table 3). GB3-3 and GB4-3 were fatigued between 20 and $200 \mathrm{lbf}-$ in for 3000 and 4000 cycles, respectively. Upon final monotonic loading, GB3-3 and GB4-3 showed comparable fracture torques and similar slopes (Figure 47). This indicates the SNTT testing protocol is reproducible. The two fatigued samples (GB3-3 and GB4-3) had lower fracture torques and higher slopes than the two samples without fatigue (GB3-1 and GB4-1) (Figure 47).

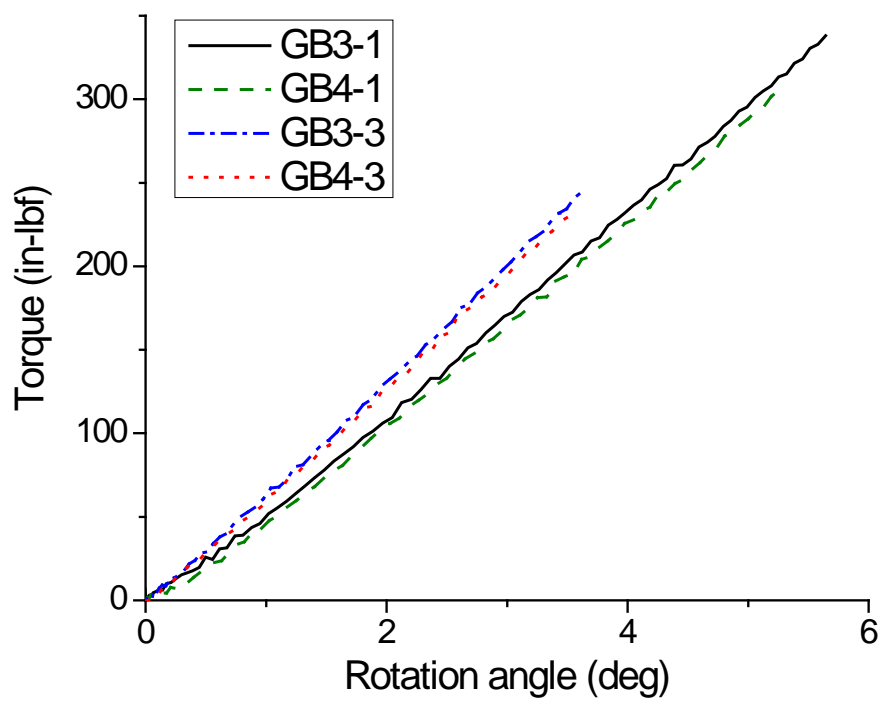

Figure 47. Comparison of the loading curves among GB3-1, GB3-3, GB4-1, and GB4-3. 


\section{DRAFT}

Microscopy showed that fatigue pre-cracks were developed in both GB3-3 (Figure 48) and GB4-3 (Figure 49). Uniformly smooth regions parallel to the notch groove, characterizing the slow unstable crack growth regions (Figure 48a and Figure 49a), and river markings perpendicular to the grooves, as a result of stable crack growth (Figure $48 \mathrm{~b}$ and Figure 49b), were observed in both samples. In addition, the striation line in GB4-3 was broad and relatively irregular (Figure 48b) compared to a thin line parallel to notch groove as seen in GB3-3 (Figure 49b).

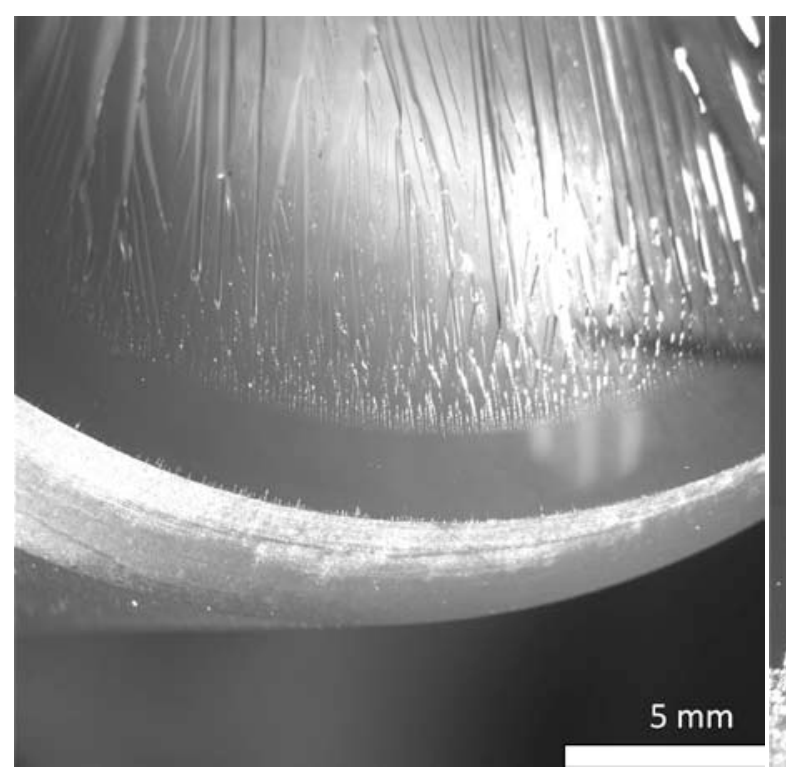

(a)

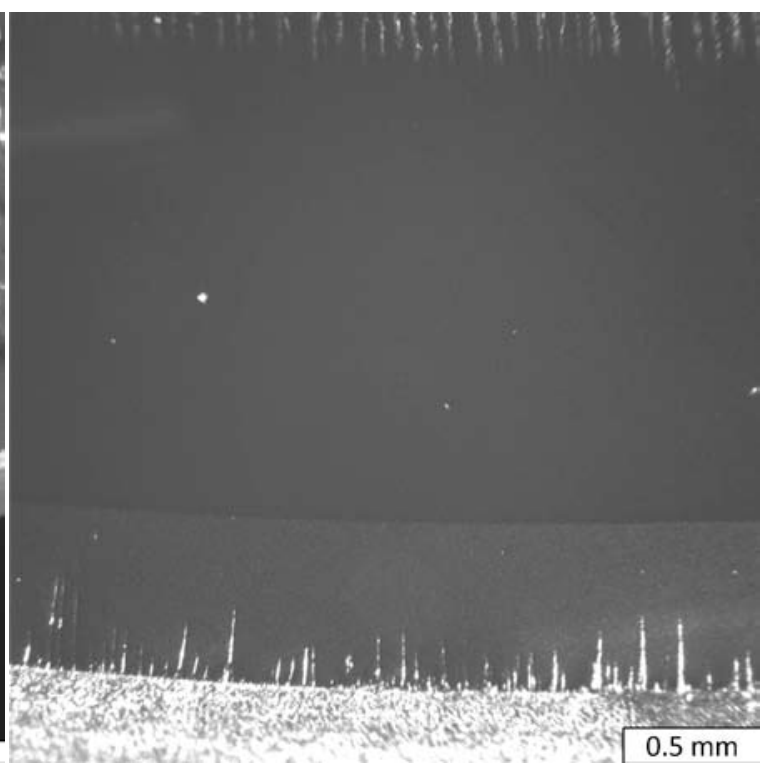

(b)

Figure 48. Images showing the fracture surface of GB3-3.

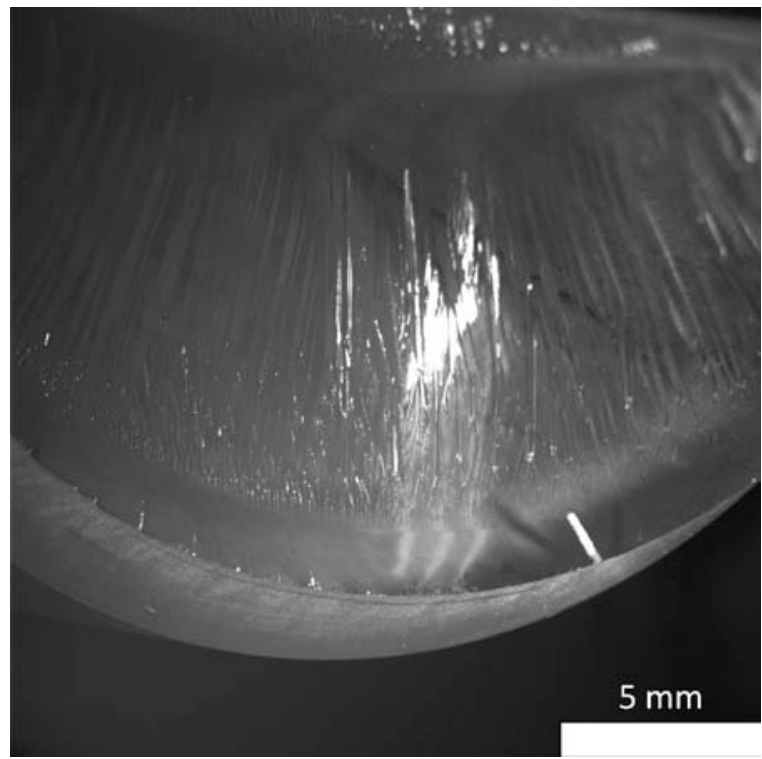

(a)

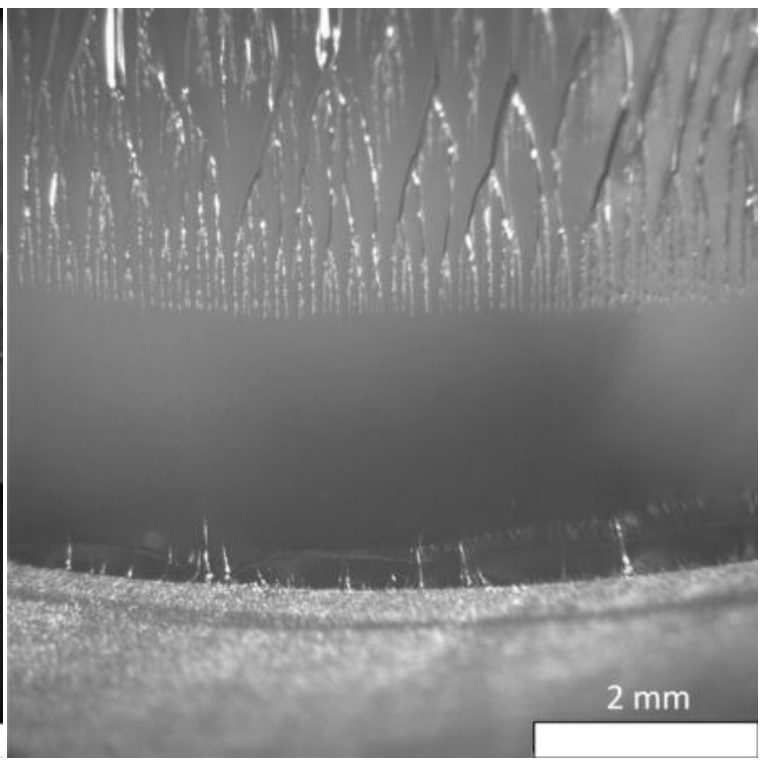

(b)

Figure 49. Images showing the fracture surface of GB4-3. 
For GB3-3 and GB4-3, the stiffness was also monitored using both a RVDT and a biaxial extensometer. From the RVDT data (Figure 50a and Figure 51a), fatigue cycle hardening was observed on GB3-3 and GB4-3, similar to that observed on GB3-2 (Figure 38a).

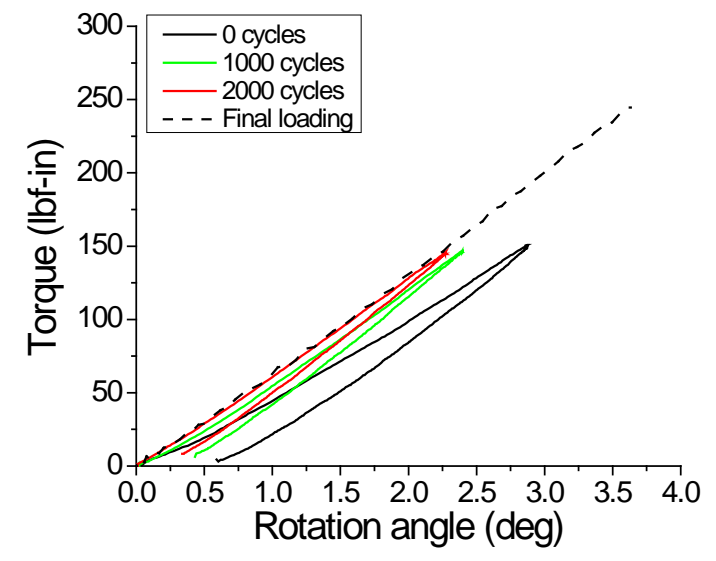

(a)

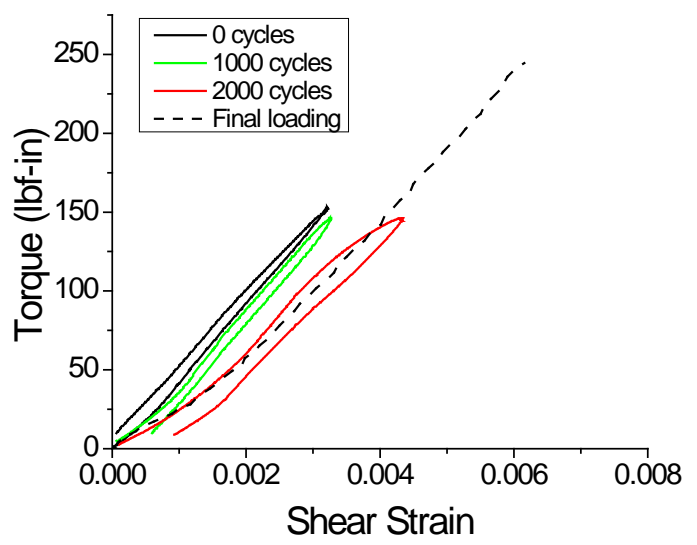

(b)

Figure 50. Effect of fatigue on stiffness of sample GB3-3 as measured from (a) load cell and RVDT, and (b) load cell and biaxial extensometer.

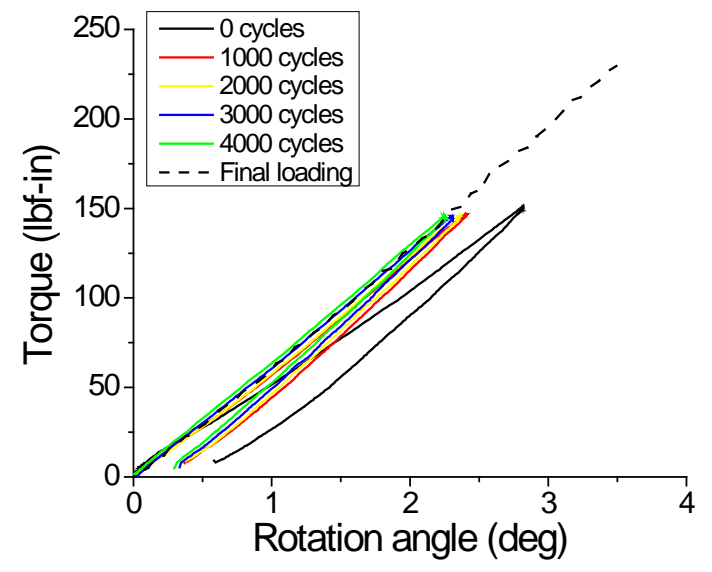

(a)

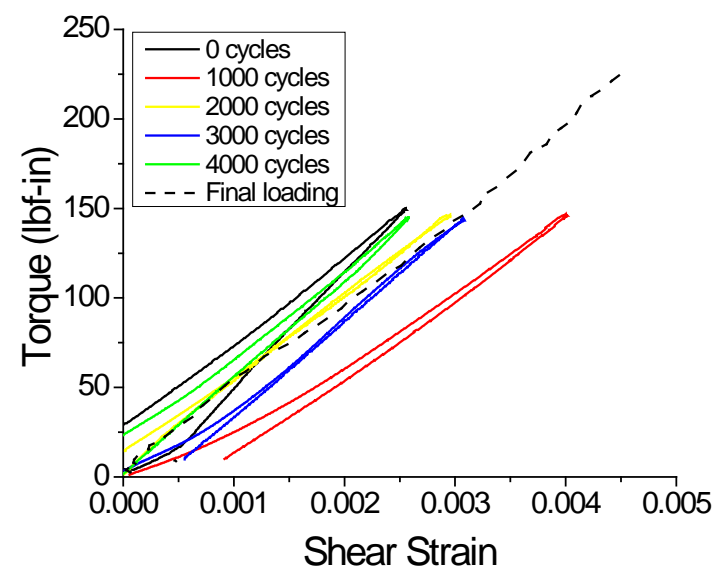

(b)

Figure 51. Effect of fatigue on stiffness of sample GB4-3 as measured from (a) load cell and RVDT, and (b) load cell and biaxial extensometer.

The extensometer data indicated a stiffness drop in GB3-3 (Figure 51b) probably due to crack growth similar to that of GB3-2 (Figure 38b). However, for GB4-3 the stiffness initially decreased for up to 3000 cycles and then increased after an additional 1000 cycles (Figure 50b). The reason for this behavior is not clear, and requires further 
investigation. One possible explanation may be related to the competition between the strain hardening and the "crack" softening occurring simultaneously in the grooved region.

Sample GB3-7 was fatigued between 20 and $200 \mathrm{lbf}-\mathrm{in}$ for 9000 cycles, which was the same condition used for GB4-6. However, the fracture torque of GB3-7 was much higher than GB4-6, i.e. $618 \mathrm{lbf}-i n$ vs. $281 \mathrm{lbf}-$ in. GB3-7 was fabricated by the same machine shop that also processed GB3-8 and GB3-9. The notch roots of these three samples were very blunt. Thus, the fatigue test performed on GB3-7 did not seem to create any pre-crack, which was confirmed by the image of its fracture surface (Figure 52).

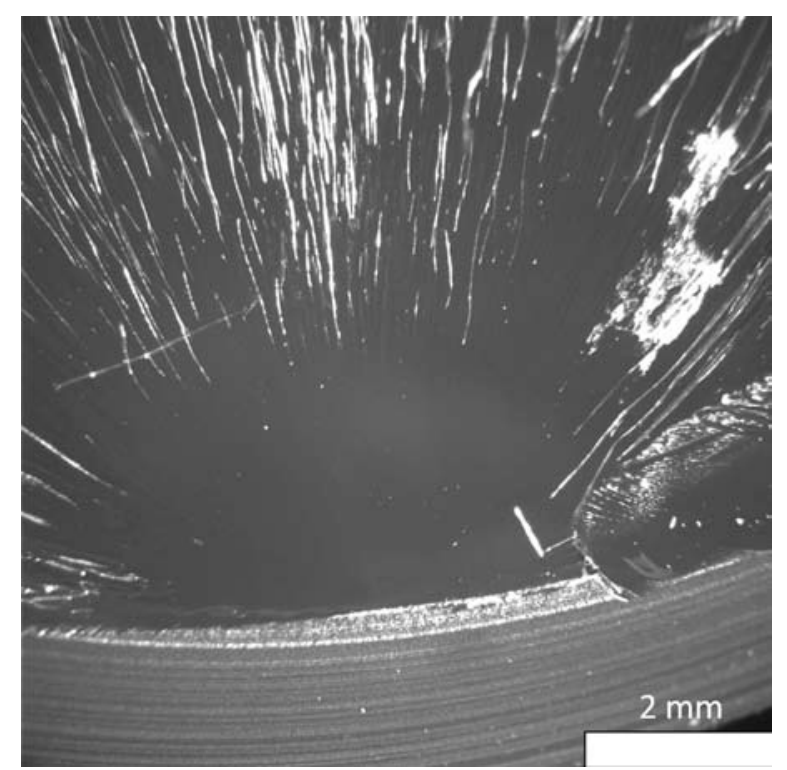

Figure 52. Images showing the fracture surface of GB3-7. 


\section{Finite Element Model Development for SNTT Epoxy Samples}

The detailed SNTT geometry design concept and the associated finite element modeling are illustrated in Figs. 53-57. In order to ensure that the crack propagation direction is perpendicular, the local coordinate of the designed mesh needs to be perpendicular to both the spiral notch and central axis of the SNTT sample as illustrated in Figure 53. Furthermore, a proper partition of the SNTT model is also needed to generate properly organized mesh profiles that are aligned with the spiral crack front as shown by the yellow line in Fig. 54 , where the red line indicates the first partition region.
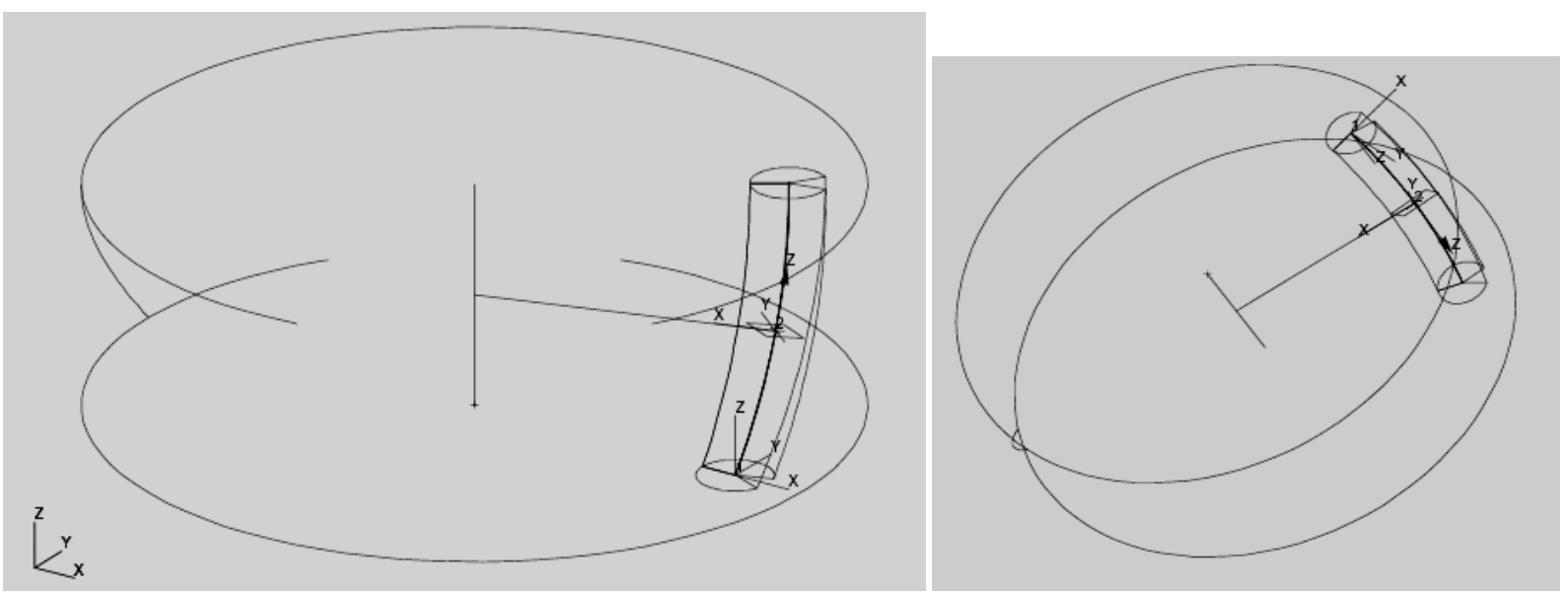

Figure 53. Schematic diagram of SNTT mesh design that allows the crack propagation to be perpendicular to the central axis of the SNTT samples.
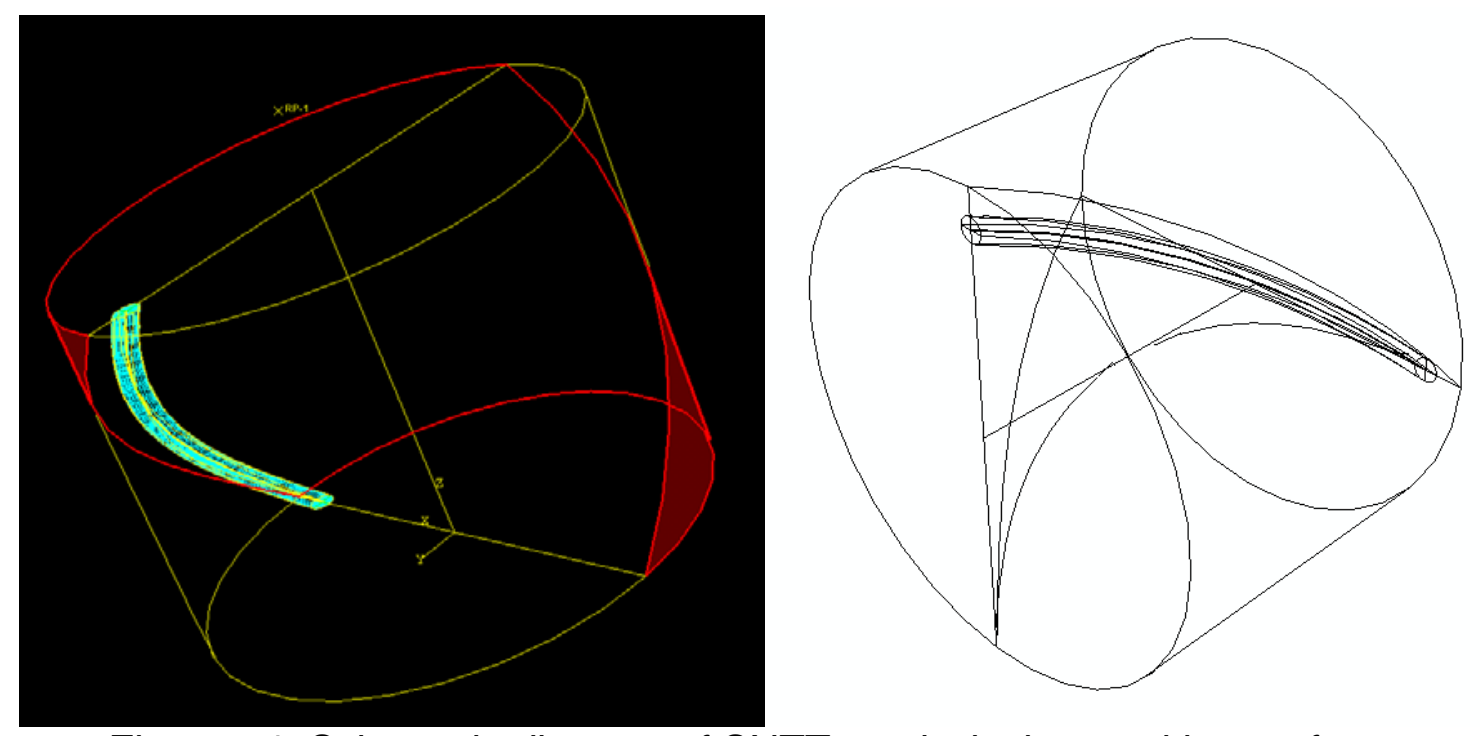

Figure 54. Schematic diagram of SNTT mesh design partition surfaces. 
A more detailed mesh design with singular elements along the crack front is illustrated in Figure 55. The completed SNTT FEM model for the epoxy sample is shown in Figure 56 with the embedded partition surfaces. An enlarged view of the FEM model is shown in Figure 57, where the red line indicates the crack seam.

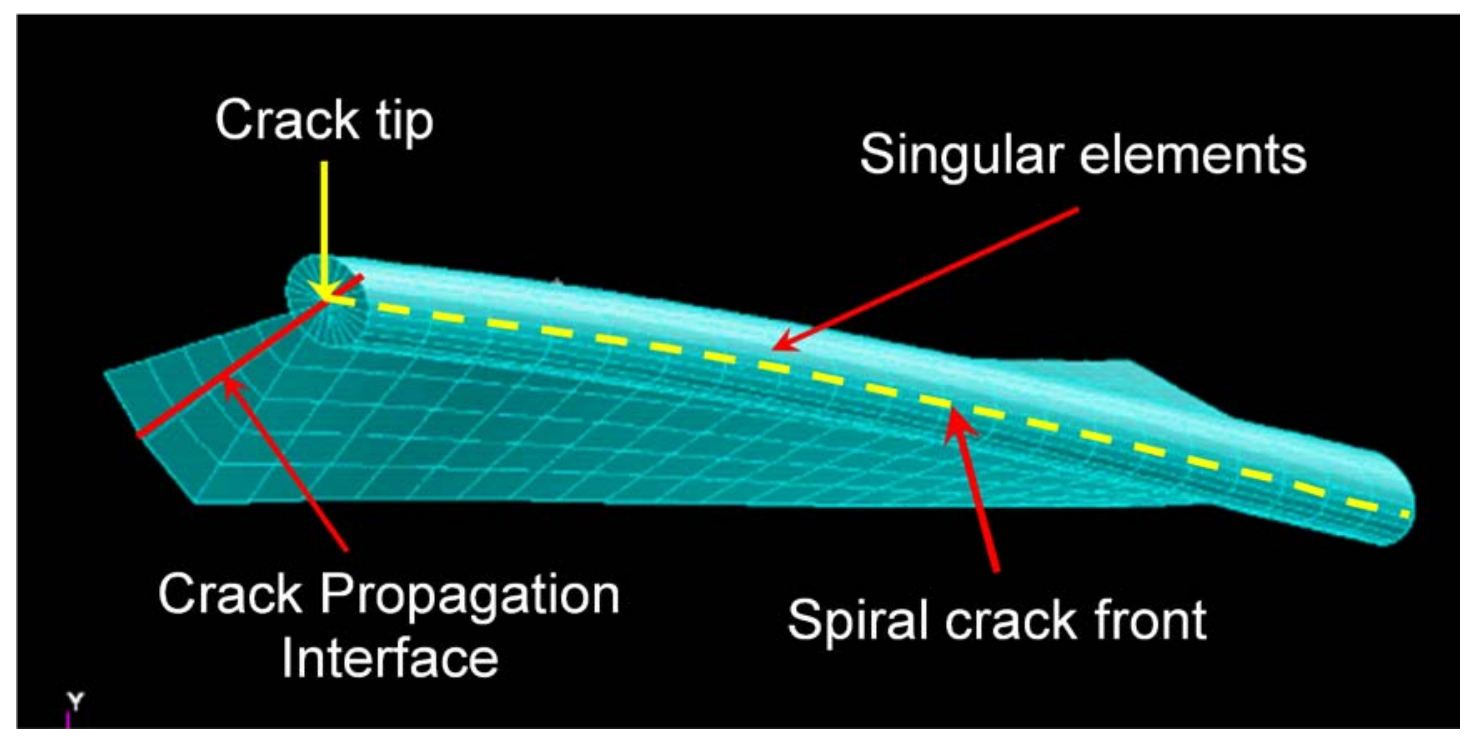

Figure 55. FEM mesh around crack front and crack tip, including the mesh boundary designed along the orientation of crack propagation.
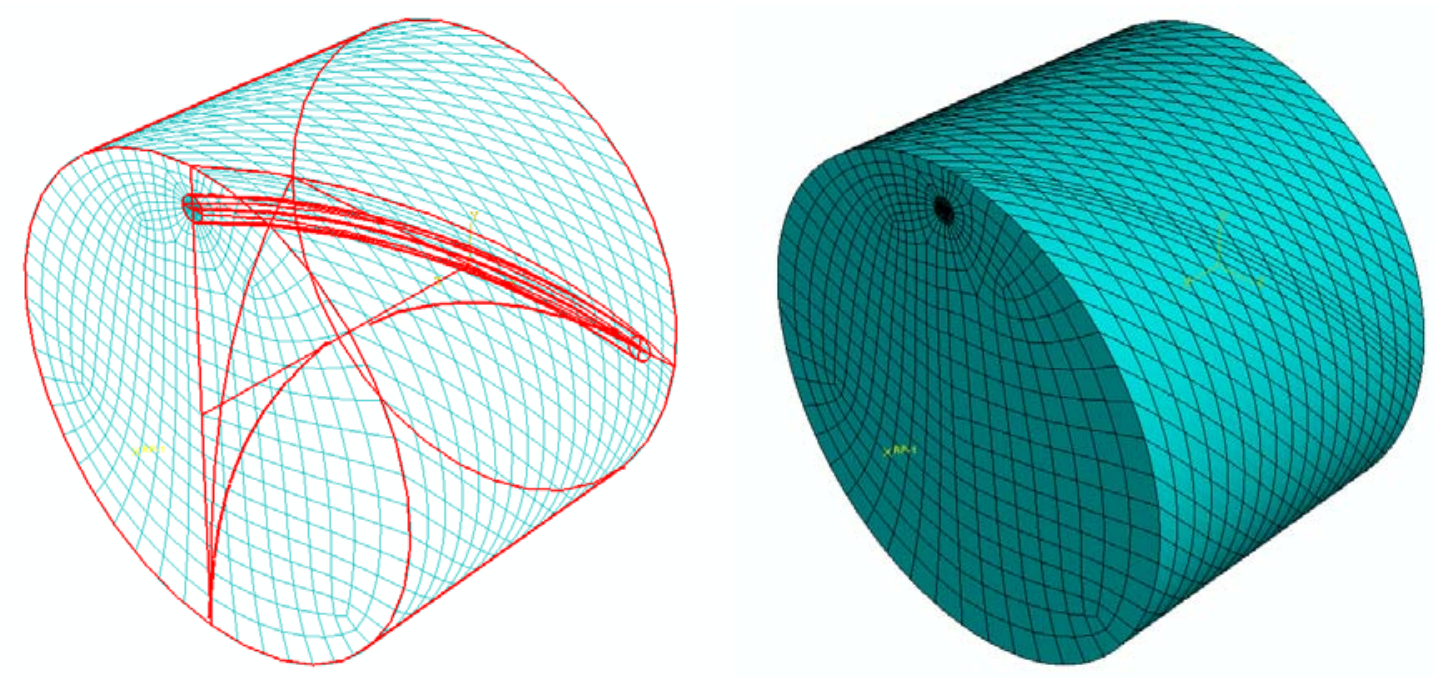

Figure 56. The FEM model designed for SNTT epoxy samples. 
DRAFT

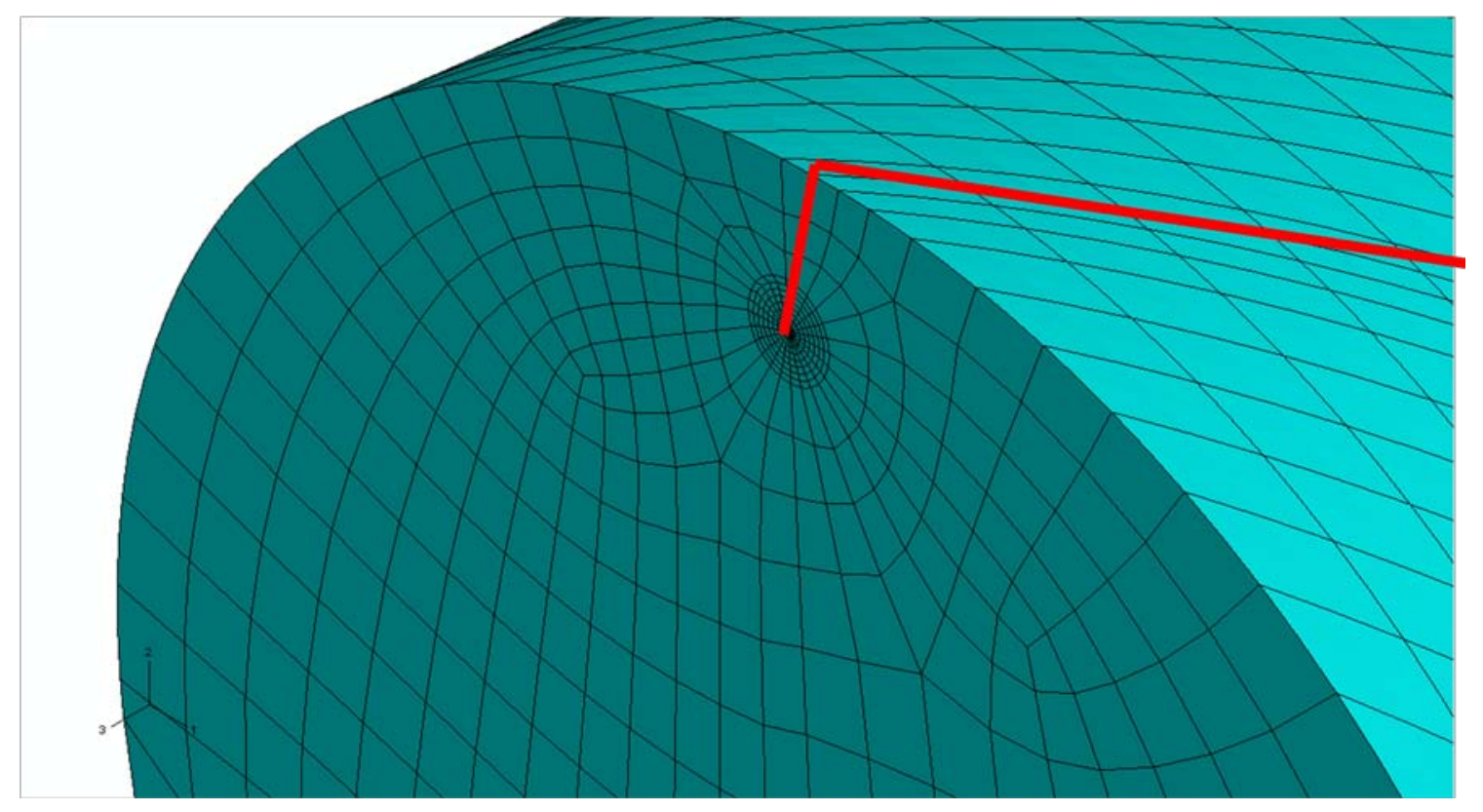

Figure 57. The enlarged view of FEM model for SNTT epoxy sample, where the red lines indicates the crack seam region. 


\section{Summary and future work}

During FY2010, we have 1) configured a SNTT testing apparatus for polymeric/ composite samples; 2) fabricated more than 30 samples from two types of epoxy materials (Gougeon Brothers and MFG); and 3) obtained fundamental knowledge on the fracture behavior of these materials through three types of testing.

To date, a total number of 30 epoxy samples were studied using spiral notch torsion test. Nine samples were fractured without fatigue (Section 4.2), 14 samples were fatigue fractured (Section 4.3), and seven samples were fractured after being fatigued (Section 4.4). For all the tested samples, brittle fracture was observed. Thus, the fracture toughness of these materials can be estimated using linear elastic finite element analysis.

However, the sharpness of the notch root seems to affect the fracture behavior, particularly the fracture torque, which in turn would affect the calculated fracture toughness. Thus, fatigue is preferred in order to introduce sharp pre-cracks in these epoxy materials. An appropriate fatigue protocol has been established to achieve controllable crack growth using the SNTT setup, which is one of the significant accomplishments in this project.

Another important finding was that the epoxy samples involved in this study tended to fail in tensile failure mode. The fracture surfaces always follow the $45^{\circ}$ spiral plane that corresponded to Mode I loading; even when the starter notch's pitch angle was deviated from $45^{\circ}$. This behavior also indicates the brittle fracture nature of epoxies.

On the other hand, this may not be the case for composite materials. Since fiber reinforced polymers can possess a large degree of anisotropy, their failures are expected to be sensitive to loading conditions. In the following quarter (Q1, FY2011), a significant effort will be focused on the effect of mixed-mode loading to the fracture of fiber glass composite materials. Since the fracture toughness of composites can be much higher than the unreinforced epoxies, proper pre-crack of SNTT composite samples will likely be needed. The experience of fatigue pre-cracking learned from epoxy polymeric materials will be beneficial when investigating polymeric composites.

The success of the fracture toughness evaluation of SNTT samples also depends on advanced finite element analysis. In the past year, geometric models designed for SNTT epoxy samples and appropriate meshing protocols were developed. In FY2011, extensive work will be performed on modeling based on the preliminary results achieved in FY2010. In addition, other factors that may affect fracture behavior of composite materials, such as loading rate and testing environments, will also be investigated. The achievements in FY2010 and the plans for FY2011 are highlighted in Table 5. 
DRAFT

Table 5. Project progress in FY2010.

\begin{tabular}{|c|c|c|c|c|c|c|}
\hline \multirow[b]{2}{*}{ Task } & \multirow[b]{2}{*}{ Milestones } & \multicolumn{4}{|c|}{ Progress, 2010} & \multirow[b]{2}{*}{ Notes } \\
\hline & & Q1 & Q2 & Q3 & Q4 & \\
\hline 1 & Sample design & & & $100 \%$ & & Completed \\
\hline 2 & Equipment preparation & & & $100 \%$ & & Completed \\
\hline 3 & Proof of concept: polymeric materials & & & $100 \%$ & & Completed \\
\hline 4 & Mixed mode study of polymeric materials & & & & $100 \%$ & Completed \\
\hline \multirow[t]{3}{*}{5} & Proof of concept: composite materials & & & & $25 \%$ & $\begin{array}{l}\text { In progress, will } \\
\text { extend to FY11 Q1 }\end{array}$ \\
\hline & & \multicolumn{4}{|c|}{ Progress, 2011} & \\
\hline & & Q1 & Q2 & Q3 & Q4 & \\
\hline 5 & Proof of concept: composite materials & \multicolumn{4}{|c|}{$25 \%$} & Extended from FY10 \\
\hline 6 & Mixed mode study of composite materials & \multicolumn{4}{|c|}{$0 \%$} & \\
\hline 7 & Loading rate effect & \multicolumn{4}{|r|}{$0 \%$} & \\
\hline 8 & Environmental effect & \multicolumn{4}{|r|}{$0 \%$} & \\
\hline
\end{tabular}




\section{References}

[Adams 1992] Adams, D. F. and E. M. Odom (1992). "Tensile and Shear Fatigue Testing of Brittle Polymers." Sampe Quarterly-Society for the Advancement of Material and Process Engineering 23(2): 29-37.

[Araki 2002] Araki, W., T. Adachi, A. Yamaji and M. Gamou (2002). "Fracture toughness of bisphenol A-type epoxy resin." Journal of Applied Polymer Science 86(9): 2266-2271.

[Cherry 1981] Cherry, B. W. and K. W. Thomson (1981). "THE FRACTURE OF HIGHLY CROSSLINKED POLYMERS .2. FRACTOGRAPHY." Journal of Materials Science 16(7): 1925-1934.

[Hayman 2008] Hayman, B., J. Wedel-Heinen and P. Brondsted (2008). "Materials challenges in present and future wind energy." Mrs Bulletin 33(4): 343-353.

[Kelly 2000] Kelly, A. and C. Zweben, Eds. (2000). Comprehensive Composite Materials. Amsterdam, Elsevier/Pergamon.

[Kensche 2006] Kensche, C. W. (2006). "Fatigue of composites for wind turbines." International Journal of Fatigue 28(10): 1363-1374.

[Li 1996] Li, H. X., R. H. Jones, J. P. Hirth and D. S. Gelles (1996). "Fracture toughness of the F-82H steel-effect of loading modes, hydrogen, and temperature." Journal of Nuclear Materials 237: 258-263.

[Nagasawa 1995] Nagasawa, M., H. Kinuhata, H. Koizuka, K. Miyamoto, T. Tanaka, H. Kishimoto and T. Koike (1995). "Mechanical Fatigue of Epoxy-Resin." Journal of Materials Science 30(5): 1266-1272.

[Owen 1975] Owen, M. J. and R. G. Rose (1975). "FRACTOGRAPHY OF POLYESTER RESINS." Journal of Materials Science 10(10): 1711-1718.

[Phillips 1978] Phillips, D. C., J. M. Scott and M. Jones (1978). "CRACKPROPAGATION IN AN AMINE-CURED EPOXIDE-RESIN." Journal of Materials Science 13(2): 311-322.

[Quinn 2007] Quinn, G. D. (2007). Fractography of Ceramics and Glasses. Natl. Inst. Stand. Techno, Gaithersburg, MD, USA.

[Sih 1974] Sih, G. C., "Strain Energy Density Factor Applied to Mixed Mode Crack Problem," International Journal of Fracture, 1974, Vol. 10, pp. 305-321.

[Tao 2007] Tao, G. and Z. H. Xia (2007). "An experimental study of uniaxial fatigue behavior of an epoxy resin by a new noncontact real-time strain measurement and control system." Polymer Engineering and Science 47(6): 780-788. 
[Wang 2000] Wang, J. A., K. C. Liu, D. E. McCabe and S. A. David (2000). "Using torsional bar testing to determine fracture toughness." Fatigue \& Fracture of Engineering Materials \& Structures 23(11): 917-927.

[Wang 2002a] Wang, J.-A. and K. C. Liu (2002). ORNL Spiral-Notch Torsion Test (SNTT) System. 2002 R\&D 100 Award, R\&D Magazine.

[Wang 2002b] J. A. Wang, K. C. Liu, and D. E. McCabe, "An Innovative Technique for Measuring Fracture Toughness of Metallic and Ceramic Materials," Fatigue and Fracture Mechanics: $33^{\text {rd }}$ Volume, ASTM STP 1417, W. G. Reuter and R. S. Piascik, Eds., pp. 757-770, December 2002

[Wang 2003a] Wang, J. A. and K. C. Liu (2003). "Fracture toughness determination using spiral-grooved cylindrical specimen and pure torsional loading." US Patent 6588283.

[Wang 2003b] Wang, J. A., K. C. Liu and D. E. McCabe (2003). "An innovative technique for measuring fracture toughness of metallic and ceramic materials." Fatigue and Fracture Mechanics: 33rd Volume 1417: 757-770.

[Wang 2006] Wang, J. A. J., I. G. Wright, M. J. Lance and K. C. Liu (2006). "A new approach for evaluating thin film interface fracture toughness." Materials Science and Engineering a-Structural Materials Properties Microstructure and Processing 426(1-2): 332-345.

[Wang 2008] Wang, J. A. J. and K. C. Liu (2008). "An innovative technique for evaluating fracture toughness of graphite materials." Journal of Nuclear Materials 381(12): $177-184$.

[Wang, H. 2002] Wang, H., L. Jiang, Y. H. He, L. J. Chen, P. K. Liaw, R. R. Seeley and D. L. Klarstrom (2002). "Infrared imaging during low-cycle fatigue of HR-120 alloy." Metallurgical and Materials Transactions a-Physical Metallurgy and Materials Science 33(4): 1287-1292.

[Yamini 1979] Yamini, S. and R. J. Young (1979). "Crack-Propagation in and Fractography of Epoxy-Resins." Journal of Materials Science 14(7): 1609-1618.

[Yamini 1980] Yamini, S. and R. J. Young (1980). "The Mechanical-Properties of EpoxyResins .2. Effect of Plastic-Deformation Upon Crack-Propagation." Journal of Materials Science 15(7): 1823-1831. 


\section{Appendix A: SNTT Testing Log}

\begin{tabular}{|c|c|c|c|}
\hline \multicolumn{4}{|c|}{ Sample ID: GB1-1 } \\
\hline \multicolumn{4}{|c|}{ Material: 117LV/229 } \\
\hline \multicolumn{4}{|c|}{ Geometry: 4" gage length, 1" diameter, $36^{\circ}$ pitch angle, $0.1^{\prime \prime}$ groove depth (nominal) } \\
\hline Date & Testing & Conditions & Results \\
\hline $03-24-2010$ & Fatigue & $\begin{array}{l}\text { Angle control, } 0.15^{\circ}-2.71^{\circ}, 2 \mathrm{~Hz} \text {, } \\
100000 \text { cycles }\end{array}$ & $\begin{array}{l}\text { No significant cracking observed. } \\
\text { Torque range changed from }(47 \text {, } \\
143) \text { to }(36,133) \text { in-lbf. }\end{array}$ \\
\hline $03-25-2010$ & Fatigue & $\begin{array}{l}\text { Torque control, } 40-160 \text { in-lbf, } 1 \mathrm{~Hz} \text {, } \\
11567 \text { cycles }\end{array}$ & $\begin{array}{l}\text { No significant cracking observed. } \\
\text { Angle range changed from }(0.89 \text {, } \\
2.46) \text { to }(0.95,2.50) \text { degree. }\end{array}$ \\
\hline $03-25-2010$ & Fatigue & $\begin{array}{l}\text { Angle control, } 2.46^{\circ}-3.20^{\circ}, 1 \mathrm{~Hz} \text {, } \\
4000 \text { cycles }\end{array}$ & $\begin{array}{l}\text { No significant cracking observed. } \\
\text { Torque range changed from (141, } \\
197) \text { to }(134,194) \text { in-lbf. }\end{array}$ \\
\hline $03-25-2010$ & Fatigue & $\begin{array}{l}\text { Angle control, } 2.46^{\circ}-3.20^{\circ}, 2 \mathrm{~Hz} \text {, } \\
22482 \text { cycles }\end{array}$ & $\begin{array}{l}\text { No significant cracking observed. } \\
\text { Torque range changed from (134, } \\
\text { 194) to }(130,190) \text { in-lbf. }\end{array}$ \\
\hline $\begin{array}{l}03-25-2010 \\
\text { to } \\
03-26-2010\end{array}$ & Fatigue & $\begin{array}{l}\text { Angle control, } 4.49^{\circ}-5.10^{\circ}, 2 \mathrm{~Hz} \text {, } \\
100000 \text { cycles }\end{array}$ & $\begin{array}{l}\text { No significant cracking observed. } \\
\text { Torque range changed from }(272 \text {, } \\
321) \text { to }(238,288) \text { in-lbf. }\end{array}$ \\
\hline 03-26-2010 & Fatigue & $\begin{array}{l}\text { Angle control, } 6.70^{\circ}-7.20^{\circ}, 2 \mathrm{~Hz} \text {, } \\
32800 \text { cycles }\end{array}$ & $\begin{array}{l}\text { No significant cracking observed. } \\
\text { Torque range changed from }(378 \text {, } \\
420) \text { to }(360,402) \text { in-lbf. }\end{array}$ \\
\hline $\begin{array}{l}03-26-2010 \\
\text { to } \\
03-28-2010\end{array}$ & Fatigue & $\begin{array}{l}\text { Angle control, } 6.428^{\circ}-7.202^{\circ}, 2 \mathrm{~Hz} \text {, } \\
286072 \text { cycles }\end{array}$ & $\begin{array}{l}\text { No significant cracking observed. } \\
\text { Torque range changed from }(367 \text {, } \\
430) \text { to }(287,353) \text { in-lbf. }\end{array}$ \\
\hline 03-08-2010 & Monotonic & Manually increased angle & Sample fractured at $801 \mathrm{lbf}\left(17.85^{\circ}\right)$ \\
\hline
\end{tabular}


DRAFT

\begin{tabular}{|l|l|l|l|}
\hline \multicolumn{3}{|l|}{ Sample ID: GB1-2 } \\
\hline Material: 117LV/229 & \multicolumn{2}{|l|}{} \\
\hline Geometry: 4" gage length, 1" diameter, 36 ${ }^{\circ}$ pitch angle, 0.1" groove depth (nominal) \\
\hline Date & Testing & Conditions & Results \\
\hline 03-29-2010 & Fatigue & $\begin{array}{l}\text { Angle control, } 5.17^{\circ}-6.43^{\circ}, 1 \mathrm{~Hz}, \\
100000 \text { cycles }\end{array}$ & $\begin{array}{l}\text { No significant cracking observed. } \\
\text { Torque range changed from (298, } \\
400) \text { to }(220,323) \text { in-lbf. }\end{array}$ \\
\hline 03-30-2010 & Fatigue & $\begin{array}{l}\text { Torque control, } 350-450 \text { in-lbf, 1 } \\
\mathrm{Hz}, 3000 \text { cycles }\end{array}$ & $\begin{array}{l}\text { No significant cracking observed. } \\
\text { Angle range changed from (6.63, } \\
7.86) \text { to (6.72, 7.98) degree. }\end{array}$ \\
\hline $\begin{array}{l}\text { 03-30-2010 } \\
\text { to }\end{array}$ & Fatigue & Angle control, $7.50^{\circ}-8.75^{\circ}, 2 \mathrm{~Hz}$ & $\begin{array}{l}\text { Initial torque range (397, 501). } \\
\text { Fractured at 500 in-lbf; final cycle } \\
\text { number unrecorded. }\end{array}$ \\
\hline
\end{tabular}

\begin{tabular}{|c|c|c|c|}
\hline \multicolumn{4}{|c|}{ Sample ID: GB1-3 } \\
\hline \multicolumn{4}{|c|}{ Material: 117LV/229 } \\
\hline \multicolumn{4}{|c|}{ Geometry: 4" gage length, 1" diameter, $36^{\circ}$ pitch angle, $0.1^{\prime \prime}$ groove depth (nominal) } \\
\hline Date & Testing & Conditions & Results \\
\hline $\begin{array}{l}03-31-2010 \\
\text { to } \\
04-02-2010\end{array}$ & Fatigue & $\begin{array}{l}\text { Torque control, } 150-200 \text { in-lbf, } 1 \\
\mathrm{~Hz}, 70000 \text { cycles }\end{array}$ & $\begin{array}{l}\text { No significant cracking observed. } \\
\text { Angle range changed from }(2.544 \text {, } \\
3.118) \text { to }(2.700,3.316) \text { degree. }\end{array}$ \\
\hline $\begin{array}{l}04-12-2010 \\
\text { to } \\
04-14-2010\end{array}$ & Fatigue & $\begin{array}{l}\text { Torque control, } 200-250 \text { in-lbf, } 1 \\
\mathrm{~Hz}, 90000 \text { cycles }\end{array}$ & $\begin{array}{l}\text { No significant cracking observed. } \\
\text { Angle range changed from }(3.478 \text {, } \\
4.078) \text { to }(5.858,6.435) \text { degree. }\end{array}$ \\
\hline 04-20-2010 & Fatigue & $\begin{array}{l}\text { Torque control, } 250 \text { - } 300 \text { in-lbf, } 1 \\
\mathrm{~Hz}, 50000 \text { cycles }\end{array}$ & $\begin{array}{l}\text { No significant cracking observed. } \\
\text { Angle range changed from }(4.397 \text {, } \\
5.020) \text { to }(5.012,5.592) \text { degree. }\end{array}$ \\
\hline 04-21-2010 & Fatigue & $\begin{array}{l}\text { Torque control, } 350-400 \text { in-lbf, } 1 \\
\mathrm{~Hz}, 30000 \text { cycles }\end{array}$ & $\begin{array}{l}\text { No significant cracking observed. } \\
\text { Angle range changed from }(6.276 \text {, } \\
6.862) \text { to }(6.845,7.424) \text { degree. }\end{array}$ \\
\hline $\begin{array}{l}04-21-2010 \\
\text { to } \\
04-22-2010\end{array}$ & Fatigue & $\begin{array}{l}\text { Torque control, } 400-450 \text { in-lbf, } 1 \\
\mathrm{~Hz}, 100000 \text { cycles }\end{array}$ & $\begin{array}{l}\text { No significant cracking observed. } \\
\text { Angle range changed from }(7.491 \text {, } \\
8.070) \text { to }(8.103,8.669) \text { degree. }\end{array}$ \\
\hline $04-22-2010$ & Fatigue & $\begin{array}{l}\text { Torque control, } 500 \text { - } 550 \text { in-lbf, } 2 \\
\mathrm{~Hz}, 50000 \text { cycles }\end{array}$ & $\begin{array}{l}\text { No significant cracking observed. } \\
\text { Angle range changed from (8.041, } \\
8.633 \text { ) to }(8.934,9.505) \text { degree. }\end{array}$ \\
\hline $04-22-2010$ & Fatigue & $\begin{array}{l}\text { Torque control, } 600-650 \text { in-lbf, } 2 \\
\mathrm{~Hz}, 50000 \text { cycles }\end{array}$ & $\begin{array}{l}\text { No significant cracking observed. } \\
\text { Angle range changed from }(10.263 \text {, } \\
10.859) \text { to }(11.186,11.758) \text { degree. }\end{array}$ \\
\hline $04-22-2010$ & Fatigue & $\begin{array}{l}\text { Angle control, } 0.5^{\circ}-6.1^{\circ}, 0.1 \mathrm{~Hz} \\
1000 \text { cycles; } 0.4^{\circ}-6.0^{\circ}, 2 \mathrm{~Hz}, 2700 \\
\text { cycles. }\end{array}$ & $\begin{array}{l}\text { Initial torque range }(2,403) \text { in-lbf. } \\
\text { Fractured after } 2700 \text { cycles, fracture } \\
\text { torque } 435 \text { in-lbf }\left(6^{\circ}\right) .\end{array}$ \\
\hline
\end{tabular}




\section{DRAFT}

\begin{tabular}{|c|c|c|c|}
\hline \multirow{2}{*}{\multicolumn{4}{|c|}{ Sample ID: GB1-4 }} \\
\hline \multicolumn{2}{|c|}{ Material: 117LV/229 } & & \\
\hline \multicolumn{4}{|c|}{ Geometry: 4" gage length, 1" diameter, $36^{\circ}$ pitch angle, $0.1^{\prime \prime}$ groove depth (nominal) } \\
\hline Date & Testing & Conditions & Results \\
\hline 05-04-2010 & Fatigue & Angle control, $1.2^{\circ}-4.8^{\circ}, 1 \mathrm{~Hz}$ & $\begin{array}{l}\text { Torque range; } \\
\text { Initial: } 27-301 \mathrm{lbf}-\text { in } \\
\text { 10k cycles: } 15-294 \mathrm{lbf}-\text { in } \\
\text { Sample fractured after } 16164 \\
\text { cycles. } \\
\text { Max torque: } 304.3 \mathrm{lbf}-\mathrm{in} \\
\text { Max angle: } 4.84^{\circ}\end{array}$ \\
\hline
\end{tabular}

\begin{tabular}{|l|l|l|l|}
\hline \multicolumn{3}{|l|}{ Sample ID: GB1-5 } \\
\hline Material: 117LV/229 \\
\hline Geometry: 4" gage length, 1" diameter, 36 ${ }^{\circ}$ pitch angle, 0.1" groove depth (nominal) \\
\hline Date & Testing & Conditions & Results \\
\hline 05-04-2010 & Fatigue & $\begin{array}{l}\text { Torque control, } 20-200 \text { in-lbf, 1 Hz, } \\
50000 \text { cycles }\end{array}$ & $\begin{array}{l}\text { No significant cracking observed. } \\
\text { Angle range changed from (0.68, } \\
3.27) \text { to (1.23, 3.82) degree. }\end{array}$ \\
\hline 05-05-2010 & Fatigue & Torque control, 30 - 300 in-lbf, 1 Hz & $\begin{array}{l}\text { Initial angle range }(1.38,4.86) \\
\text { degree. Fractured after 6316 cycles, } \\
\text { at 302 in-lbf }\left(5.17^{\circ}\right) .\end{array}$ \\
\hline
\end{tabular}

\begin{tabular}{|l|l|l|l|}
\hline \multicolumn{3}{|l|}{ Sample ID: GB1-6 } \\
\hline Material: 117LV/229 \\
\hline Geometry: 4" gage length, 1" diameter, 36 ${ }^{\circ}$ pitch angle, 0.1" groove depth (nominal) \\
\hline Date & Testing & Conditions & Results \\
\hline 05-05-2010 & Fatigue & $\begin{array}{l}\text { Torque control, 30 - 300 in-lbf, 1 Hz, } \\
5500 \text { cycles }\end{array}$ & $\begin{array}{l}\text { Angle range changed from }(1.2, \\
4.88) \text { to }(1.45,5.38) \text { degree. }\end{array}$ \\
\hline 05-05-2010 & Monotonic & $\begin{array}{l}\text { Torque increase from 10 in-lbf to } \\
1200 \text { in-lbf at 40 in-lbf/sec. }\end{array}$ & Fractured at 596 in-lbf $\left(9.436^{\circ}\right)$. \\
\hline
\end{tabular}

\begin{tabular}{|l|l|l|l|}
\hline \multicolumn{3}{|l|}{ Sample ID: GB1-7 } \\
\hline Material: 117LV/229 & \multicolumn{2}{|l|}{} \\
\hline Geometry: 4" gage length, 1" diameter, 36 & pitch angle, 0.1" groove depth (nominal) \\
\hline Date & Testing & Conditions & Results \\
\hline 05-07-2010 & Fatigue & $\begin{array}{l}\text { Torque control, 20 - 200 in-lbf, 1 Hz, } \\
\text { 260000 cycles }\end{array}$ & $\begin{array}{l}\text { Angle range changed from (0.67, } \\
\text { 3.24) to (1.70, 3.98) degree. }\end{array}$ \\
\hline 05-10-2010 & Monotonic & $\begin{array}{l}\text { Torque increase from zero to 1000 in- } \\
\text { lbf at 40 in-lbf/sec. }\end{array}$ & Fractured at 357 in-lbf (5.868 \\
\hline
\end{tabular}




\section{DRAFT}

\begin{tabular}{|l|l|l|l|}
\hline \multicolumn{2}{|l|}{ Sample ID: GB2-1 } \\
\hline Material: 117LV/XH10B \\
\hline Geometry: 4" gage length, 1" diameter, 36 ${ }^{\circ}$ pitch angle, 0.1" groove depth (nominal) \\
\hline Date & Testing & Conditions & Results \\
\hline 05-10-2010 & Monotonic & $\begin{array}{l}\text { Torque increase from zero to } 1000 \text { in- } \\
\text { Ibf at } 40 \text { in-lbf/sec. }\end{array}$ & Fractured at 774 in-lbf $\left(10.01^{\circ}\right)$. \\
\hline
\end{tabular}

\begin{tabular}{|l|l|l|l|}
\hline \multicolumn{3}{|l|}{ Sample ID: GB2-2 } \\
\hline Material: 117LV/XH10B \\
\hline Geometry: 4" gage length, 1" diameter, 36 ${ }^{\circ}$ pitch angle, 0.1" groove depth (nominal) \\
\hline Date & Testing & Conditions & Results \\
\hline 05-10-2010 & Fatigue & $\begin{array}{l}\text { Torque control, 20 - 200 in-lbf, 1 Hz, } \\
\text { 150000 cycles }\end{array}$ & $\begin{array}{l}\text { Angle range changed from }(-0.5, \\
1.74) \text { to }(0.32,2.54) \text { degree. }\end{array}$ \\
\hline 05-12-2010 & Monotonic & $\begin{array}{l}\text { Torque increase from zero to 1000 in- } \\
\text { lbf at 40 in-lbf/sec. }\end{array}$ & Fractured at 865 in-lbf $\left(13.83^{\circ}\right)$. \\
\hline
\end{tabular}




\section{DRAFT}

\begin{tabular}{|c|c|c|c|}
\hline \multicolumn{4}{|c|}{ Sample ID: GB2-3 } \\
\hline \multicolumn{4}{|c|}{ Material: 117LV/XH10B } \\
\hline \multicolumn{4}{|c|}{$\begin{array}{l}\text { Geometry: } 4 \text { " gage length, 1" diameter, } 28^{\circ} \text { pitch angle, } 0.2^{\prime \prime} \text { groove depth (nominal), root sharpened with } \\
\text { razor blade }\end{array}$} \\
\hline Date & Testing & Conditions & Results \\
\hline $05-12-2010$ & Fatigue & $\begin{array}{l}\text { Torque control, } 30-300 \text { in-lbf, } 2 \mathrm{~Hz}, \\
\sim 100 \text { cycles }\end{array}$ & Fractured at $289 \mathrm{in}-\mathrm{lbf}\left(4.95^{\circ}\right)$ \\
\hline
\end{tabular}

\begin{tabular}{|c|c|c|c|}
\hline \multicolumn{4}{|c|}{ Sample ID: GB2-4 } \\
\hline \multicolumn{4}{|c|}{ Material: 117LV/XH10B } \\
\hline \multicolumn{4}{|c|}{$\begin{array}{l}\text { Geometry: 4" gage length, 1" diameter, } 28^{\circ} \text { pitch angle, } 0.2^{\prime \prime} \text { groove depth (nominal), root sharpened with } \\
\text { razor blade }\end{array}$} \\
\hline Date & Testing & Conditions & Results \\
\hline $05-12-2010$ & Fatigue & $\begin{array}{l}\text { Torque control, } 30-300 \text { in-lbf, } 1 \mathrm{~Hz} \text {, } \\
1660 \text { cycles }\end{array}$ & Fractured at $303 \mathrm{in}-\mathrm{lbf}\left(5.22^{\circ}\right)$ \\
\hline
\end{tabular}


DRAFT

\begin{tabular}{|c|c|c|c|}
\hline \multicolumn{4}{|c|}{ Sample ID: GB2-5 } \\
\hline \multicolumn{4}{|c|}{ Material: 117LV/XH10B } \\
\hline \multicolumn{4}{|c|}{$\begin{array}{l}\text { Geometry: } 4 " \text { gage length, } 1 \text { " diameter, } 20^{\circ} \text { pitch angle, } 0.3^{\prime \prime} \text { groove depth (nominal), root sharpened with } \\
\text { razor blade }\end{array}$} \\
\hline Date & Testing & Conditions & Results \\
\hline $05-12-2010$ & Fatigue & $\begin{array}{l}\text { Torque control, } 10-100 \text { in-lbf, } 1 \mathrm{~Hz} \text {, } \\
60,000 \text { cycles }\end{array}$ & No detectable crack \\
\hline $\begin{array}{l}05-13-2010 \\
\text { to } \\
05-20-2010\end{array}$ & Fatigue & $\begin{array}{l}\text { Torque control, } 10-100 \text { in-lbf, } 2 \mathrm{~Hz} \text {, } \\
1,200,000 \text { cycles }\end{array}$ & No detectable crack \\
\hline ? & Fatigue & $\begin{array}{l}\text { Torque control, } 10-100 \text { in-lbf, } 2 \mathrm{~Hz} \text {, } \\
694,760 \text { cycles }\end{array}$ & \\
\hline $\begin{array}{l}05-20-2010 \\
\text { to } \\
05-26-2010\end{array}$ & Fatigue & $\begin{array}{l}\text { Torque control, } 10-100 \text { in-lbf, } 2 \mathrm{~Hz} \text {, } \\
1,054,223 \text { cycles }\end{array}$ & No detectable crack \\
\hline 05-26-2010 & Fatigue & $\begin{array}{l}\text { Torque control, } 15-150 \text { in-lbf, } 1 \mathrm{~Hz} \text {, } \\
41795 \text { cycles }\end{array}$ & Fractured at $153.8 \mathrm{in}-\mathrm{lbf}(4.634 \mathrm{deg})$ \\
\hline
\end{tabular}

\begin{tabular}{|c|c|c|c|}
\hline \multicolumn{4}{|c|}{ Sample ID: GB2-6 } \\
\hline \multicolumn{4}{|c|}{ Material: 117LV/XH10B } \\
\hline \multicolumn{4}{|c|}{ Geometry: 4" gage length, 1" diameter, $20^{\circ}$ pitch angle, $0.3^{\prime \prime}$ groove depth (nominal) } \\
\hline Date & Testing & Conditions & Results \\
\hline 05-07-2010 & Monotonic & $\begin{array}{l}\text { Torque increase from } 10 \mathrm{in}-\mathrm{lbf} \text { to } \\
1200 \mathrm{in}-\mathrm{lbf} \text { at } 40 \mathrm{in}-\mathrm{lbf} / \mathrm{sec} .\end{array}$ & Fractured at $447 \mathrm{in}-\mathrm{lbf}\left(6.37^{\circ}\right)$ \\
\hline
\end{tabular}




\section{DRAFT}

\begin{tabular}{|c|c|c|c|}
\hline \multicolumn{4}{|c|}{ Sample ID: GB3-1 } \\
\hline \multicolumn{4}{|c|}{ Material: 117LV/229 } \\
\hline \multicolumn{4}{|c|}{ Geometry: 4" gage length, 1" diameter, 0.125 " groove depth } \\
\hline Date & Testing & Conditions & Results \\
\hline 07-21-2010 & monotonic & $40 \mathrm{lbf}-\mathrm{in} / \mathrm{sec}$ to $1000 \mathrm{lbf}$ & Fractured at $338 \mathrm{lbf}$-in \\
\hline
\end{tabular}

\begin{tabular}{|c|c|c|c|}
\hline \multicolumn{4}{|c|}{ Sample ID: GB3-2 } \\
\hline \multicolumn{4}{|c|}{ Material: 117LV/229 } \\
\hline \multicolumn{4}{|c|}{ Geometry: 4" gage length, 1" diameter, 0.122 " groove depth } \\
\hline Date & Testing & Conditions & Results \\
\hline $07-27-2010$ & Fatigue & $20-200$ lbf-in, $1 \mathrm{~Hz}$ & $\begin{array}{l}\text { Fractured after } 5139 \text { cycles at } 198 \\
\text { lbf-in }\end{array}$ \\
\hline
\end{tabular}

\begin{tabular}{|c|c|c|c|}
\hline \multicolumn{4}{|c|}{ Sample ID: GB3-3 } \\
\hline \multicolumn{4}{|c|}{ Material: 117LV/229 } \\
\hline \multicolumn{4}{|c|}{ Geometry: 4" gage length, 1" diameter, 0.122" groove depth } \\
\hline Date & Testing & Conditions & Results \\
\hline $07-28-2010$ & Fatigue & 20 -200 lbf-in, $1 \mathrm{~Hz}$ & Fatigued for 3000 cycles \\
\hline $07-28-2010$ & Mono & $40 \mathrm{lbf}-i n / \mathrm{sec}$ to $1000 \mathrm{lbf}$ & Fractured at $244 \mathrm{lbf}$-in \\
\hline
\end{tabular}

\begin{tabular}{|c|c|c|c|}
\hline \multicolumn{4}{|c|}{ Sample ID: Batch3-4 } \\
\hline \multicolumn{4}{|c|}{ Material: 117LV/229 } \\
\hline \multicolumn{4}{|c|}{ Geometry: 4" gage length, 1" diameter, 0.077 " groove depth } \\
\hline Date & Testing & Conditions & Results \\
\hline $06-30-2010$ & Fatigue & $30-300$ lbf-in, $1 \mathrm{~Hz}$ & $\begin{array}{l}\text { Fractured after } 3368 \text { cycles @ } 297 \\
\text { lbf-in. }\end{array}$ \\
\hline
\end{tabular}

\begin{tabular}{|c|c|c|c|}
\hline \multicolumn{4}{|c|}{ Sample ID: Batch 3-5 } \\
\hline \multicolumn{4}{|c|}{ Material: 117LV/229 } \\
\hline \multicolumn{4}{|c|}{ Geometry: 4" gage length, 1" diameter, 0.091" groove depth } \\
\hline Date & Testing & Conditions & Results \\
\hline 07-01-2010 & Fatigue & 30 -300 lbf-in, 1Hz & $\begin{array}{l}\text { Fractured after } 220 \text { cycles @ } 296.7 \\
\text { lbf-in. }\end{array}$ \\
\hline
\end{tabular}

\begin{tabular}{|c|c|c|c|}
\hline \multicolumn{4}{|c|}{ Sample ID: Batch 3-6 } \\
\hline \multicolumn{4}{|c|}{ Material: 117LV/229 } \\
\hline \multicolumn{4}{|c|}{ Geometry: 4" gage length, 1" diameter, 0.090" groove depth } \\
\hline Date & Testing & Conditions & Results \\
\hline 07-01-2010 & monotonic & $40 \mathrm{lbf}-\mathrm{in} / \mathrm{sec}$ to $1000 \mathrm{lbf}$ & Fractured at $384 \mathrm{lbf}-\mathrm{in}, 5.57^{\circ}$ \\
\hline
\end{tabular}


DRAFT

\begin{tabular}{|c|c|c|c|}
\hline \multicolumn{4}{|c|}{ Sample ID: GB3-7 } \\
\hline \multicolumn{4}{|c|}{ Material: 117LV/229 } \\
\hline \multicolumn{4}{|c|}{ Geometry: 4" gage length, 1" diameter, 0.102" groove depth } \\
\hline Date & Testing & Conditions & Results \\
\hline $07-30-2010$ & Fatigue & $20-200$ lbf-in, $1 \mathrm{~Hz}$ & Fatigued for 9000 cycles \\
\hline $07-30-2010$ & Mono & $40 \mathrm{lbf}-\mathrm{in} / \mathrm{sec}$ to $500 \mathrm{lbf}$ & Did not fracture \\
\hline \multicolumn{4}{|c|}{ Groove root sharpened with a razor blade } \\
\hline $07-30-2010$ & Mono & $40 \mathrm{lbf}-\mathrm{in} / \mathrm{sec}$ to $1000 \mathrm{lbf}$ & Fractured at $618 \mathrm{lbf}$-in \\
\hline
\end{tabular}

\begin{tabular}{|c|c|c|c|}
\hline Sample ID: & $33-8$ & & \\
\hline Material: 11 & $V / 229$ & & \\
\hline Geometry: 4 & gage leng & " diameter, 0.206" groov & \\
\hline Date & Testing & Conditions & Results \\
\hline Groove root & harpened & a razor blade & \\
\hline $07-30-2010$ & Mono & $40 \mathrm{lbf}-\mathrm{in} / \mathrm{sec}$ to $1000 \mathrm{lbf}$ & Fractured at $343 \mathrm{lbf}$-in \\
\hline
\end{tabular}

\begin{tabular}{|c|c|c|c|}
\hline Sample ID: & B3-9 & & \\
\hline Material: 11 & $-V / 229$ & & \\
\hline Geometry: 4 & gage leng & 1" diameter, 0.298" groove & \\
\hline Date & Testing & Conditions & Results \\
\hline Groove root & NOT sharp & & \\
\hline $07-30-2010$ & Mono & $40 \mathrm{lbf}-\mathrm{in} / \mathrm{sec}$ to $1000 \mathrm{lbf}$ & Fractured at $430 \mathrm{lbf}-\mathrm{in}$ \\
\hline
\end{tabular}




\section{DRAFT}

\begin{tabular}{|c|c|c|c|}
\hline \multicolumn{4}{|c|}{ Sample ID: GB4-1 } \\
\hline \multicolumn{4}{|c|}{ Material: 117LV/229 } \\
\hline \multicolumn{4}{|c|}{ Geometry: 4" gage length, 1" diameter, 0.128 " groove depth } \\
\hline Date & Testing & Conditions & Results \\
\hline 07-21-2010 & monotonic & $40 \mathrm{lbf}-\mathrm{in} / \mathrm{sec}$ to $1000 \mathrm{lbf}$ & Fractured at $305 \mathrm{lbf}-\mathrm{in}$ \\
\hline
\end{tabular}

\begin{tabular}{|c|c|c|c|}
\hline \multicolumn{4}{|c|}{ Sample ID: GB4-2 } \\
\hline \multicolumn{4}{|c|}{ Material: $117 \mathrm{LV} / 229$} \\
\hline \multicolumn{4}{|c|}{ Geometry: 4" gage length, 1" diameter, 0.127 " groove depth } \\
\hline Date & Testing & Conditions & Results \\
\hline $07-28-2010$ & Fatigue & $20-200 \mathrm{lbf}-\mathrm{in}$ & $\begin{array}{l}\text { Fractured after } 3308 \text { cycles at } 197 \\
\text { lbf-in }\end{array}$ \\
\hline
\end{tabular}

\begin{tabular}{|c|c|c|c|}
\hline \multicolumn{4}{|c|}{ Sample ID: GB4-3 } \\
\hline \multicolumn{4}{|c|}{ Material: $117 \mathrm{LV} / 229$} \\
\hline \multicolumn{4}{|c|}{ Geometry: 4" gage length, 1" diameter, 0.124" groove depth } \\
\hline Date & Testing & Conditions & Results \\
\hline $07-27-2010$ & Fatigue & $20-200$ lbf-in & Fatigued for 4000 cycles \\
\hline $07-27-2010$ & Mono & $40 \mathrm{lbf}-\mathrm{in} / \mathrm{sec}$ to $1000 \mathrm{lbf}$ & Fractured at $235 \mathrm{lbf}-\mathrm{in}$ \\
\hline
\end{tabular}

\begin{tabular}{|l|l|l|l|}
\hline \multicolumn{5}{|l|}{ Sample ID: GB4-4 } \\
\hline Material: 117LV/229 \\
\hline Geometry: 4" gage length, 1" diameter, 0.092" groove depth \\
\hline Date & Testing & Conditions & Results \\
\hline 07-21-2010 & monotonic & 40 lbf-in/sec to 1000 lbf & Fractured at 404 lbf-in \\
\hline
\end{tabular}

\begin{tabular}{|c|c|c|c|}
\hline \multicolumn{4}{|c|}{ Sample ID: GB4-5 } \\
\hline \multicolumn{4}{|c|}{ Material: $117 \mathrm{LV} / 229$} \\
\hline \multicolumn{4}{|c|}{ Geometry: 4" gage length, 1" diameter, 0.106" groove depth } \\
\hline Date & Testing & Conditions & Results \\
\hline $07-29-2010$ & Fatigue & $20-200$ lbf-in & Fatigued for 10000 cycles \\
\hline $07-29-2010$ & Fatigue & $25-250 \mathrm{lbf}-\mathrm{in}$ & $\begin{array}{l}\text { Fractured after } 80 \text { cycles at } 240 \text { lbf- } \\
\text { in }\end{array}$ \\
\hline
\end{tabular}

\begin{tabular}{|c|c|c|c|}
\hline \multicolumn{4}{|c|}{ Sample ID: GB4-6 } \\
\hline \multicolumn{4}{|c|}{ Material: 117LV/229 } \\
\hline \multicolumn{4}{|c|}{ Geometry: 4" gage length, 1" diameter, 0.107" groove depth } \\
\hline Date & Testing & Conditions & Results \\
\hline $07-29-2010$ & Fatigue & $20-200$ lbf-in & Fatigued for 9000 cycles \\
\hline $07-29-2010$ & Mono & $40 \mathrm{lbf}-\mathrm{in} / \mathrm{sec}$ to $1000 \mathrm{lbf}$ & Fractured at $281 \mathrm{lbf}-$ in \\
\hline
\end{tabular}


DRAFT

\begin{tabular}{|c|c|c|c|}
\hline \multicolumn{4}{|c|}{ Sample ID: MFG-1 } \\
\hline \multicolumn{4}{|c|}{ Material: RIM135/RIMH1366 } \\
\hline \multicolumn{4}{|c|}{ Geometry: 4" gage length, 1" diameter, 0.084" groove depth } \\
\hline Date & Testing & Conditions & Results \\
\hline $07-21-2010$ & monotonic & $40 \mathrm{lbf}-\mathrm{in} / \mathrm{sec}$ to $2000 \mathrm{lbf}$ & Fractured at $1013 \mathrm{lbf}$-in \\
\hline
\end{tabular}

\begin{tabular}{|c|c|c|c|}
\hline \multicolumn{4}{|c|}{ Sample ID: MFG-2 } \\
\hline \multicolumn{4}{|c|}{ Material: RIM135/RIMH1366 } \\
\hline \multicolumn{4}{|c|}{ Geometry: 4" gage length, 1" diameter, 0.078" groove depth } \\
\hline Date & Testing & Conditions & Results \\
\hline 07-21-2010 & Fatigue & $\begin{array}{l}60-600 \text { lbf-in (testing machine did } \\
\text { not response fast enough for this } \\
\text { range of torque) }\end{array}$ & $\begin{array}{l}\text { Fractured after } \sim 500 \text { cycles at } 558 \\
\text { lbf-in }\end{array}$ \\
\hline
\end{tabular}

\begin{tabular}{|c|c|c|c|}
\hline \multicolumn{4}{|c|}{ Sample ID: MFG-3 } \\
\hline \multicolumn{4}{|c|}{ Material: RIM135/RIMH1366 } \\
\hline \multicolumn{4}{|c|}{ Geometry: 4" gage length, 1" diameter, 0.081" groove depth } \\
\hline Date & Testing & Conditions & Results \\
\hline $08-16-2010$ & Fatigue & $30-300$ lbf-in, $1 \mathrm{~Hz}$ & $\begin{array}{l}\text { Fractured after } 7084 \text { cycles at } 294 \\
\text { lbf-in }\end{array}$ \\
\hline
\end{tabular}

